\title{
AVALIAÇÃO ESTÉTICA DO PERFIL FACIAL DE INDIVÍDUOS COM FISSURA TRANSFORAME INCISIVO UNILATERAL REABILITADOS PELO HOSPITAL DE REABILITAÇÃO DE ANOMALIAS CRANIOFACIAIS
}

\author{
ARACI MALAGODI DE ALMEIDA
}

Dissertação apresentada ao Hospital de Reabilitação de Anomalias Craniofaciais da Universidade de São Paulo para a obtenção do título de MESTRE em Ciências da Reabilitação.

Área de Concentração: Fissuras Orofaciais 
UNIVERSIDADE DE SÃO PAULO

HOSPITAL DE REABILITAÇÃO DE ANOMALIAS CRANIOFACIAIS

\title{
AVALIAÇÃO ESTÉTICA DO PERFIL FACIAL DE INDIVÍDUOS COM FISSURA TRANSFORAME INCISIVO UNILATERAL REABILITADOS PELO HOSPITAL DE REABILITAÇÃO DE ANOMALIAS CRANIOFACIAIS
}

ARACI MALAGODI DE ALMEIDA

Orientador: Prof. Dr. Leopoldino Capelozza Filho

\author{
Dissertação apresentada ao Hospital de \\ Reabilitação de Anomalias Craniofaciais da \\ Universidade de São Paulo para a obtenção do \\ título de MESTRE em Ciências da \\ Reabilitação. \\ Área de Concentração: Fissuras Orofaciais
}




\section{UNIVERSIDADE DE SÃO PAULO \\ HOSPITAL DE REABILITAÇÃO DE ANOMALIAS CRANIOFACIAIS}

R. Sílvio Marchione, 3-20

Caixa Postal: 1501

17012-900 - Bauru -SP - Brasil

Telefone: (14) 3235-8000

Prof. Dr. Adolpho José Melfi - Reitor da USP

Prof. Dr. José Alberto de Souza Freitas - Superintendente do HRAC - USP

Autorizo, exclusivamente, para fins acadêmicos e científicos, a reprodução total ou parcial desta dissertação.

Araci Malagodi de Almeida

Bauru, de de

\footnotetext{
Almeida, Araci Malagodi

A64a Avaliação estética do perfil facial de indivíduos com fissura transforame incisivo unilateral reabilitados pelo Hospital de Reabilitação de Anomalias Craniofaciais./ Araci Malagodi de Almeida. Bauru-SP, 2005. 90f. : il.; $31 \mathrm{~cm}$.

Dissertação (Mestrado em Ciências da Reabilitação - Área de Concentração Fissuras Orofaciais) - HRAC - USP

Cópia revisada em Orientador: Prof. Dr. Leopoldino Capelozza Filho

Descritores: 1. fissuras labiopalatinas; 2. estética facial em fissuras; 3. avaliação estética subjetiva
} 


\section{FOLHA DE APROVAÇÃO}

Dissertação apresentada e defendida por Araci Malagodi de Almeida e aprovada pela Comissão Julgadora em

Prof.(a) Dr.(a):

Instituição:

Prof.(a) Dr.(a):

Instituição:

Prof.(a) Dr.(a):

Instituição:

Prof. Dr. Leopoldino Capelozza Filho

HRAC-USP (Orientador)

Prof. ${ }^{\text {a }}$ Dr. ${ }^{\text {a. }}$ Inge Elly Kiemle Trindade

Presidente da Comissão de Pós-graduação do HRAC-USP

Data de depósito da dissertação junto à SPG 


\section{ARACI MALAGODI DE ALMEIDA}

17 de setembro de 1959

São Paulo - SP

$1979-1982$

$1983-1985$

$1983-1993$

$1985-1985$

1985 - Atual

1985 - Atual

$1985-1987$

1986 - Atual

$2002-2005$

Associações
Nascimento

Curso de Odontologia - Faculdade de Odontologia de Bauru da Universidade de São Paulo

Residência Odontológica em Ortodontia Corretiva no Hospital de Pesquisa e Reabilitação de Lesões Lábio-Palatais da Universidade de São Paulo, Bauru, São Paulo

Auxiliar cirúrgica do Prof. Dr. Reinaldo Mazzottini, em cirurgias ortognáticas e de traumas realizadas no Hospital de Pesquisa e Reabilitação de Lesões Lábio-Palatais da Universidade de São Paulo

Aperfeiçoamento em Ortodontia Preventiva e Interceptiva pela Sociedade de Promoção Social do Fissurado Lábio Palatal, PROFIS, São Paulo, Brasil

Professora no Curso de Ortodontia Preventiva e Interceptiva na Sociedade de Promoção Social do Fissurado Lábio Palatal, PROFIS, São Paulo, Brasil

Atividade em consultório particular em Bauru - SP

Especialização em Ortodontia pela Universidade de São Paulo, USP, São Paulo, Brasil

Ortodontista no Hospital de Reabilitação de Anomalias Craniofaciais, USP, Bauru, São Paulo

Curso de Pós-Graduação em Ciências da Reabilitação, área de concentração Fissuras Orofaciais, nível Mestrado, no Hospital de Reabilitação de Anomalias Craniofaciais da Universidade de São Paulo

APCD - Associação Paulista de Cirurgiões Dentistas

ABO - Associação Brasileira de Odontologia 
$D_{\text {edicatóRIa }}$ 
Aas meus pais, Anileal e Vilma

Tela apartunidade da vida,

Pela recanhecimenta da caráter

Tela amar e carinha sempre presentes

Apesar da distancia...

Aas meus irmãas, Walquiria e Waldir, sabrinhas Tiaga, Raquel, Guilherme, Enrica, Caia, Murila e Vitar, cunhadas Bruna e Magali

Pela amar que nas une

Cada vez maiar...

à Virginia

Pela carinha e campanheirisma destes anas

Aas pacientes da HRaC

Razãa de tuda ista... 


\section{Agradecimentos}


Agradecimenta à Deus

$\mathcal{O}$ dam da vida realmente é alga divina Acardar de manhã, alhar a céu... A leeleza das cares enche as alhas e a caraçãa Escalher querer ser feliz au nãa... Obrigada meu Deus Pela vida, pela alegria e pela farça que sinta dentra de mim. 
Prafessar Dr. Jasé Allerta de Sauza Freitas

Obrigada

$\mathcal{O}$ sanha tornou-se realidade.

A missãa de reabilitar está senda cumprida.

$\mathcal{N}$ a cameça, tuda naua, descanhecida

Na presente, canhecimenta recanhecida.

Eualuçãa que permite avaliaçãa.

Nãa mais da radiagrafia au das madelas, mas

da face!

Retrata das passiliilidades e limitaçães.

Passibilidades que canfartam,

Limitaçães que estimulam.

Aprender, ensinar, fazer e carrigir.

Obrigada par tarnar issa passúuel.

Pesquisadara: Araci Malagadi de Almeida

Orientadar: Praf. Dr. Leapaldina Capelazza Filha 
Agradecimentas especiais

Omar Gabriel

Existem pessaas que nãa parecem deste munda Daminam a tempa, travam lutas carajasamente Ocupam espaças, inwadem nassas caraçães e nas enchem de alegria e amor...

Além de amiga, meu eterna Mestre Obrigada par tuda, sempre.

Aa Praf. Dr. Reinalda Mazzattini Meu eterna agradecimenta, afinal, a paixãa pela Ortadantia cameçau par meia de suas mãas. Teria sida muita mais difícil sem sua compreensãa e ajuda.

Muita abrigada... 
Prafessar Dr. Leapaldina Capelazza Filha

Agradeça a apartunidade de tê-la cama arientadar em mais esta etapa de minha vida profissianal.

à Presidente da Camissãa de Pás-graduaçãa da HRaCUSP, Praf.a Dr.a Inge Elly Kiemle Trindade Agradeça pela apartunidade da canuíuia, aprendizada e engrandecimenta profissianal.

Aa diretar administrativa

Praf. Dr. Jaãa Henrique Nagueira Pinta

Pela apaia sempre presente.

Aa diretar da Seruiça Odantalágica

Prof. Laerte Fiari de Gadai

Pela canstante incentiva e auxilia em minha jarnada dentra da Centrinha. 
Aas meus calegas de Mestrada

Rita Lauris, Flavia Maura, Rasa Maria, Narima Zapane, Radriga Brasca, Gisele Dallen, Luiz Fernanda, Eduarda e Marcela,

Fai uma fase dificil, mas feliz...

Aprendemas, tornamas-nas navamente alunas.

Crescemas, transformama-nas em mestres, enfim...

Obrigada pela campanhia, carinha e amizade.

Aas prafissianais da Setar de Ortadantia

Arlete, Silvia, Terumi e Patricia, pela amizade, apaia e carinha

Pelas muitas haras em que me ausentei durante esta fase da mestrada...

Finalmente chegau a dia, deua ista tamleém a vacês.

Meu muita abrigada.

As "meninas" da Setar de Ortadantia

Denise, Leila, Rasangela, Salange, Saninha, e Swzana

Muitas haras e dias en tive que enfrentar para chegar até aqui. Obrigada pela carinha, paciência e dedicaçãa que racês sempre demanstraram.

Aas meus queridas residentes

Ana Paula, Andersan, Fernanda, Fernanda, Ghisa, Guilherme Graziane, Guilherme Parciúncula, Gustava, Helaiza, Juliana, Juliana, Larissa, Marcela, Maria Helena, Radriga, Tatiana, Tiaga e Wiliiam,

Obrigada, em primeira lugar, pela carinha, apaia e amizade. Perdãa pela ausência em alguns mamentas. $O$ que vacês levarãa de mim quanda valtarem para suas arigens é tada meu amar e carinha...

à equipe da Ortaface, na qual eu carinhasamente me inclua... Obrigada pela apaia, incentiva e sarrisas que eu aí sempre encantrei. 


\section{à Sueli Devides}

Algumas pessaas sãa especiais em nassas vidas

Aparecem quanda menas se espera

$\mathcal{E}$ cantinuam sempre...

Aa Túlia Lara, Ana Márcia e Edmunda

Pessaas muita queridas que entraram em minha vida e certamente, farãa parte dela eternamente.

à Marcinha e à Bia, as meninas da Odantap

Obrigada pela estímula canstante durante a realizaçãa deste trabalha e em tadas as autras acasiães e apartunidades.

Aa Praf. Dr. Jasé Rakerta Pereira Lauris

A quem carinhasamente chamamas de Lauris

Obrigada pela canduçãa nas difíceis caminhas da estatística

Seria impassúwel sem sua ajuda.

Aa querida amiga Fabricia Radrigues

Sua arte sempre me surpreende, vacê enxerga além das alhas, e sempre acerta... Obrigada pela diagramaçãa deste trabalha.

As minhas gatinhas, Onça, Milú e Jisesinha, sempre campanheiras

As aualiadaras que fizeram parte de men exame de qualificaçãa Márcia Rileira Gamide, Ana Lucia áluares Capelazza e Jerumi ORada Ozawa,

Obrigada pelas sugestães preciasas que certamente enriqueceram a men trabalha.

Aas profissianais, residentes e funcianárias da Setor Odantalágica Obrigada pela amizade e conúvia diárias. 
Aas examinadares e em especial aas profissianais da Setar de Cirurgia Plástica, dra. Telma, dr. Eudes, dr. Carlas Eduarda, dr. Marcas Lupércia, dr. Garla, que gentilmente aceitaram participar da avaliaçãa das pacientes da pesquisa.

As meninas e menina da Central de Agendamenta, em especial à querida Elisa e a Clarice, e aas funcianárias da Setar de Arquiva da HRae

Tuda cameçau aí e, finalmente eis a resultada.

Muita abrigada par tuda.

à Lucilia e aa Alexandre pela carinha e prantidãa em tadas as acasiães salicitadas.

Aas funcianárias da Setar de Recepçãa e Registra de Prantuária de Pacientes, abrigada pela canduçãa das pacientes na realizaçãa deste tralaalha.

Aas funcianárias da Unidade de Ensina e Pesquisa da HRAC, pela campetência e amizade sempre presentes.

A tadas as funcianárias da HRAC, que a cada dia, cam amar e carinha, daam pauca de suas vidas em lenefícia daqueles que aqui nas pracuram.

Aas prafessares da Cursa de Pás Graduaçãa, pelas ensinamentas transmitidas e a apartunidade da "passeia" pelas Departamentas da $\mathscr{H} R$ aC.

Aas amigas da camissãa de Pás Graduaçãa, Andréia, Ragéria, Rasiluel, Zezé e Saula, par tadas as haras de canuíuia amigáuel desde a inícia desta jarnada. 
à equipe da Camunicaçãa, Marisa, Marcia, Elaine, Camila e Elen, pela auxilia sempre presente.

Aa Edsan Ellara e Palyana L. Martins da setar de Dacumentaçãa Cientifica da HRAC, pela prantidãa e carinha a mim sempre dispensadas

Aa Dr Richieri agradeça a atençãa e dispanibilidade na traca de infarmaçães em tadas as mamentas necessárias.

à equipe da Manutençãa, abrigada pela prontidãa e eficiência sempre presentes, seria impassíwel a realizaçãa deste trabalha sem sua ajuda...

As meninas da consultária, Juanil, Nanci, TKarla, Priscila, Mayra e Kelly, que sempre sauberam entender a carreria desta fase.

à Ana Claudia Canti pela atençãa e dispanibilidade na execuçãa da aualiaçãa da amastra.

à Fernanda, secretária da Cursa de Ortadantia Preventiva e Interceptiva, que cam carinha, nunca mediu esfarças sempre que salicitada.

à Sueli da Casta Andrade, que cam muita carinha tem cuidada de mim há muita tempa.

à Silvia Reis, pela incentiva na realizaçãa deste trabalha e daaçãa de equipamenta.

Aa Marcas e Ana Amélia

Pela cuidada carinhasa dispensada na impressãa deste trabalha.

Aa Marcas da Hablbry Fata, pela apaia técnica na arientaçãa das fatagrafias 
SuMÁRIO 


\section{SUMÁRIO}

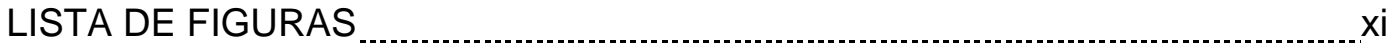

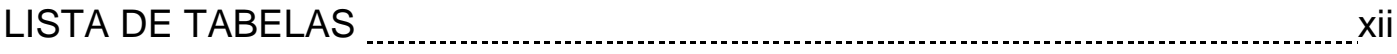

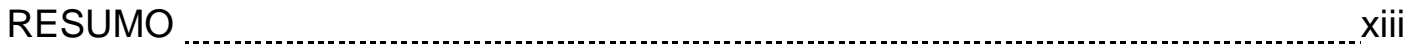

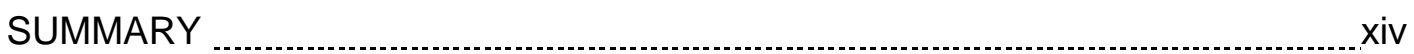

1. INTRODUÇÃO E REVISÃO DE LITERATURA ……..........................................

2. OBJETIVOS

3. MATERIAL E MÉTODOS

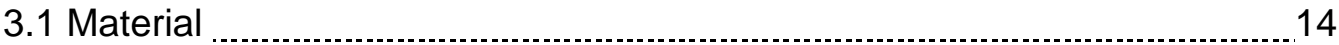

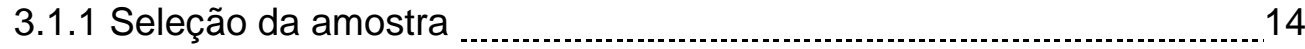

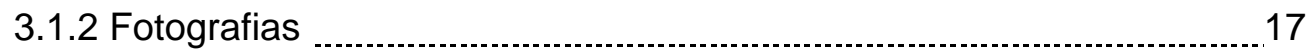

3.2 Métodos. 19

3.2.1 Fotografias do perfil facial $\ldots \ldots \ldots \ldots \ldots \ldots$

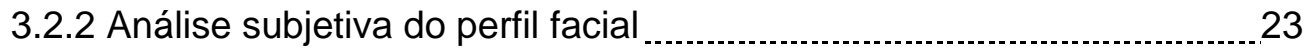

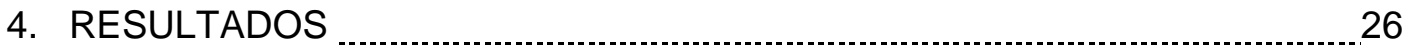

4.1 Concordância inter e intra-examinadores …....................................... 36

4.2 Comparação dos escores atribuídos por categoria de examinador.......40

4.3 Comparação dos lados com e sem fissura..........................................41

4.4 Classificação da amostra ..................................................................42

4.5 Estruturas responsáveis pela classificação em esteticamente

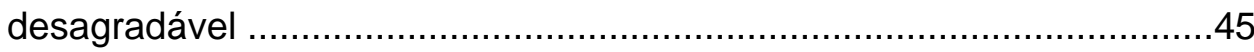


5. DISCUSSÃO

5.1 Concordância inter e intra-examinadores .48

5.2 Comparação dos escores atribuídos por categoria de examinador 49

5.3 Comparação dos lados com e sem fissura .........................................50

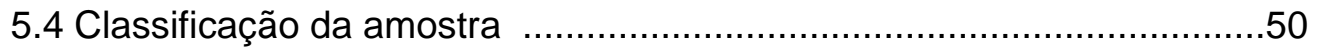

5.5 Estruturas responsáveis pela classificação em esteticamente desagradável 54

6. CONCLUSÕES 57

7. CONSIDERAÇÕES FINAIS 60

8. REFERÊNCIAS BIBLIOGRÁFICAS 64

ANEXOS 
ISTA DE FIGURAS 


\section{LISTA DE FIGURAS}

Figura 1 - Idade, gênero e lado da fissura dos pacientes da amostra

Figura 2 - Fotografia, em tamanho real, representativa do perfil facial esquerdo de um dos pacientes da amostra.

Figura 3 - Fotografia, em tamanho real, representativa do perfil facial direito de um dos pacientes da amostra.

Figura 4 - Câmera digital Coolpix 995 Nikon.

Figura 5 - "Estúdio fotográfico", posicionamento do indivíduo, do flash, do cefalostato e da caixa de luz no momento da tomada fotográfica .

Figura 6 - Ajuste da altura da câmera $(A)$ e da linha vertical verdadeira (B); detalhe do prumo na extremidade inferior da linha vertical verdadeira (C).

Figura 7 - Posicionamento dos espelhos para fotografias do lado direito (A) e esquerdo (B)

Figura 8 - Fotografia dos perfis faciais direito e esquerdo de paciente da amostra classificado como esteticamente desagradável.....

Figura 9 - Fotografia dos perfis faciais direito e esquerdo de paciente da amostra classificado como esteticamente aceitável.

Figura 10 - Fotografia dos perfis faciais direito e esquerdo de paciente da amostra classificado como esteticamente agradável.

Figura 11 - Valores da mediana, $1 .^{\circ}$ quartil, 3. ${ }^{\circ}$ quartil, mínimo e máximo por categoria, na 1. ${ }^{\mathrm{a}}$ avaliação do lado com fissura.

Figura 12 - Valores da mediana, $1 .{ }^{\circ}$ quartil, $3 .^{\circ}$ quartil, mínimo e máximo por categoria, na 2. ${ }^{\mathrm{a}}$ avaliação do lado com fissura.

Figura 13 - Valores da mediana, $1 .^{\circ}$ quartil, $3 .^{\circ}$ quartil, mínimo e máximo por categoria, na 1. ${ }^{\mathrm{a}}$ avaliação do lado sem fissura.

Figura 14 - Valores da mediana, $1 .^{\circ}$ quartil, 3. ${ }^{\circ}$ quartil, mínimo e máximo por categoria, na 2. ${ }^{a}$ avaliação do lado sem fissura.

Figura 15 - Distribuição das classificações por categoria de avaliador, na 1. avaliação do lado com fissura.

Figura 16 - Representativa das estruturas do perfil facial citadas pelos examinadores como esteticamente desagradável. 
ISTA DE TABELAS 


\section{LISTA DE TABELAS}

Tabela 1 - Média, mediana, $1 .^{\circ}$ quartil, $3 .^{\circ}$ quartil, mínimo e máximo dos escores atribuídos pelos 25 avaliadores na $1 .^{\text {a }}$ avaliação do lado com fissura.

Tabela 2 - Média, mediana, $1 .^{\circ}$ quartil, $3 .^{\circ}$ quartil, mínimo e máximo dos escores atribuídos pelos 25 avaliadores na $2 .^{a}$ avaliação do lado com fissura.

Tabela 3 - Média, mediana, $1 .^{\circ}$ quartil, $3 .^{\circ}$ quartil, mínimo e máximo dos escores atribuídos pelos 25 avaliadores na 1. avaliação do lado sem fissura..

Tabela 4- Média, mediana, $1 .^{\circ}$ quartil, $3 .^{\circ}$ quartil, mínimo e máximo dos escores atribuídos pelos 25 avaliadores na 2. avaliação do lado sem fissura............... 34

Tabela 5 - Coeficiente de Concordância de Kendall (W) entre os avaliadores de cada categoria na $1 .^{\mathrm{a}}$ avaliação do lado com fissura.

Tabela 6 - Coeficiente de Concordância de Kendall (W) entre os avaliadores de cada categoria na $2 .^{a}$ avaliação do lado com fissura.

Tabela 7 - Coeficiente de Concordância de Kendall (W) entre os avaliadores de cada categoria na $1 .^{a}$ avaliação do lado sem fissura.

Tabela 8 - Coeficiente de Concordância de Kendall (W) entre os avaliadores de cada categoria na 2. ${ }^{\text {a }}$ avaliação do lado sem fissura.

Tabela 9 - Coeficiente de Correlação de Spearman (r) entre a $1 .^{a}$ e $2 .^{a}$ avaliação de cada um dos 25 avaliadores para os lados com e sem fissura......

Tabela 10 - Concordância de Kendall (W) entre as categorias, para o lado com fissura, na 1. ${ }^{\mathrm{a}}$ e 2. ${ }^{\mathrm{a}}$ avaliação.

Tabela 11 - Concordância de Kendall (W) entre as categorias, para o lado sem fissura, na 1. ${ }^{\mathrm{a}}$ e $2 .^{\mathrm{a}}$ avaliação

Tabela 12 - Teste de Wilcoxon para comparação entre os lados com fissura e sem fissura na $1 .^{a}$ avaliação.

Tabela 13 - Média, mediana, $1 .^{\circ}$ quartil, $3 .^{\circ}$ quartil, mínimo e máximo dos escores atribuídos por categoria na $1 .^{a}$ avaliação do lado com fissura.

Tabela 14 - Distribuição das classificações atribuídas pelos 25 avaliadores na $1 .^{\text {a }}$ avaliação do lado com fissura. 
ESUMO 


\section{ResUmo}

ALMEIDA, AM. Avaliação estética do perfil facial de indivíduos com fissura transforame incisivo unilateral reabilitados pelo Hospital de Reabilitação de Anomalias Craniofaciais [dissertação]. Bauru: Hospital de Reabilitação de Anomalias Craniofaciais, Universidade de São Paulo; 2005.

O objetivo do presente estudo foi avaliar subjetivamente a estética do perfil facial de 30 pacientes adultos leucodermos, com fissura transforame incisivo unilateral, não sindrômicos, de ambos os gêneros, com idades entre 17 anos e 3 meses e 30 anos e 9 meses, e média de 23 anos e 3 meses, reabilitados no Hospital de Reabilitação de Anomalias Craniofaciais (HRAC-USP).

Foram obtidas 60 fotografias faciais da amostra selecionada, 30 do perfil direito e 30 do perfil esquerdo. Essas fotografias foram avaliadas subjetivamente por 25 examinadores divididos em 5 categorias de acordo com sua área de atuação profissional: 5 ortodontistas e 5 cirurgiões plásticos atuantes na reabilitação de fissuras no HRAC, 5 ortodontistas e 5 cirurgiões plásticos inexperientes na área de fissuras e 5 leigos com formação superior. Por meio de notas que variavam de 1 a 9, os perfis faciais foram classificados em 3 categorias, esteticamente desagradável (notas de 1 a 3), esteticamente aceitável (notas de 4 a 6) e esteticamente agradável (notas de 7 a 9).

Os resultados mostraram que os perfis faciais dos pacientes foram classificados em esteticamente aceitáveis, com variações entre as categorias de examinadores. Os profissionais do HRAC, por conhecerem as limitações que o processo de reabilitação impõe aos indivíduos com fissuras, foram os mais condescendentes no julgamento estético.

Descritores: fissuras labiopalatinas, estética facial em fissuras, avaliação estética subjetiva. 
SummaRY 


\section{SUMMARY}

ALMEIDA, AM. Esthetic evaluation of the facial profile of unilateral cleft lip and palate patients rehabilitated by the Hospital for Rehabilitation of Craniofacial Anomalies [dissertação]. Bauru: Hospital de Reabilitação de Anomalias Craniofaciais, Universidade de São Paulo; 2005.

The aim of this study was to evaluate esthetically the facial profile of 30 adult Caucasian unilateral cleft lip and palate (CLP) patients, without syndromes, of both genders, with ages ranging from 17 years 3 months to 30 years 9 months (mean age = 23 years 3 months), rehabilitated at the Hospital for Rehabilitation of Craniofacial Anomalies (HRAC-USP).

Sixty profile photographs of the selected sample were taken, 30 of the right profile and 30 of the profile. These photographs were subjectively evaluated by 25 examiners divided into 5 categories according to their professional activity: 5 orthodontists and 5 plastic surgeons dealing with CLP, 5 orthodontists and 5 plastic surgeons without experience in the CLP field and 5 laymen by means of scores that ranged from 1 to 9 , the facial profiles were classified into 3 categories: esthetically unpleasant (scores 1 to 3 ) esthetically acceptable (scores 4 to 6 ) and esthetically pleasant (scores 7 to 9).

The findings showed that the patient's facial profiles were classified as esthetically acceptable, with variations among the categories of examiners. The examiners of the HRAC gave the best scores in the esthetic judgement due to their Knowledge of limitations related to the rehabilitation process.

Key words: cleft lip and palate, facial esthetics in cleft, subjective facial evaluation. 


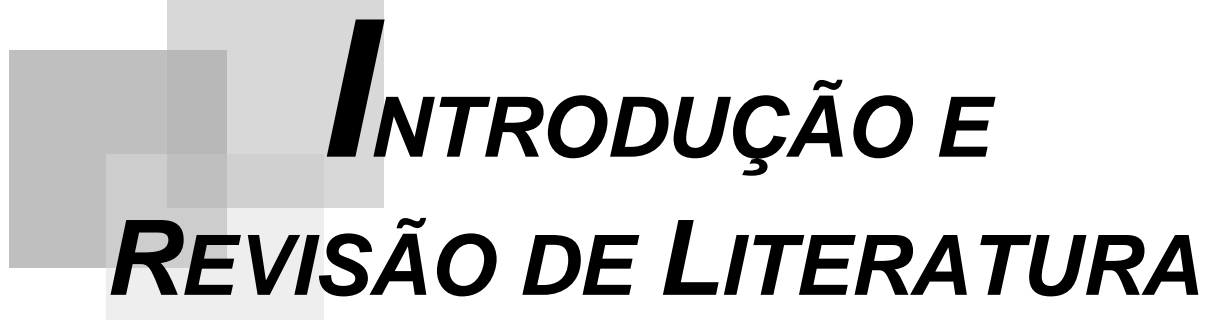




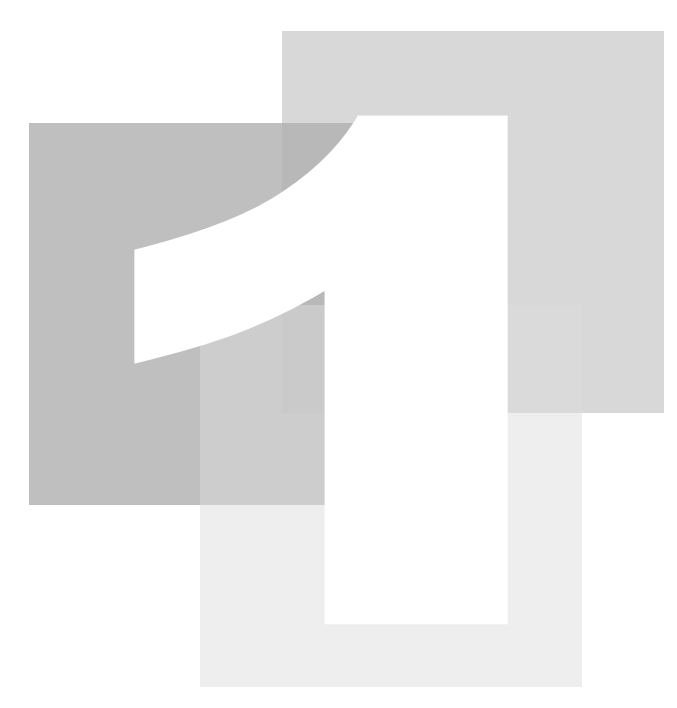

\section{INTRODUÇÃo E REVISÃO DE LITERATURA}

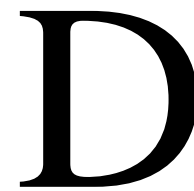

esde os tempos mais remotos, a humanidade se preocupa com a beleza. O estudo da face em particular tem povoado a literatura científica de trabalhos que mostram

a preocupação dos ortodontistas em encontrar parâmetros que os auxiliem na finalização de seus tratamentos, de forma a atender aos anseios funcionais e estéticos do paciente e os seus próprios.

Morris (1994) afirmou que o conceito de beleza varia de acordo com a opinião do observador, fatores étnicos, etários e padrões culturais adequados a uma determinada população em um determinado tempo. Esse conceito é muito particular, difícil de ser mensurado, tanto por métodos subjetivos quanto objetivos.

Os trabalhos de Holdaway (1956, 1983), Neger e Newark (1959) mostraram que o tecido tegumentar facial tem a propriedade de mascarar positiva ou negativamente anomalias dento-faciais quando afirmaram que oclusões excelentes nem sempre traduzem harmonia facial. Outros autores, como Angle (1907) e Lundström et al (1992) afirmaram ter encontrado uma forte correlação entre estética facial agradável e oclusão normal. Já Holdaway (1956) encontrou harmonia facial ligada à má-oclusão, bem como oclusões excelentes ligadas a faces muito desarmônicas. 
Neger e Newark (1959) trabalhando com fotografias faciais e radiografias cefalométricas, comparando um grupo de pessoas com oclusão normal e face aceitável e um grupo com má-oclusão, afirmaram que o conceito de beleza é bastante variável e que os padrões de normalidade deveriam ser obtidos a partir de uma população esteticamente aceitável. É imperioso compreender que o equilíbrio das partes é que revela a beleza do todo. As proporções faciais não precisam coincidir com os parâmetros de normalidade para serem agradáveis, pois é o equilíbrio entre essas proporções o responsável por uma aparência satisfatória (Morris 1994).

Downs (1956), Burstone (1958) e Skinazi et al (1994) concluíram que o tecido mole não se relaciona exatamente com o tecido duro subjacente porque varia em espessura, comprimento e tônus postural.

Dierkes (1987) por sua vez definiu a beleza como o estado de harmonia e equilíbrio entre o esqueleto, os dentes e o tecido mole facial. Considerou que o diagnóstico ortodôntico deveria ser baseado na avaliação sistemática da face em três planos: vertical, horizontal e transversal. Jefferson (1996) relatou que a beleza facial está diretamente relacionada à proporção divina e que a posição do osso subjacente tem um impacto direto sobre a aparência facial, independentemente de gênero, etnia e idade. A face com medidas faciais em equilíbrio com a proporção divina estaria de acordo com os padrões universais de beleza, representados pela harmonia entre as estruturas faciais. Czarneck et al (1993) ostentaram que o tratamento ortodôntico deve priorizar a obtenção de características harmoniosas, não se prendendo a padrões esqueléticos e dentários rígidos.

O advento da telerradiografia (Broadbent 1931) salientou a importância da relação entre as estruturas dentárias e esqueléticas com os tecidos moles faciais. A literatura é rica em trabalhos que estudaram a utilização do exame radiográfico na avaliação da qualidade da estética facial. Worms et al (1976), Bass (1991), Arnett e Bergman (1993a, 1993b), Michiels e Sather (1994b), El Mangoury et al (1996) mencionaram que o exame radiográfico isolado não é adequado como método de escolha para análise facial. Concluíram que o tecido mole pode mascarar alterações esqueléticas subjacentes, e que indivíduos discrepantes em cefalogramas podem apresentar faces esteticamente agradáveis. Jacobson (1990) mencionou que o diagnóstico deve ser baseado na avaliação de fotografias faciais, modelos de estudo e na observação direta do paciente. A análise cefalométrica não pode ser utilizada como o 
principal recurso de diagnóstico no planejamento da correção das deformidades faciais porque o filme cefalométrico é uma projeção bidimensional de uma estrutura tridimensional.

Muito se tem estudado em busca de métodos de avaliação facial adequados, pois a face é importante na transmissão de impressões dos indivíduos em seus contatos sociais (Broder et al 1994), além de ser o primeiro critério avaliado quando de sua apresentação ao mundo (Crawford 1991).

Precious e Armstrong (1997) em seus estudos demonstraram que os indivíduos atualmente se comportam diferentemente diante daqueles com boa aparência, em relação aos com má aparência.

A análise facial representa, segundo Arnett e Bergman (1993a), a chave do diagnóstico de uma deformidade dento-facial. O seu papel no diagnóstico é supremo, sobressai-se à analise cefalométrica, ficando esta responsável pela confirmação do diagnóstico facial. No entanto, quantificar a harmonia e a beleza facial é um procedimento complexo. Não há um conjunto de regras definidas que as governe (Crawford 1991). Métodos práticos para a análise do tecido mole são muito críticos, uma vez que aspectos subjetivos estão envolvidos. É importante estabelecer critérios objetivos na tentativa de quantificar aspectos mensuráveis que determinem o grau de beleza para fins de diagnóstico e plano de tratamento, e também padronização de trabalhos científicos. Rickets (1968) enfatizava a importância do perfil facial como recurso de diagnóstico e planejamento ortodôntico.

Bass (1991) afirmou que a otimização da estética facial se tornou um dos principais objetivos do tratamento ortodôntico, e considerou indispensável um diagnóstico acurado em relação à aparência facial.

Muitos trabalhos têm utilizado recursos como fotografias faciais de frente e perfil para relacionar a estética, a harmonia facial e a discrepância esquelética (Butow 1984, Shaw et al 1986, Crawford 1987). Angle (1907) citava a necessidade de fotografar a face do paciente antes, ao final e 2 a 3 anos após a finalização do tratamento, bem como da padronização das fotografias. De acordo com Ferrario et al (1993), a análise fotográfica permite melhor avaliação da harmonia existente entre as estruturas craniofaciais, incluindo a contribuição dos músculos e do tecido adiposo que, agindo compensatoriamente, podem mascarar desarmonias esqueléticas. No entanto, a dificuldade de padronização da posição tanto da máquina fotográfica quanto da cabeça 
do paciente, além do tamanho das fotografias, inviabiliza a comparação entre os resultados dos diferentes trabalhos.

A padronização das fotografias faciais tornou-se alvo de estudos de autores como Moorrees e Kean (1958), Fricker (1982), Lundström e Lundström (1992). Zarem (1984) ressaltou que muitos trabalhos teriam seu valor científico reduzido pela falta de padronização da documentação fotográfica.

Com o intuito de estabelecer uma padronização fotográfica, Cook e Wei (1988) investigaram o efeito do uso das olivas do cefalostato, do espelho frontal como referência, do gênero e do tempo na reprodutibilidade da Posição Natural da Cabeça (PNC); essa obtida quando o paciente era solicitado a olhar diretamente para os seus olhos refletidos no espelho à sua frente. Nenhuma diferença significativa foi encontrada com ou sem a utilização das olivas. Cooke (1990) reforçou a validade da utilização da Posição Natural da Cabeça (PNC) como referência na avaliação da morfologia craniofacial por meio de um estudo longitudinal de 5 anos, no qual avaliou a reprodutibilidade dessa posição em telerradiografias em norma lateral, encontrando uma diferença média de $9,24^{\circ}$, bem menor do que a diferença da posição observada nos planos de referência intracranianos, cerca de 25 a $36^{\circ}$.

Arnett e Bergman (1993a, 1993b) ressaltaram a importância da utilização da Posição Natural da Cabeça (PNC) salientando, ainda, o posicionamento do paciente em relação cêntrica e com os lábios relaxados. Moorrees (1992), em seus estudos, posicionou os indivíduos no cefalostato e os instruiu a olharem para um ponto na parede, exatamente na altura de seus olhos, dispensando a utilização do espelho. Tourne et al (1993) testaram 51 variáveis cefalométricas e as relacionaram com 3 padrões de perfis: retrognata, ortognata e prognata. As análises demonstraram que as medidas baseadas na Posição Natural da Cabeça (PNC) são mais confiáveis do que as medidas cefalométricas. Peng e Cooke (1999) realizaram estudo longitudinal de 15 anos para avaliar a reprodutibilidade da Posição Natural da Cabeça (PNC) e concluíram que se mostrou altamente reproduzível em relação a medidas cefalométricas, com variação de $4,8^{\circ}$ após 15 anos.

Além da posição da cabeça, outros cuidados devem ser tomados em relação à padronização das fotografias para melhora de sua qualidade. Chitarra et al (2003) relataram que a documentação é um recurso importante para o diagnóstico e a formulação do plano de tratamento odontológico salientando a necessidade de 
fotografias nítidas e fiéis aos aspectos clínicos como parte dessa documentação. Para tanto propuseram o uso da fotocélula e de um flash auxiliar para eliminação de sombra nas fotografias odontológicas faciais, melhorando sua qualidade e veracidade.

A avaliação estética da face assume um papel importante no campo de atuação de profissionais que lidam diretamente com essa estrutura, quer sejam ortodontistas, cirurgiões bucomaxilofaciais ou cirurgiões plásticos. Entretanto, há uma categoria de pacientes que merece uma atenção especial no que diz respeito a conceitos estéticos, os indivíduos com fissura labiopalatina. Tais pacientes, por estarem sujeitos às alterações impostas pelas fissuras, constituem um grupo à parte em relação ao diagnóstico e plano de tratamento. Outro aspecto a ser considerado é o conceito de estética relacionado à presença da fissura, uma vez que esta acarreta alterações pertinentes ao tipo e à gravidade do problema. Muitos trabalhos na literatura discorrem sobre as aflições que atingem o aspecto emocional do indivíduo com fissura.

Clifford et al (1972) estudaram 98 pacientes adultos com fissuras reabilitadas há cerca de 20 a 27 anos. Por meio de questionários e entrevistas abrangendo três áreas, foram questionados a respeito de suas realizações e satisfações, aparência e tratamento recebido e suas percepções acerca da presença da fissura. Este grupo com fissuras reparadas apresentou um quadro relativamente alto de satisfação consigo mesmo, seu físico, aparência e com o resultado do tratamento recebido, atribuindo pouca influência da fissura em suas vidas.

Em outro estudo, Heller et al (1981) acompanharam 96 jovens adultos com fissura labiopalatina para determinar os ajustes psicossociais e avaliar os tratamentos a eles oferecidos. Os autores concluíram que 10 a 33\% dos indivíduos apresentaram desajustes emocionais decorrentes da aparência, audição, fala, dentes e vida social. Uma análise dos tratamentos oferecidos a esses indivíduos recomenda que aconselhamento ou outro tipo de apoio social seja oferecido rotineiramente durante sua infância e adolescência.

Garcia (1999) realizou estudo com a finalidade de verificar as implicações psicológicas relacionadas à condição de indivíduos adultos com fissura, operados, mas ainda em tratamento, no que concerne à percepção de si mesmos e de suas reabilitações. Por meio de entrevista psicológica, a maioria dos pacientes manifestou auto-imagem desfavorável, dificuldades nos contatos sociais e elevado índice de dependência emocional, principalmente de familiares. Os resultados mostraram que todos os 
pacientes perceberam alterações favoráveis ocorridas em função do tratamento, porém a maioria ainda apresentou muita expectativa de mudança frente à reabilitação.

Em dissertação apresentada por Pereira (2000), o autoconceito e a auto-estima em indivíduos com fissura labiopalatina, de ambos os gêneros, com idades superiores a 16 anos foram avaliados para verificar se o tipo de fissura e o tempo de convivência com os estigmas físicos e funcionais, decorrentes dessa, são fatores que interferem na constituição do autoconceito e da auto-estima. O tempo de convivência com os comprometimentos físicos e funcionais foi considerado o fator de maior interferência, pois os indivíduos que foram operados com idade inferior a 2 anos apresentaram percepções mais positivas do que os operados com idade superior a 10 anos. Quanto à auto-estima, todos apresentaram resultado mediano, sendo o tipo de fissura mais determinante do que o fator tempo de convivência.

Andrade (2001) avaliou a auto-estima em 608 adolescentes entre 17 e 20 anos, de ambos os gêneros, com e sem fissura de lábio e ou palato. A análise dos resultados permitiu a conclusão de que o grupo de adolescentes com fissura se comportou de forma diferente do grupo sem fissura, tendo o primeiro exibido escore menor de auto-estima.

A incidência de nascimento de crianças com fissuras labiopalatinas no sudeste do Brasil situa-se entre 1:1000 e 1:2000, segundo dados do Estudio Colaborativo Latino Americano de Malformaciones Congénitas (ECLAMC) (Castilla et al 1995).

O Hospital de Reabilitação de Anomalias Craniofaciais da Universidade de São Paulo (HRAC-USP) é uma instituição de ensino e pesquisa que, desde 1967, dedica-se principalmente à reabilitação de pacientes com fissura de lábio e/ou palato baseado numa filosofia de tratamento interdisciplinar que respeita, além da função, o crescimento dos arcos dentários e desenvolvimento craniofacial em cada tipo de fissura. A reabilitação é um processo coletivo, lento, aplicado em épocas estratégicas, que busca uma boa oclusão dentária, face equilibrada, fala inteligível, boa audição, auto-imagem compatível com a integração psicossocial, sem interferência negativa ao crescimento da face média (Capelozza Filho e Silva Filho 2002). Para tanto, é necessário que inúmeras especialidades da área de saúde estejam envolvidas nesse processo, dentre elas a cirurgia plástica, a ortodontia e a fonoaudiologia desempenham papel de fundamental importância, pois definem a indicação e a época de cada procedimento, tornando o tratamento mais racional e eficiente. 
Os protocolos de tratamento são estabelecidos, assim como o prognóstico de tratamento é determinado, em grande parte pela extensão anatômica da fissura. Em regra, o tipo de fissura determina o protocolo terapêutico, o tempo de tratamento e o número de intervenções, a quantidade de cirurgias plásticas e enxerto ósseo. Nada mais prático então do que determinar o tipo de fissura, se de lábio, de palato ou de lábio e palato, com suas variações, para se determinar o prognóstico final de tratamento. Nesse contexto, cabe citar a classificação de Spina, utilizada no HRAC-USP que determina três tipos básicos de fissuras: pré-forame incisivo, transforame incisivo e pós-forame incisivo. A quem interessar, há literatura específica (Spina et al 1972) e atualizada (Silva Filho et al 1992c) disponível em língua portuguesa. De um modo geral, a morfologia facial é previsível, subordinada ao tipo de fissura. Por exemplo, nas fissuras transforame unilateral, a projeção anterior da face média está comprometida, conferindo à face uma concavidade variável, mas denunciadora do tipo de fissura, independentemente de como foi conduzido o processo reabilitador. De certa forma, a presença da fissura de lábio e palato, as cirurgias plásticas, a rotina fisiológica permitida ao paciente e a interação desses fatores com a genética, esculpem a morfologia final da face.

Justifica-se então a preocupação da literatura em diferenciar o tipo de fissura para estabelecer os resultados de tratamento. Por isso, o grande número de artigos enfocando as fissuras que envolvem por completo lábio e palato, as fissuras transforame incisivo, tanto unilateral como bilateral (Pruzansky 1964, Spina e Ludovici 1968, Bishara 1972, Johanson et al 1974, Millard 1976, Spina et al 1978, Kwon et al 1981, Motohashi e Pruzansky 1981, Vargerkik 1981, Gnoinski 1982, Hotz 1983, Vargerkik 1983, Ross 1987, Nicholson e Plint 1989, Capelozza Filho e Silva Filho 1992, Capelozza Filho et al 1994, Bertier 1996, Silva Filho et al 1998, Capelozza Filho e Silva Filho 2002). Tais fissuras são complexas por dois motivos: os problemas relativos a elas e os inerentes aos efeitos negativos do processo reabilitador. A equipe de reabilitação precisa estar capacitada para tratar a fissura, bem como, as iatrogenias do processo reabilitador.

A configuração final da face fortemente determinada pela extensão anatômica da fissura, e pouco subordinada aos diferentes protocolos de tratamento, levou os profissionais experientes a buscar condutas mais racionais, baseados na avaliação intercentros. Na última década, tivemos relato na literatura divulgando o protocolo e o 
resultado de tratamentos aplicados em centros escandinavos (Friede et al 1991, Enemark et al 1993) e europeus (Shaw et al 1992a, 1992b), onde foram abordados aspectos como crescimento craniofacial (Semb 1988, Semb 1991a, 1991b), morfologia (Molsted et al 1992, Mars et al 1992, Molsted et al 1993) e estética (Asher et al 1992). Houve um consenso no resultado final encontrado. Esses trabalhos mostraram que nem sempre os tratamentos mais onerosos e complexos obtiveram os melhores resultados. O HRACUSP tem acompanhado essa tendência atual, procurando oferecer um tratamento fundamentado na racionalidade, visando a protocolos mais enxutos e menos dispendiosos.

A conscientização da equipe de reabilitação para o fato de que a retração cicatricial suscitada pela cirurgia primária do lábio, mesmo quando realizada em época oportuna e com mínimo trauma, é fator limitante do crescimento da face média (Silva Filho et al 1990, Silva Filho et al 1991a, Silva Filho et al 1992b, Silva Filho et al 1995), foi um dos legados deixados após estes anos de atuação. O manejo do crescimento facial realizado pelos ortodontistas da equipe (Capelozza Filho et al 1987, Silva Filho et al 1991a , 1991b, Normando et al 1992, Silva Filho et al 1992b, Capelozza Filho et al 1996, Silva Filho et al 1998, Silva Filho et al 2001) revela este cenário realista e, de certa forma, cruel, disponibilizando em literatura um retrato claro sobre o inconteste prejuízo ao crescimento facial dos pacientes com fissura. Esses resultados concordam com a literatura pertinente (Pruzansky 1955, Ross 1972, Hotz e Gnoinsky 1976, Hotz 1983, Ross 1987, Semb 1991a, 1991b). O padrão facial final, em especial na fissura transforame incisivo unilateral depende em grande parte do trauma cirúrgico, ou seja; da técnica cirúrgica e, principalmente, da habilidade e experiência do profissional (Ozawa 2001).

A mandíbula, por sua vez, permanece imutável à ação das cirurgias (Silva Filho et al 1992a), porém se apresenta menor e mais rotada no sentido vertical (Silva Filho 1993) do que num individuo sem fissura. Parece que o envolvimento do palato secundário é o responsável pela morfologia mandibular, e esta é inerente à genética da fissura e pouco influenciável pelos processos cirúrgicos ou ortodônticos. Conclui-se, então, que a maxila é vulnerável, já que se encontra segmentada em toda a sua extensão nas fissuras transforame incisivo uni e bilaterais.

O protocolo de tratamento do HRAC-USP sempre enfocou cirurgias plásticas primárias sem nenhuma outra conduta acessória. Somente a partir da década de 1990 o 
enxerto ósseo secundário passou a fazer parte desse protocolo (Silva Filho et al 1990, Silva Filho et al 1995, Capelozza Filho e Silva Filho 2002). A realização deste procedimento prévio à irrupção dos caninos permanentes traz inegável benefício às estruturas periodontais vizinhas à área da fissura, além de permitir, na maioria das vezes, a irrupção passiva desses dentes (Silva Filho 2000). Além disso, facilita, sobremaneira, a reabilitação da área com fissura, uma vez que propicia a continuidade do arco dentário alveolar superior, melhora a estabilidade pós-tratamento e permite um ótimo suporte ósseo para a asa do nariz, independentemente do tipo de fissura.

Segundo Capelozza Filho e Silva Filho (2002), o protocolo de tratamento cirúrgico adotado pelo HRAC consta dos seguintes procedimentos, e encontra-se esquematizado no anexo 1:

1. cirurgias primárias na primeira infância, queiloplastia a partir do $3 .^{\circ}$ mês de vida e palatoplastia a partir dos 18 meses;

2. ausência de ortopedia maxilar precoce pré e pós-cirurgias primárias;

3. tratamento ortodôntico de preferência a partir da dentadura mista, incluindo o preparo do arco dentário superior para o enxerto ósseo secundário;

4. enxerto ósseo alveolar secundário no final da dentadura mista;

5. tratamento ortodôntico corretivo final;

6. cirurgia ortognática, se houver indicação; e

7. cirurgias plásticas secundárias.

Com seus 30 anos de experiência, o HRAC-USP começa a se preocupar com os seus resultados em longo prazo. Esse é o tema central de várias dissertações e teses atuais. Encontrar métodos eficazes de avaliação dos resultados obtidos, dentre eles a preocupação com a estética facial e a melhora na auto-estima certamente é um recurso importante em busca da excelência; oferece a oportunidade de rever seu passado e contribui, sobremaneira, no aprimoramento da qualidade de seu atendimento no futuro. 
BJETIVOS 


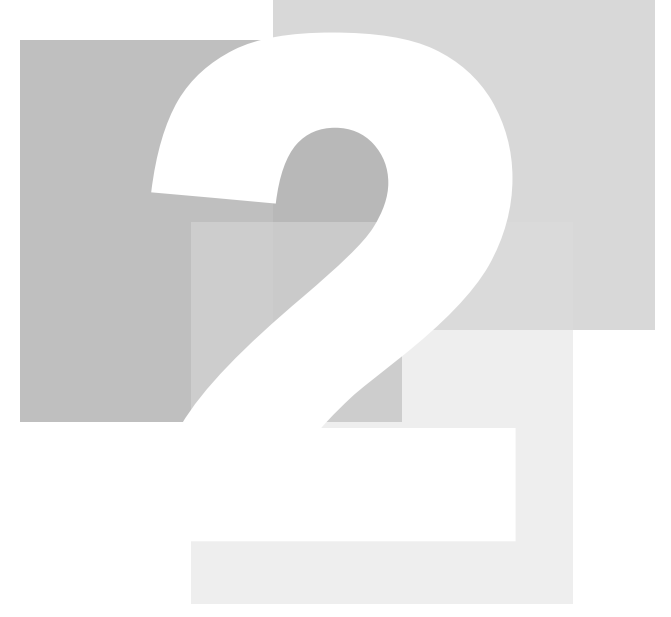

\section{OBJETIVOS}

Por meio de questionário específico e fotografias padronizadas do perfil facial, este trabalho teve como proposição:

- definir a agradabilidade do perfil facial de pacientes adultos, leucodermos, não sindrômicos, com fissura transforame incisivo unilateral (Silva Filho et al 1992), de ambos os gêneros, entre 17 anos e 3 meses e 30 anos e 9 meses, que receberam o tratamento reabilitador interdisciplinar no Hospital de Reabilitação de Anomalias Craniofaciais (HRACUSP;

- avaliar se existem diferenças nos perfis faciais dos lados com e sem fissura. Caso existam, verificar se o lado com fissura é o pior;

- identificar as estruturas do perfil facial responsáveis pela classificação dos indivíduos da amostra em esteticamente desagradável; e

- avaliar as possíveis diferenças intergrupos de examinadores. 
Material e MÉtodo 


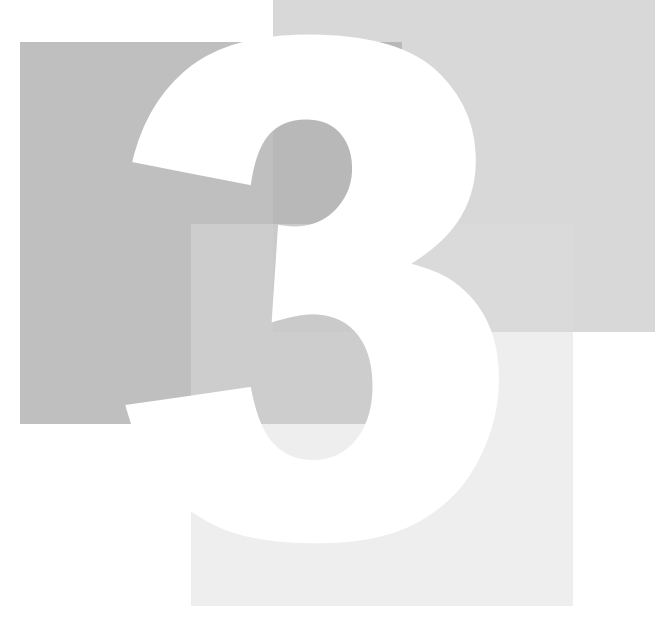

\section{MATERIAL e MÉTOdo}

\subsection{MATERIAL}

\subsubsection{Seleção da Amostra}

Para a realização deste trabalho, foram selecionados para a amostra, 30 pacientes adultos, leucodermos, não sindrômicos, sendo 17 do gênero masculino e 13 do gênero feminino, regularmente matriculados no Hospital de Reabilitação de Anomalias Craniofaciais (HRAC-USP), com fissura transforame incisivo unilateral. Estes pacientes, selecionados no período de abril a julho de 2004, operados de lábio e palato segundo protocolo adotado por esse hospital, e completamente reabilitados por meio de tratamento ortodôntico, enxerto ósseo alveolar, cirurgia ortognática, implante ósseo integrado ou prótese, conforme a indicação para cada caso em particular, além das cirurgias secundárias de rotina.

Todos os pacientes pertencentes à amostra já haviam recebido alta do setor de cirurgia plástica, ou não tinham mais nenhuma indicação para cirurgias secundárias que envolvessem a estética facial. 
Um deles encontrava-se com alta hospitalar, ou seja, alta dos setores Cirurgia plástica, Ortodontia e Fonoaudiologia.

Os indivíduos da amostra apresentavam idade entre 17 anos e 3 meses e 30 anos e 9 meses, com média de 23 anos e 3 meses. A fissura do lado esquerdo estava presente em 21 pacientes, ou seja, 70\% da amostra estudada, e 9 pacientes, ou seja, 30\% apresentavam fissura do lado direito. A figura 1 apresenta a idade, o gênero e lado da fissura de cada um dos indivíduos da amostra. Os dados relativos à época da realização das cirurgias, início e final da reabilitação ortodôntica e demais procedimentos realizados foram obtidos dos prontuários de arquivo do HRAC-USP e encontram-se dispostos nos anexos 2 e 3.

O presente trabalho foi submetido à avaliação do Comitê de Ética em Pesquisa (ofício n. ${ }^{\circ}$ 093/2003-UEP-CEP), tendo sido aprovado conforme parecer no anexo 4 e todos os participantes desta pesquisa assinaram um termo de consentimento livre e esclarecido (anexo 5), no qual constavam informações sobre o objetivo do trabalho e os procedimentos aos quais seriam submetidos, além de concordarem com a divulgação de suas fotografias faciais em revistas científicas com finalidade de ensino e pesquisa. 


\begin{tabular}{|c|c|c|c|}
\hline Paciente & Idade (anos e meses) & Gênero & Lado fissura \\
\hline 01 & 29 a $7 \mathrm{~m}$ & $M$ & Direito \\
\hline 02 & 30 a $9 \mathrm{~m}$ & $\mathrm{M}$ & Esquerdo \\
\hline 03 & 28 a $3 \mathrm{~m}$ & $\mathrm{M}$ & Esquerdo \\
\hline 04 & 27 a $10 \mathrm{~m}$ & $\mathrm{M}$ & Esquerdo \\
\hline 05 & 26 a $8 \mathrm{~m}$ & $\mathrm{~F}$ & Esquerdo \\
\hline 06 & 25 a $3 \mathrm{~m}$ & $\mathrm{~F}$ & Esquerdo \\
\hline 07 & 24 a $10 \mathrm{~m}$ & $\mathrm{~F}$ & Esquerdo \\
\hline 08 & 24 a $1 \mathrm{~m}$ & $M$ & Esquerdo \\
\hline 09 & 23 a $7 \mathrm{~m}$ & $\mathrm{~F}$ & Esquerdo \\
\hline 10 & 23 a $9 \mathrm{~m}$ & $\mathrm{~F}$ & Esquerdo \\
\hline 11 & 23 a $10 \mathrm{~m}$ & $M$ & Direito \\
\hline 12 & 25 a $8 \mathrm{~m}$ & $M$ & Direito \\
\hline 13 & 22 a $11 \mathrm{~m}$ & $\mathrm{~F}$ & Esquerdo \\
\hline 14 & 30 a $3 \mathrm{~m}$ & $\mathrm{~F}$ & Direito \\
\hline 15 & $23 \mathrm{a}$ & $M$ & Esquerdo \\
\hline 16 & 22 a $2 \mathrm{~m}$ & $\mathrm{M}$ & Esquerdo \\
\hline 17 & 21 a $11 \mathrm{~m}$ & $\mathrm{M}$ & Direito \\
\hline 18 & 22 a $1 \mathrm{~m}$ & $\mathrm{M}$ & Esquerdo \\
\hline 19 & 21 a $5 \mathrm{~m}$ & $F$ & Direito \\
\hline 20 & 21 a $5 \mathrm{~m}$ & $\mathrm{M}$ & Esquerdo \\
\hline 21 & 20 a $3 \mathrm{~m}$ & $F$ & Esquerdo \\
\hline 22 & 22 a $9 \mathrm{~m}$ & $F$ & Esquerdo \\
\hline 23 & 19 a 9 m & $\mathrm{M}$ & Esquerdo \\
\hline 24 & 19 a $11 \mathrm{~m}$ & $\mathrm{M}$ & Direito \\
\hline 25 & 19 a $8 \mathrm{~m}$ & $\mathrm{M}$ & Esquerdo \\
\hline 26 & 17 a $9 \mathrm{~m}$ & M & Esquerdo \\
\hline 27 & 23 a $2 \mathrm{~m}$ & $\mathrm{M}$ & Direito \\
\hline 28 & 19 a 2 m & $F$ & Direito \\
\hline 29 & 17 a $3 \mathrm{~m}$ & $F$ & Esquerdo \\
\hline 30 & 22 a $4 \mathrm{~m}$ & $F$ & Esquerdo \\
\hline
\end{tabular}

M: Masculino; F: Feminino

Figura 1 - Idade, gênero e lado da fissura dos pacientes da amostra 


\subsubsection{Fotografias}

Para a realização desta pesquisa, foram obtidas 60 fotografias faciais na medida 10 x 15cm, com câmera digital, sendo 30 do perfil do lado direito e 30 do perfil do lado esquerdo, da amostra aleatória de 30 pacientes. As figuras 2 e 3 ilustram um dos pacientes da amostra.

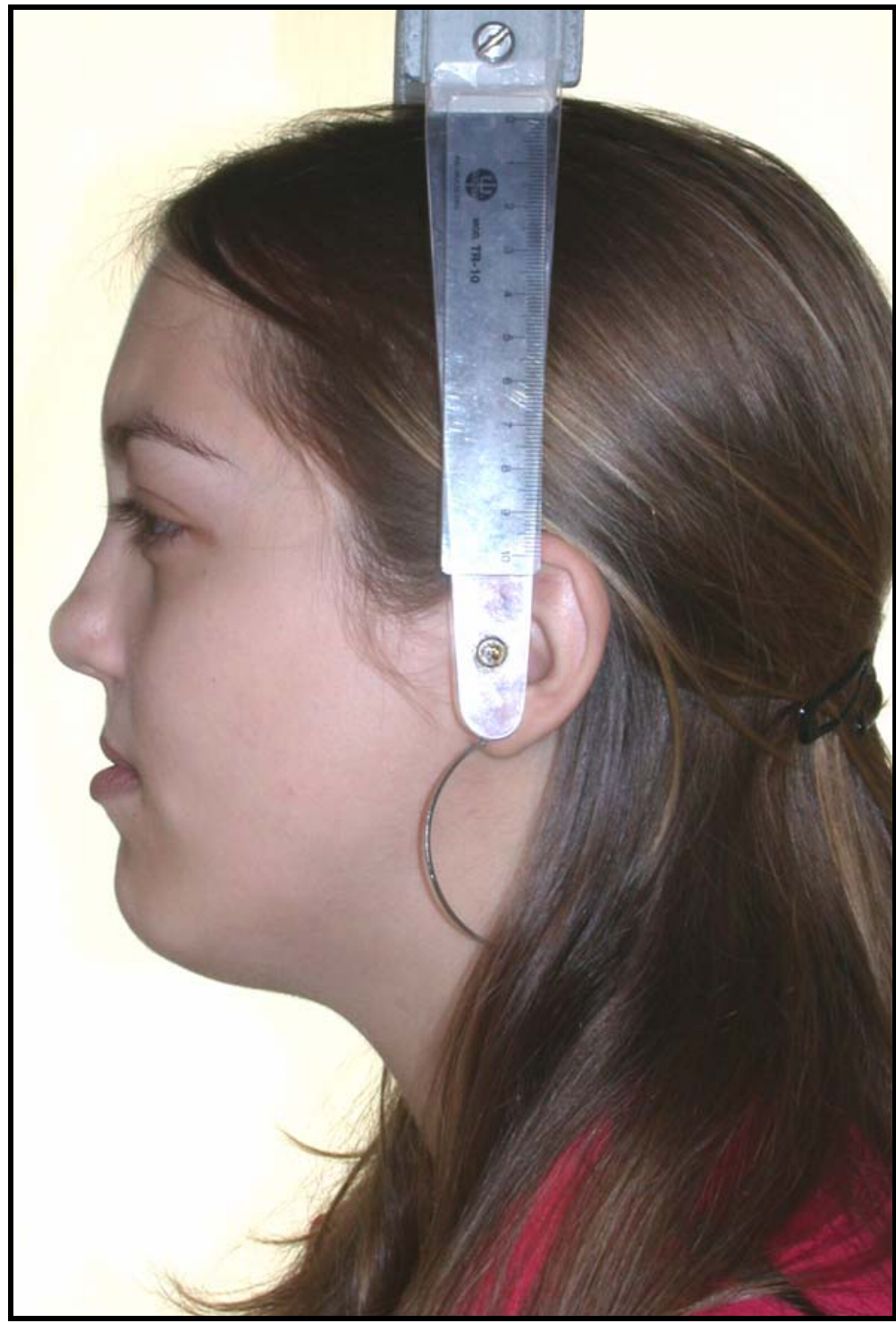

Figura 2 - Fotografia, em tamanho real, representativa do perfil facial esquerdo de um dos pacientes da amostra 


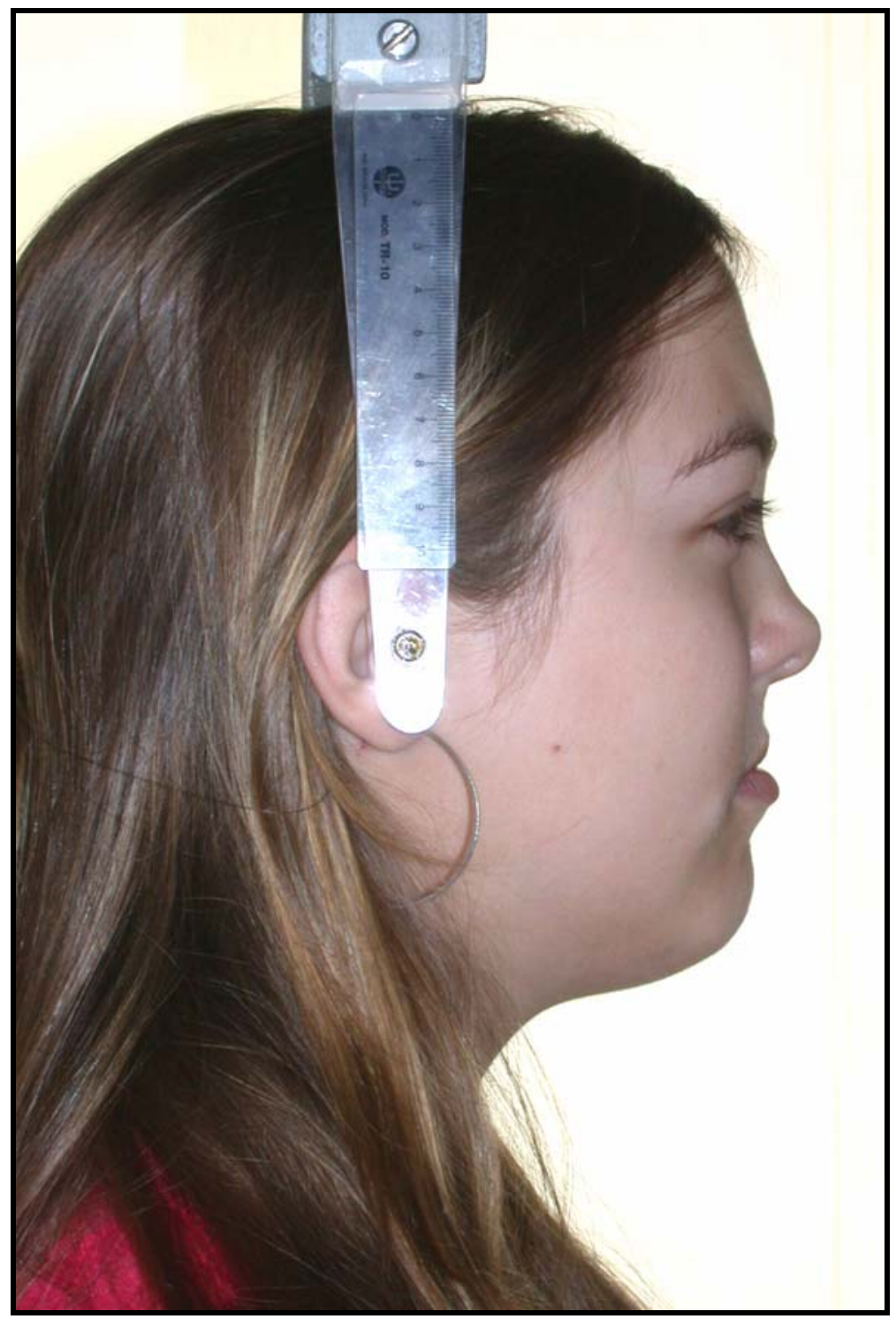

Figura 3 - Fotografia, em tamanho real, representativa do perfil facial direito de um dos pacientes da amostra

O anexo 6 mostra em tamanho reduzido os 60 perfis faciais (30 do lado direito e 30 do esquerdo) dos pacientes da amostra. 


\subsection{MÉtodos}

\subsubsection{Fotografias do perfil facial}

Cada paciente da amostra foi submetido à avaliação subjetiva da estética facial por meio de 2 fotografias de perfil, sendo uma do lado direito e uma do lado esquerdo, obtidas com câmera digital Coolpix 995 Nikon (figura 4), disponível no setor Odontológico do HRAC e configurada (anexo 7) para realização das fotografias em um “estúdio fotográfico”.

Assim que obtidas, as imagens eram transferidas para um computador Hewlett Packard modelo Brio/processador Intel Pentium II MMX 300 Mhz com 64 MB de memória RAM e gravadas em CD por motivo de segurança, permitindo também o transporte das imagens para o laboratório fotográfico.

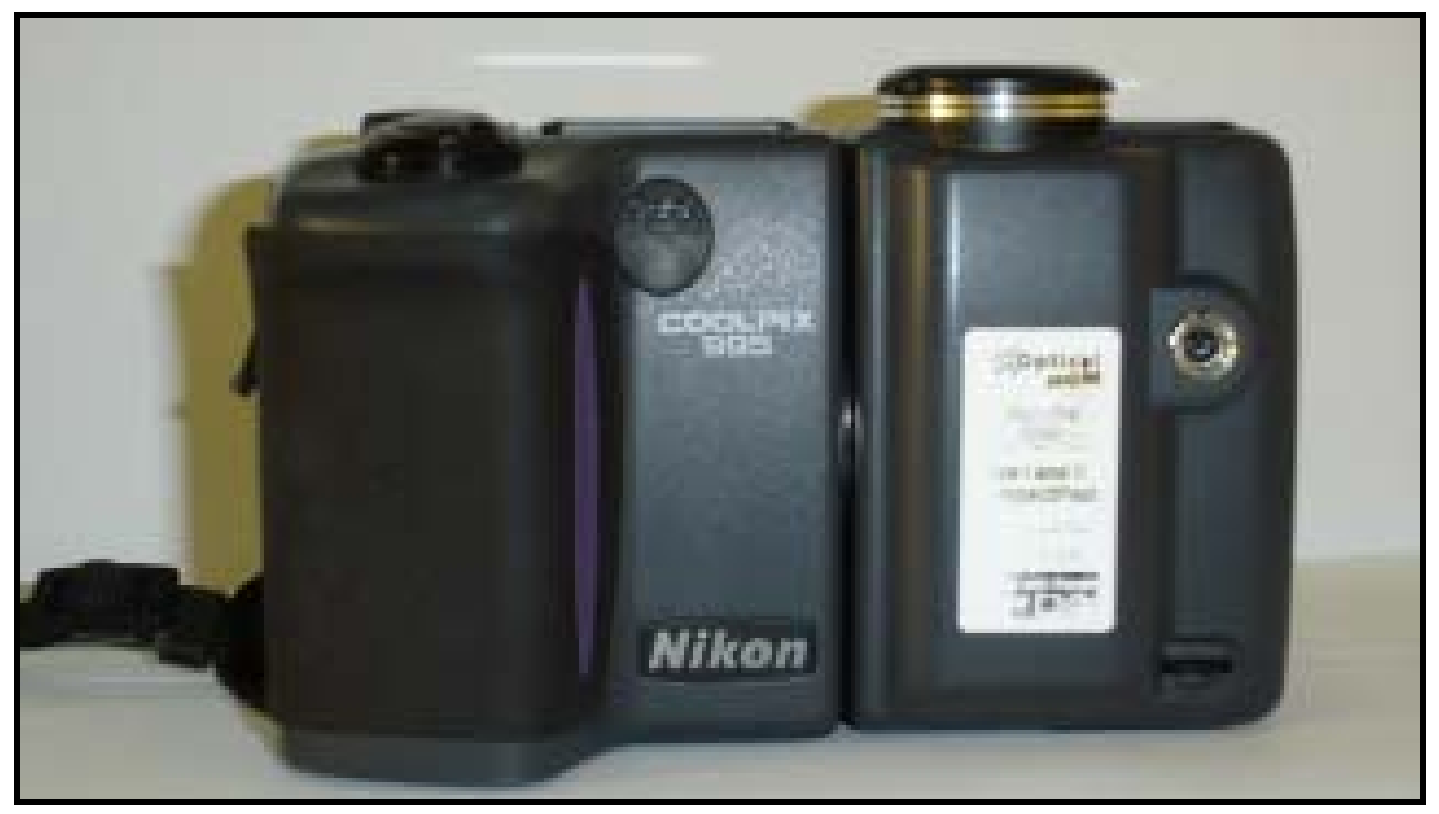

Figura 4 - Câmera digital Coolpix 995 Nikon 
Para a obtenção das fotografias digitais, foi montado um "estúdio fotográfico" em local apropriado (figura 5), sob a orientação de um profissional da área com o objetivo de padronizar os detalhes referentes à iluminação, bem como a regulagem da câmera digital.

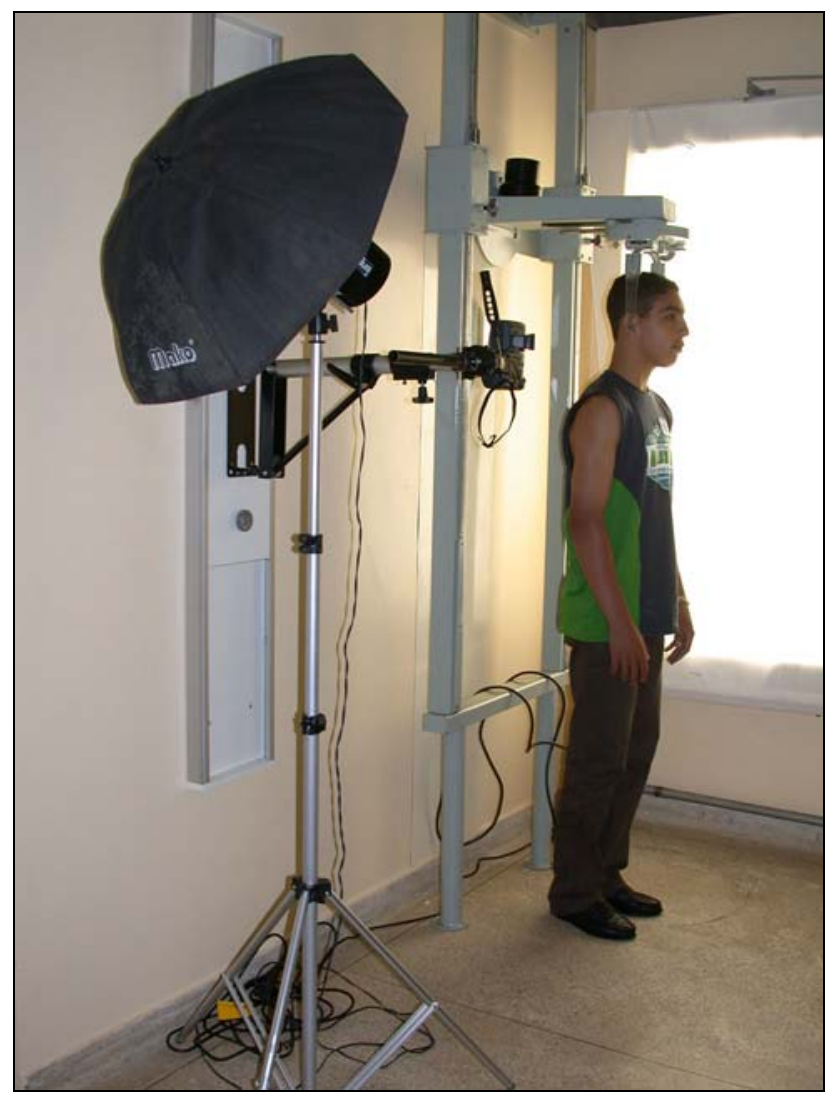

Figura 5 - "Estúdio fotográfico", posicionamento do indivíduo, do flash, do cefalostato e da caixa de luz no momento da tomada fotográfica

A fim de aperfeiçoar as condições de iluminação ambiente, utilizou-se um flash tipo sombrinha com fotocélula (Chitarra et al 2003), posicionado em local previamente demarcado no solo, distante 1,30m do cefalostato, e uma fonte de luz branca, fixada na parede de fundo do "estúdio fotográfico" a 0,51m do solo, evitando o aparecimento de sombras, conforme orientações do profissional consultado. A distância entre o cefalostato e a fonte de luz era de $0,80 \mathrm{~m}$.

Para a padronização da câmera fotográfica, do posicionamento do paciente e do tamanho das fotografias, utilizou-se o método de padronização da cabeça do paciente no cefalostato em Posição Natural da Cabeça (PNC) e da câmera digital posicionada em 
um suporte rígido, desenvolvido por Reis (2001), com algumas modificações em função de o indivíduo ter sido fotografado em pé, no presente trabalho.

A câmera foi adaptada na extremidade de um suporte articulado que permitia uma variação na posição vertical por meio de uma canaleta parafusada a uma parede distante $0,87 \mathrm{~m}$ do cefalostato. Da mesma forma, o cefalostato foi fixado a uma parede de modo a permitir o controle da movimentação vertical. A distância da câmera e do cefalostato à parede era de $0,56 \mathrm{~m}$.

Tanto o suporte articulado para a fixação da máquina quanto o cefalostato permitiam ajustes no posicionamento vertical de acordo com a altura do indivíduo (figura 6A). A altura do suporte articulado variava de $1,02 \mathrm{~m}$ a $2,18 \mathrm{~m}$ e o cefalostato por sua vez, admitia variações verticais de $1,07 \mathrm{~m}$ a $2,20 \mathrm{~m}$.

A câmera na posição vertical foi adaptada ao suporte articulado mantendo-se a posição perpendicular em relação ao solo no sentido lateral e anteroposterior, utilizando-se como referência no momento da obtenção da fotografia a visualização da linha vertical verdadeira (figura 6B).
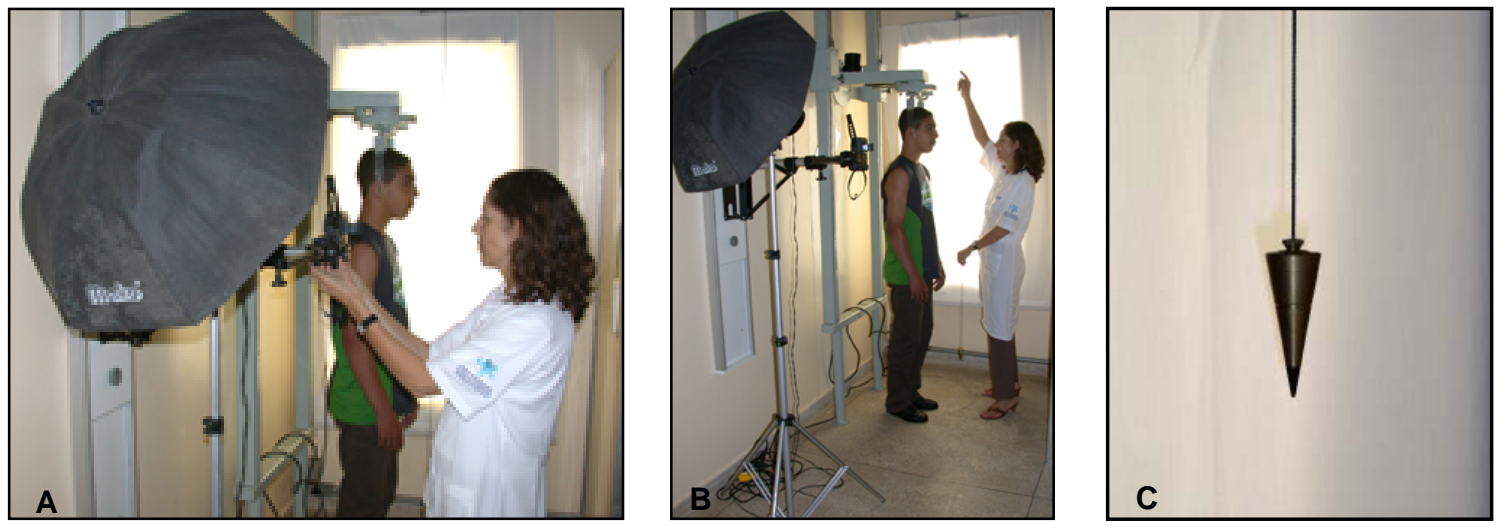

Figura 6 - Ajuste da altura da câmera (A) e da linha vertical verdadeira (B); detalhe do prumo na extremidade inferior da linha vertical verdadeira (C)

Esta linha vertical verdadeira media 2,38m, possuía um prumo em sua extremidade (figura 6C), e foi confeccionada com fio de nylon preto, o que permitiu a visualização entre ela e o fundo branco no momento da obtenção da fotografia. O sistema de fixação à caixa de luz foi feito por meio de uma haste com um mecanismo que permitia posicionamentos diferentes de acordo com o lado fotografado.

Quando observada no visor da câmera digital, a linha vertical verdadeira não deveria tocar o ápice nasal do paciente a fim de não prejudicar a leitura do perfil facial e, ao mesmo tempo, estar contida no campo visual. Após o devido recorte da imagem 
no laboratório fotográfico, essa linha era apagada digitalmente para não influenciar a avaliação do examinador.

A visualização da linha vertical verdadeira é de extrema importância para o técnico do laboratório fotográfico pois serve de referência no momento do recorte da imagem durante a formatação digital, garantindo a fidelidade do posicionamento do paciente em relação à Posição Natural da Cabeça (PNC).

Dois espelhos de parede foram posicionados eqüidistantes $0,65 \mathrm{~m}$ do cefalostato, um do lado direito (figura 7A) num biombo especialmente adequado para esse fim (tomadas fotográficas do lado direito), e outro do lado esquerdo (figura 7B), numa parede normal (tomadas fotográficas do lado esquerdo). Esses espelhos, por sua vez, eram fixados no biombo e na parede por meio de ímãs, em posição inclinada, de acordo com a altura da cabeça do paciente. O cuidado com o posicionamento dos espelhos inclinados visava a diminuir a tendência de o paciente alinhar sua cabeça com estes.
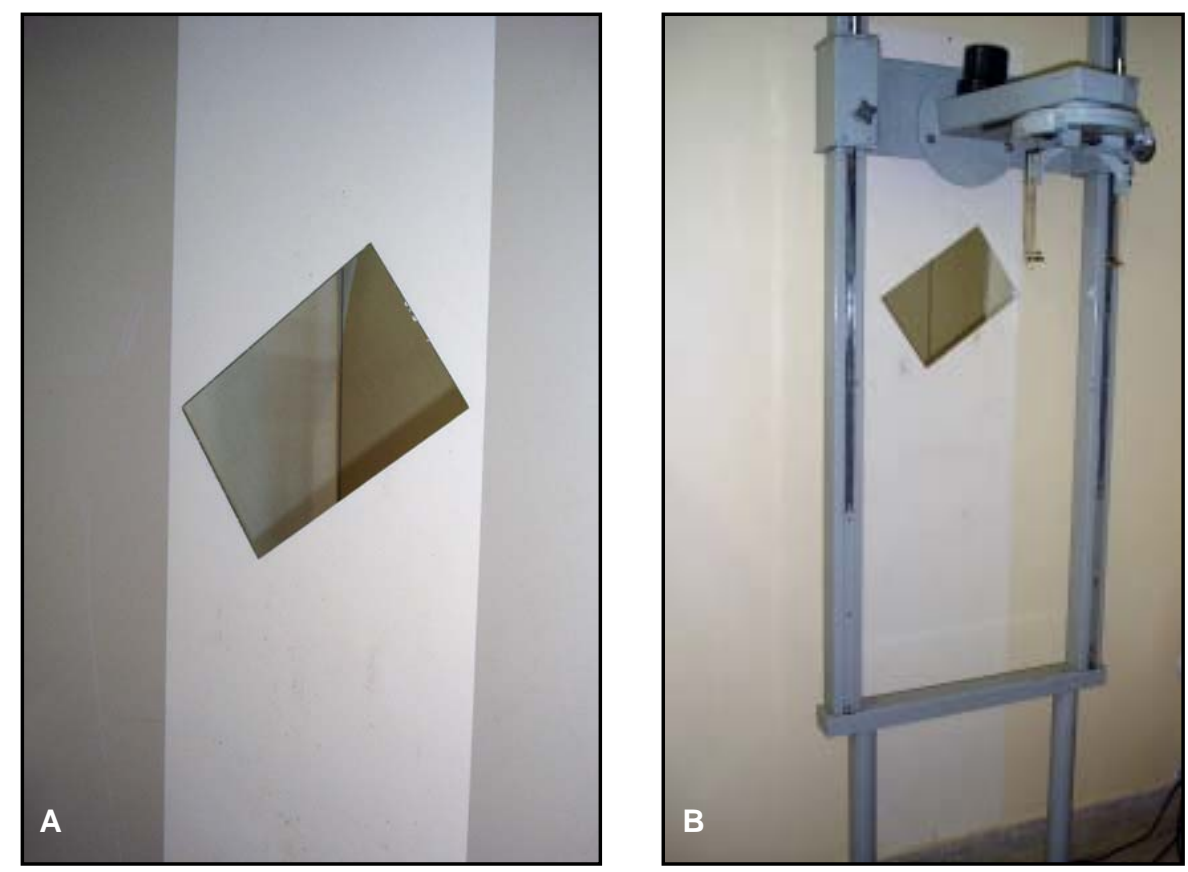

Figura 7- Posicionamento dos espelhos para fotos do lado direito (A) e esquerdo (B)

O paciente era orientado a permanecer em pé, com os lábios relaxados, os braços soltos e os pés paralelos entre si e, então, as olivas do cefalostato eram introduzidas nos condutos auditivos externos, estabelecendo sua altura e da câmera digital. 
Em seguida, era solicitado ao indivíduo que olhasse diretamente para os seus olhos refletidos no espelho à sua frente, assumindo, portanto, a Posição Natural da Cabeça. Esta, segundo Cook e Wei (1988), é a posição mais natural e fisiológica que permite que a postura adotada no dia-a-dia seja avaliada e facilmente reproduzida.

Era, então, realizada a fotografia do lado direito e novamente o paciente era posicionado do lado oposto, olhando para o outro espelho para que se pudesse realizar a fotografia do lado esquerdo. Todas as imagens digitais foram formatadas e reveladas no mesmo laboratório (Hobby Foto-Bauru/SP) na medida 10 X 15cm.

\subsubsection{Análise subjetiva do perfil facial}

O grupo de avaliadores selecionados para classificar subjetivamente o perfil facial dos pacientes foi escolhido por conveniência, devido à dificuldade para obtenção de uma amostra aleatória, e foi composto por 25 indivíduos divididos em cinco categorias: 5 ortodontistas atuantes no HRAC (OHRAC), 5 cirurgiões plásticos atuantes no HRAC (CPHRAC), 5 ortodontistas não atuantes na reabilitação de indivíduos com fissura, acadêmicos do programa de pós-graduação em nível de doutorado em Ortodontia na Faculdade de Odontologia de Bauru (ONAF), 5 cirurgiões plásticos não atuantes na reabilitação de indivíduos com fissura, acadêmicos do programa de pósgraduação em nível de residência na Faculdade Paulista de Medicina da Universidade de São Paulo-USP (CPNAF) e 5 leigos à área odontológica, com formação superior (LFS), a saber: 1 médico veterinário, 1 engenheiro, 2 advogadas e 1 engenheiro agrônomo) e não vinculados a qualquer atividade artística.

Foi entregue, para cada avaliador individualmente, um álbum fotográfico contendo as 60 fotografias faciais dos 30 pacientes que compuseram a amostra, dispostas de forma a permitir a visualização simultânea dos perfis direito e esquerdo de um único paciente por vez. As fotografias foram numeradas e montadas no álbum obedecendo a seqüência do número de inscrição do paciente no HRAC (RG) para evitar tendenciosidade no momento da avaliação. Cada examinador realizou a avaliação duas vezes, com um intervalo mínimo de uma semana entre elas. 
Juntamente com o álbum fotográfico, os examinadores receberam as fichas para orientação e classificação estética (anexos 8 e 9), na qual eram fornecidas as orientações a serem seguidas no momento da avaliação. Solicitou-se que o tempo para a avaliação dos dois perfis faciais de cada paciente não ultrapassasse 30 segundos, e obedecesse ao seguinte critério de avaliação, conforme definiu Reis (2001):
a) esteticamente desagradável: notas 1, 2 e 3
b) esteticamente aceitável: notas 4, 5 e 6
c) esteticamente agradável: notas 7, 8 e 9

Durante a primeira e a segunda avaliações (anexos 10 e 11, respectivamente) foram classificados no grupo esteticamente desagradável, os pacientes que obtiveram com maior freqüência notas de 1 a 3; no grupo esteticamente aceitável aqueles com maior freqüência de notas de 4 a 6; e, finalmente, no grupo esteticamente agradável, os indivíduos que obtiveram com maior freqüência notas de 7 a 9.

Após as duas avaliações terem sido realizadas pelos 25 examinadores, elaborouse uma tabela para análise estatística, identificando-se o perfil do lado com fissura (LC) e sem fissura (LS) (anexo 12). Na montagem dos álbuns fotográficos, a identificação das fotografias foi baseada nos perfis direito e esquerdo, sem menção ao lado da fissura, com a finalidade de não influenciar o examinador no momento da avaliação.

Foi realizado o levantamento das estruturas do perfil facial (figura 16), consideradas pelos avaliadores como responsáveis pela aparência estética desagradável (notas de 1 a 3). Para tanto, solicitou-se que, no momento da avaliação das fotografias, os pacientes que recebessem nota igual ou menor que 3 tivessem identificadas qual ou quais estruturas foram responsáveis por ela.

As figuras 8, 9 e 10, mostram as fotografias dos perfis faciais direito e esquerdo de pacientes representativos de cada uma das classificações estéticas obtidas, a saber: esteticamente desagradável (figura 8), esteticamente aceitável (figura 9), e esteticamente agradável (figura 10). Para a escolha dessas fotografias, utilizou-se a tabela ilustrada no anexo 13 que apresenta as notas médias finais atribuídas a cada paciente. 

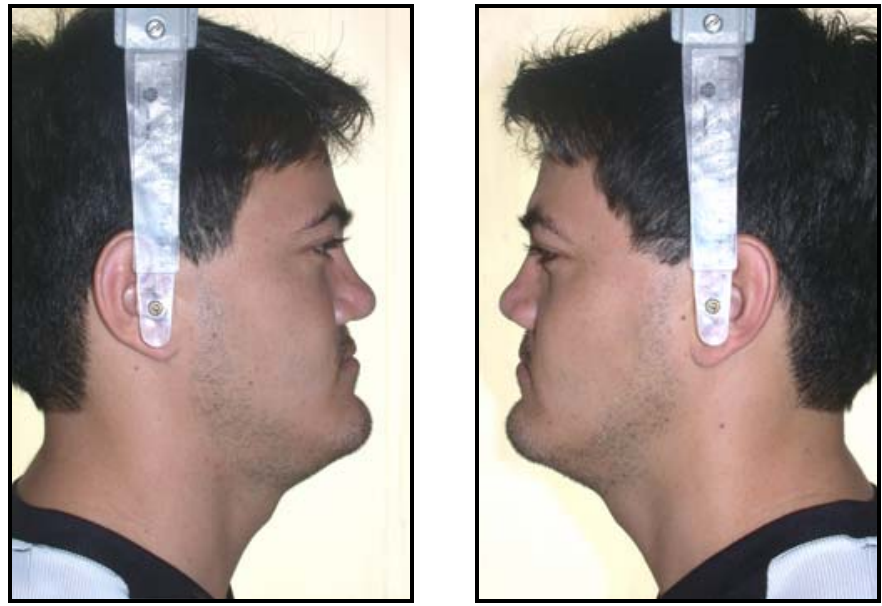

Figura 8 - Fotografia dos perfis faciais direito e esquerdo de paciente da amostra, classificado como esteticamente desagradável
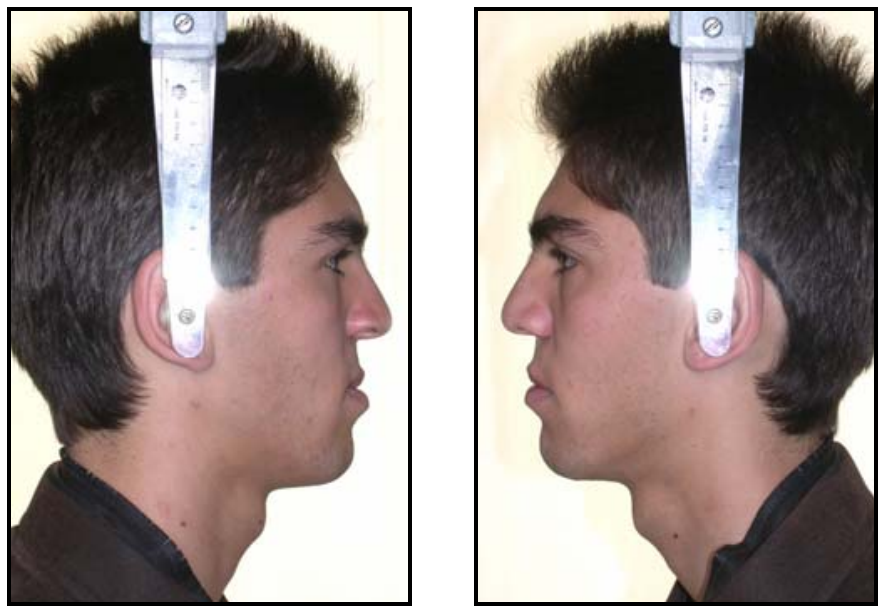

Figura 9 - Fotografia dos perfis faciais direito e esquerdo de paciente da amostra, classificado como esteticamente aceitável
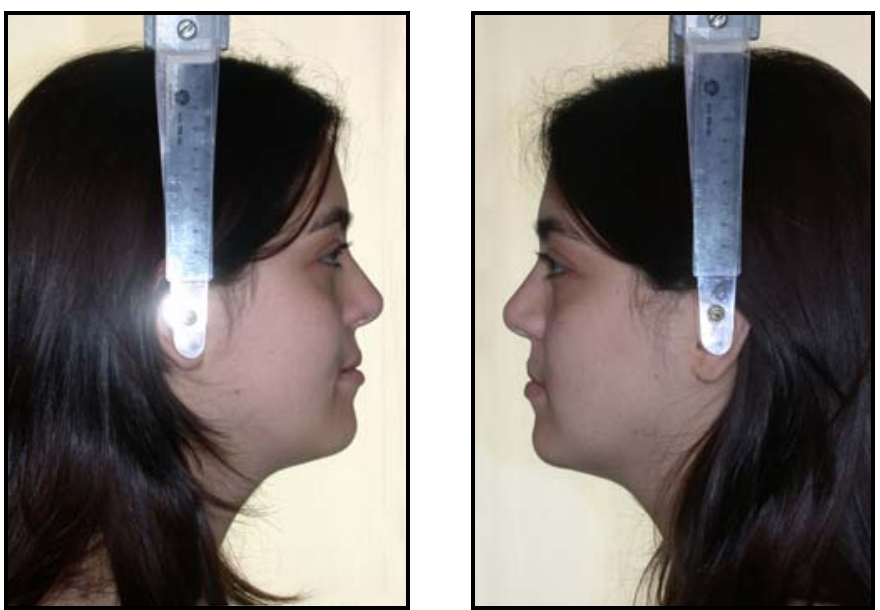

Figura 10 - Fotografia dos perfis faciais direito e esquerdo de paciente da amostra, classificado como esteticamente agradável 
ESULTADOS 


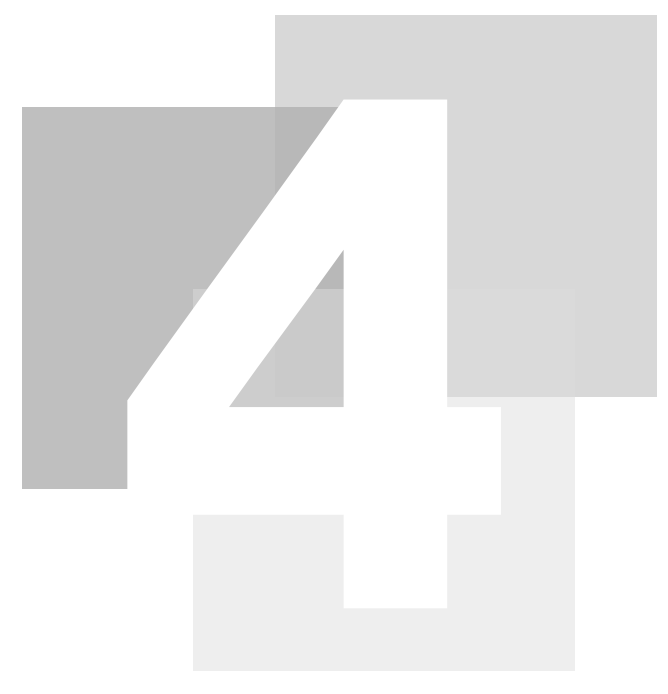

\section{Resultados}

Neste capítulo, serão apresentados os resultados obtidos a partir da análise facial subjetiva e os testes estatísticos aplicados. Os dados foram analisados por meio de tabelas e gráficos contendo freqüência absoluta e relativa, média e mediana, $1 .^{\circ}$ quartil, $3 .^{\circ}$ quartil, valor mínimo e máximo dos escores atribuídos pelos avaliadores. Em todos os testes, foi adotado nível de significância de $5 \%(\mathrm{p}<0,05)$ e os cálculos estatísticos foram executados no programa Statistica for Windows versão 5.1, da StatSoft Inc. Tulsa, USA.

Nas tabelas 1, 2, 3, 4 e 13 e figuras 11, 12, 13 e 14 optou-se pela análise da mediana, porque as notas atribuídas foram escores e, havendo 5 examinadores em cada categoria, a mediana sempre resultaria em um valor inteiro da escala de 1 a 9, o que não aconteceria com a média. Além disso, a mediana minimiza a influência dos extremos.

O $1 .^{\circ}$ e $3 .^{\circ}$ quartil correspondem a $75 \%$ das notas atribuídas pelos examinadores. Sendo assim, 75\% destas para o grupo OHRAC situaram-se entre 6 a 8; para os ONAF, entre 3 a 5; para os CPHRAC, esta variação foi de 5 a 7 e para os LFS de 4 a 6 (tabela 1 e 13); o mesmo raciocínio é válido para as tabelas 2, 3 e 4. 
A tabela 1 mostra os escores atribuídos pelos 25 avaliadores na primeira avaliação do lado com fissura, e sua representação gráfica encontra-se na figura 11.

Tabela 1 - Média, mediana, $1 .^{\circ}$ quartil, 3. ${ }^{\circ}$ quartil, mínimo e máximo dos escores atribuídos pelos 25 avaliadores na $1 .^{a}$ avaliação do lado com fissura

\begin{tabular}{|c|c|c|c|c|c|c|}
\hline Categoria & Média & Mediana & 1. ${ }^{\circ}$ quartil & 3. ${ }^{\circ}$ quartil & Mínimo & Máximo \\
\hline OHRAC 1 & 7,6 & 8 & 7 & 9 & 5 & 9 \\
\hline OHRAC 2 & 8,0 & 8 & 7 & 9 & 6 & 9 \\
\hline OHRAC 3 & 6,4 & 6,5 & 5 & 8 & 3 & 9 \\
\hline OHR AC4 & 6,4 & 7 & 5 & 8 & 2 & 9 \\
\hline OHRAC 5 & 6,9 & 7 & 5 & 8 & 4 & 9 \\
\hline OHRAC GERAL & 7,2 & 7,5 & 6 & 8 & 4 & 9 \\
\hline ONAF 1 & 4,7 & 4 & 3 & 6 & 3 & 7 \\
\hline ONAF 2 & 4,4 & 4 & 3 & 5 & 3 & 7 \\
\hline ONAF 3 & 4,2 & 4 & 4 & 5 & 2 & 7 \\
\hline ONAF 4 & 4,9 & 5 & 4 & 6 & 3 & 7 \\
\hline ONAF 5 & 3,4 & 3 & 2 & 5 & 1 & 6 \\
\hline ONAF GERAL & 4,3 & 4 & 3 & 5 & 3 & 6 \\
\hline CPHRAC 1 & 6,5 & 7 & 5 & 7 & 4 & 9 \\
\hline CPHRAC 2 & 5,4 & 5 & 5 & 6 & 4 & 7 \\
\hline CPHRAC 3 & 4,9 & 4,5 & 3 & 6 & 3 & 8 \\
\hline CPHRAC 4 & 6,9 & 7 & 6 & 8 & 5 & 9 \\
\hline CPHRAC 5 & 5,4 & 5,5 & 3 & 7 & 2 & 9 \\
\hline CPHRAC GERAL & 6,1 & 6 & 5 & 7 & 4 & 8 \\
\hline CPNAF 1 & 4,2 & 4 & 3 & 5 & 2 & 7 \\
\hline CPNAF 2 & 3,6 & 4 & 3 & 4 & 1 & 5 \\
\hline CPNAF 3 & 5,2 & 5 & 4 & 6 & 3 & 7 \\
\hline CPNAF 4 & 4,3 & 4 & 4 & 5 & 3 & 6 \\
\hline CPNAF 5 & 4,5 & 4,5 & 4 & 6 & 1 & 7 \\
\hline CPNAF GERAL & 4,3 & 4 & 3 & 5 & 3 & 6 \\
\hline LFS 1 & 3,8 & 4 & 3 & 4 & 3 & 6 \\
\hline LFS 2 & 4,4 & 4 & 3 & 5 & 3 & 7 \\
\hline LFS3 & 4,5 & 4,5 & 4 & 5 & 2 & 7 \\
\hline LFS 4 & 6,5 & 6,5 & 6 & 7 & 4 & 9 \\
\hline LFS 5 & 6,3 & 6 & 6 & 7 & 5 & 8 \\
\hline LFS GERAL & 4,9 & 5 & 4 & 6 & 3 & 7 \\
\hline
\end{tabular}

OHRAC: Ortodontista do Hospital de Reabilitação de Anomalias Craniofaciais, ONAF: Ortodontista não atuante em fissuras, CPHRAC: Cirurgião Plástico do Hospital de Reabilitação de Anomalias Craniofaciais, CPNAF: Cirurgião Plástico não atuante em fissuras, LFS: Leigos com formação superior 


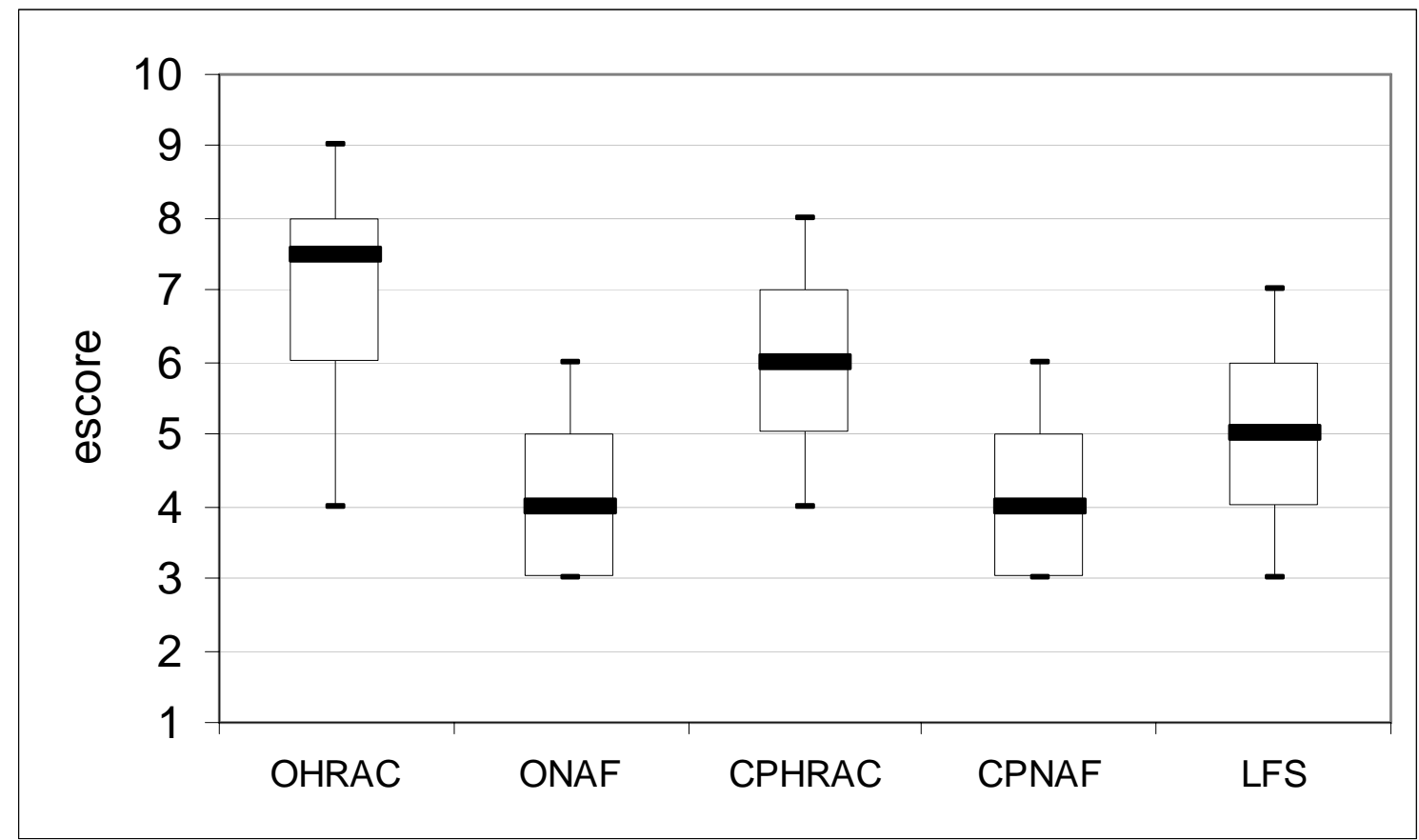

OHRAC: Ortodontista do Hospital de Reabilitação de Anomalias Craniofaciais, ONAF: Ortodontista não atuante em fissuras, CPHRAC: Cirurgião Plástico do Hospital de Reabilitação de Anomalias Craniofaciais, CPNAF: Cirurgião Plástico não atuante em fissuras, LFS: Leigos com formação superior

Figura 11 - Valores da mediana, $1 .^{\circ}$ quartil, $3 .^{\circ}$ quartil, mínimo e máximo por categoria, na $1 .^{a}$ avaliação do lado com fissura 
A tabela 2 apresenta os escores atribuídos pelos 25 avaliadores na segunda avaliação do lado com fissura e sua representação gráfica encontra-se na figura 12.

Tabela 2 - Média, mediana, $1 .^{\circ}$ quartil, 3. ${ }^{\circ}$ quartil, mínimo e máximo dos escores atribuídos pelos 25 avaliadores na 2. ${ }^{\text {a }}$ avaliação do lado com fissura

\begin{tabular}{|c|c|c|c|c|c|c|}
\hline Categoria & Média & Mediana & 1. ${ }^{\circ}$ quartil & 3. ${ }^{\circ}$ quartil & Mínimo & Máximo \\
\hline OHRAC 1 & 6,7 & 7 & 5 & 8 & 3 & 9 \\
\hline OHRAC 2 & 7,3 & 7 & 7 & 8 & 5 & 9 \\
\hline OHRAC 3 & 6,1 & 6 & 5 & 7 & 3 & 8 \\
\hline OHRAC 4 & 5,5 & 5,5 & 4 & 7 & 2 & 9 \\
\hline OHRAC5 & 7,5 & 8 & 6 & 8 & 5 & 9 \\
\hline OHRAC GERAL & 6,7 & 7 & 6 & 8 & 4 & 8 \\
\hline ONAF 1 & 5,5 & 5 & 4 & 6 & 4 & 8 \\
\hline ONAF 2 & 4,6 & 4 & 4 & 5 & 2 & 8 \\
\hline ONAF 3 & 5,0 & 4,5 & 4 & 6 & 3 & 8 \\
\hline ONAF 4 & 5,6 & 6 & 5 & 6 & 4 & 8 \\
\hline ONAF 5 & 4,0 & 4 & 3 & 5 & 2 & 5 \\
\hline ONAFGERAL & 4,9 & 5 & 4 & 6 & 3 & 8 \\
\hline CPHRAC 1 & 7,0 & 7 & 6 & 8 & 5 & 9 \\
\hline CPHRAC 2 & 6,1 & 6 & 6 & 7 & 5 & 7 \\
\hline CPHRAC 3 & 4,9 & 5 & 4 & 6 & 3 & 7 \\
\hline CPHRAC 4 & 6,7 & 7 & 6 & 7 & 6 & 8 \\
\hline CPHRAC 5 & 6,6 & 7 & 5 & 8 & 4 & 9 \\
\hline CPHRAC GERAL & 6,4 & 7 & 6 & 7 & 5 & 8 \\
\hline CPNAF 1 & 3,3 & 3 & 3 & 4 & 2 & 4 \\
\hline CPNAF 2 & 4,8 & 5 & 4 & 6 & 2 & 7 \\
\hline CPNAF 3 & 4,5 & 4 & 3 & 6 & 2 & 7 \\
\hline CPNAF 4 & 5,0 & 5 & 4 & 6 & 3 & 7 \\
\hline CPNAF 5 & 3,7 & 4 & 3 & 4 & 2 & 6 \\
\hline CPNAF GERAL & 4,1 & 4 & 4 & 5 & 2 & 6 \\
\hline LFS 1 & 4,4 & 5 & 4 & 5 & 3 & 6 \\
\hline LFS 2 & 5,2 & 5 & 4 & 7 & 3 & 8 \\
\hline LFS 3 & 4,7 & 5 & 4 & 5 & 3 & 6 \\
\hline LFS4 & 5,9 & 6 & 5 & 6 & 5 & 7 \\
\hline LFS 5 & 6,7 & 7 & 6 & 8 & 5 & 8 \\
\hline LFS GERAL & 5,3 & 5 & 5 & 6 & 3 & 7 \\
\hline
\end{tabular}

OHRAC: Ortodontista do Hospital de Reabilitação de Anomalias Craniofaciais, ONAF: Ortodontista não atuante em fissuras, CPHRAC: Cirurgião Plástico do Hospital de Reabilitação de Anomalias Craniofaciais, CPNAF: Cirurgião Plástico não atuante em fissuras, LFS: Leigos com formação superior 


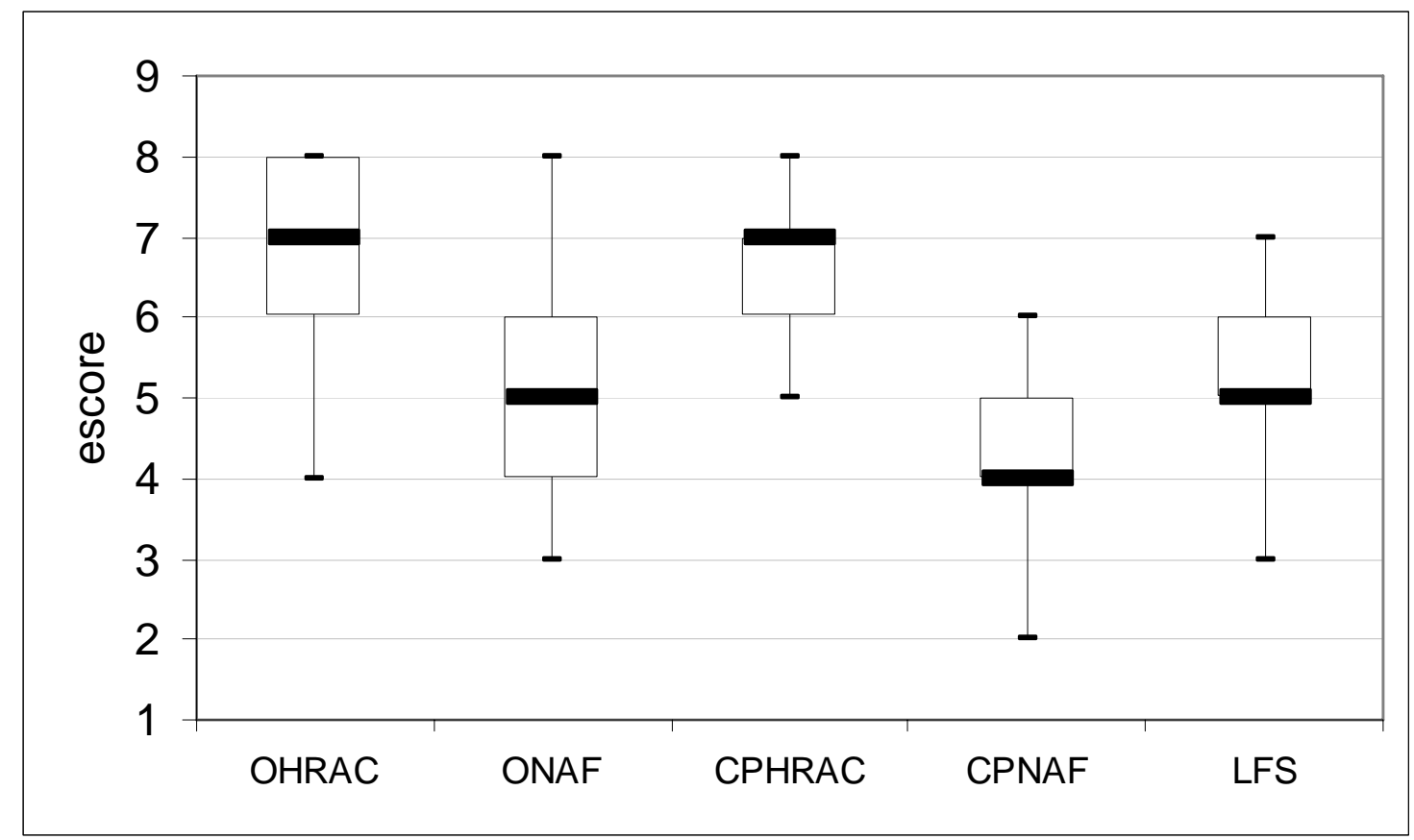

OHRAC: Ortodontista do Hospital de Reabilitação de Anomalias Craniofaciais, ONAF: Ortodontista não atuante em fissuras, CPHRAC: Cirurgião Plástico do Hospital de Reabilitação de Anomalias Craniofaciais, CPNAF: Cirurgião Plástico não atuante em fissuras, LFS: Leigos com formação superior

Figura 12 - Valores da mediana, $1 .^{\circ}$ quartil, $3 .^{\circ}$ quartil, mínimo e máximo por categoria, na $2 .^{a}$ avaliação do lado com fissura 
A tabela 3 mostra os escores atribuídos pelos 25 avaliadores na primeira avaliação do lado sem fissura, e sua representação gráfica encontra-se na figura 13.

Tabela 3 - Média, mediana, $1 .^{\circ}$ quartil, $3 .^{\circ}$ quartil, mínimo e máximo dos escores atribuídos pelos 25 avaliadores na $1{ }^{\text {a }}$ avaliação do lado sem fissura

\begin{tabular}{|c|c|c|c|c|c|c|}
\hline Categoria & Média & Mediana & 1. ${ }^{\circ}$ quartil & 3. ${ }^{\circ}$ quartil & Mínimo & Máximo \\
\hline OHRAC 1 & 7,9 & 8 & 7 & 9 & 6 & 9 \\
\hline OHRAC 2 & 8,0 & 8 & 7 & 9 & 6 & 9 \\
\hline OHRAC 3 & 6,5 & 7 & 6 & 8 & 4 & 9 \\
\hline OHRAC 4 & 6,5 & 7 & 5 & 8 & 2 & 9 \\
\hline OHRAC5 & 7,0 & 7 & 6 & 8 & 4 & 9 \\
\hline OHRAC GERAL & 7,3 & 7,5 & 6 & 8 & 4 & 9 \\
\hline ONAF 1 & 4,6 & 4 & 3 & 6 & 3 & 7 \\
\hline ONAF 2 & 4,5 & 4 & 3 & 5 & 3 & 7 \\
\hline ONAF 3 & 4,4 & 4 & 4 & 5 & 3 & 7 \\
\hline ONAF 4 & 5,0 & 5 & 4 & 6 & 3 & 7 \\
\hline ONAF 5 & 3,7 & 4 & 2 & 5 & 1 & 6 \\
\hline ONAF GERAL & 4,5 & 4 & 4 & 5 & 3 & 7 \\
\hline CPHRAC 1 & 6,7 & 7 & 6 & 8 & 4 & 9 \\
\hline CPHRAC 2 & 5,4 & 5 & 5 & 6 & 4 & 7 \\
\hline CPHRAC3 & 5,3 & 5 & 3 & 7 & 3 & 8 \\
\hline CPHRAC 4 & 7,3 & 7,5 & 6 & 8 & 5 & 9 \\
\hline CPHRAC 5 & 5,9 & 6 & 5 & 8 & 3 & 9 \\
\hline CPHRAC GERAL & 6,4 & 6 & 5 & 8 & 4 & 8 \\
\hline$\overline{\text { CPNAF } 1}$ & 4,2 & 4 & 3 & 5 & 2 & 7 \\
\hline CPNAF 2 & 3,6 & 4 & 3 & 4 & 1 & 5 \\
\hline CPNAF 3 & 5,2 & 5 & 4 & 6 & 3 & 7 \\
\hline CPNAF 4 & 4,3 & 4 & 4 & 5 & 3 & 6 \\
\hline CPNAF 5 & 4,5 & 4,5 & 4 & 6 & 1 & 7 \\
\hline CPNAF GERAL & 4,3 & 4 & 3 & 5 & 3 & 6 \\
\hline LFS 1 & 3,8 & 3,5 & 3 & 5 & 3 & 6 \\
\hline LFS 2 & 4,6 & 4 & 3 & 6 & 3 & 8 \\
\hline LFS 3 & 5,2 & 5 & 4 & 6 & 2 & 8 \\
\hline LFS 4 & 6,5 & 6,5 & 6 & 7 & 4 & 9 \\
\hline LFS 5 & 6,4 & 6 & 6 & 7 & 5 & 8 \\
\hline LFS GERAL & 5,3 & 5 & 5 & 6 & 3 & 8 \\
\hline
\end{tabular}

OHRAC: Ortodontista do Hospital de Reabilitação de Anomalias Craniofaciais, ONAF: Ortodontista não atuante em fissuras, CPHRAC: Cirurgião Plástico do Hospital de Reabilitação de Anomalias Craniofaciais, CPNAF: Cirurgião Plástico não atuante em fissuras, LFS: Leigos com formação superior 


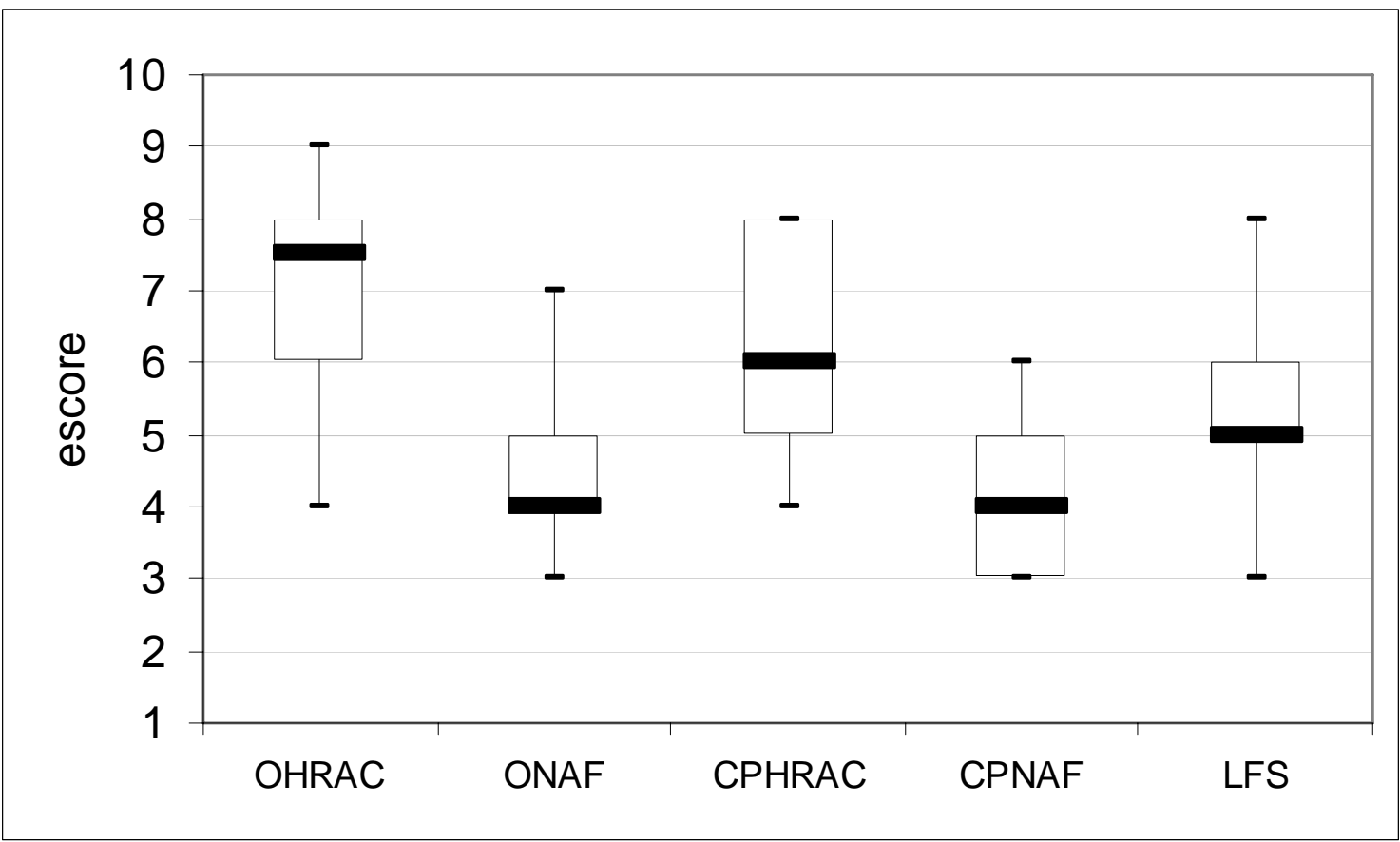

OHRAC: Ortodontista do Hospital de Reabilitação de Anomalias Craniofaciais, ONAF: Ortodontista não atuante em fissuras, CPHRAC: Cirurgião Plástico do Hospital de Reabilitação de Anomalias Craniofaciais, CPNAF: Cirurgião Plástico não atuante em fissuras, LFS: Leigos com formação superior

Figura 13 - Valores da mediana, $1 .^{\circ}$ quartil, $3 .^{\circ}$ quartil, mínimo e máximo por categoria, na $1 .^{a}$ avaliação do lado sem fissura 
A tabela 4 mostra os escores atribuídos pelos 25 avaliadores na segunda avaliação do lado sem fissura e sua representação gráfica encontra-se na figura 14 .

Tabela 4 - Média, mediana, $1 .^{\circ}$ quartil, 3. ${ }^{\circ}$ quartil, mínimo e máximo dos escores atribuídos pelos 25 avaliadores na 2 . $^{\text {a }}$ avaliação do lado sem fissura

\begin{tabular}{|c|c|c|c|c|c|c|}
\hline Categoria & Média & Mediana & 1. ${ }^{\circ}$ quartil & 3. ${ }^{\circ}$ quartil & Mínimo & Máximo \\
\hline OHRAC 1 & 6,9 & 7,5 & 6 & 8 & 3 & 9 \\
\hline OHRAC 2 & 7,2 & 7 & 6 & 8 & 5 & 9 \\
\hline OHRAC 3 & 6,3 & 6 & 5 & 7 & 3 & 8 \\
\hline OHRAC 4 & 5,6 & 6 & 4 & 7 & 2 & 9 \\
\hline OHRAC 5 & 7,4 & 8 & 7 & 8 & 5 & 9 \\
\hline OHRAC GERAL & 6,7 & 7 & 6 & 8 & 4 & 8 \\
\hline ONAF 1 & 5,6 & 5,5 & 5 & 6 & 4 & 8 \\
\hline ONAF 2 & 4,7 & 4 & 4 & 6 & 2 & 8 \\
\hline ONAF 3 & 5,1 & 5 & 4 & 6 & 3 & 8 \\
\hline ONAF 4 & 5,6 & 6 & 5 & 6 & 4 & 8 \\
\hline ONAF 5 & 4,0 & 4 & 3 & 5 & 2 & 5 \\
\hline ONAF GERAL & 5,0 & 5 & 4 & 6 & 3 & 8 \\
\hline CPHRAC 1 & 7,0 & 7 & 6 & 8 & 5 & 9 \\
\hline CPHRAC 2 & 6,2 & 6 & 6 & 7 & 5 & 7 \\
\hline CPHRAC 3 & 5,0 & 5 & 4 & 6 & 3 & 7 \\
\hline CPHRAC 4 & 7,0 & 7 & 7 & 7 & 6 & 8 \\
\hline CPHRAC 5 & 6,8 & 7 & 5 & 8 & 5 & 9 \\
\hline CPHRAC GERAL & 6,5 & 7 & 6 & 7 & 5 & 8 \\
\hline CPNAF 1 & 3,4 & 3 & 3 & 4 & 2 & 5 \\
\hline CPNAF 2 & 4,9 & 5 & 4 & 6 & 3 & 6 \\
\hline CPNAF 3 & 4,5 & 4 & 3 & 6 & 2 & 7 \\
\hline CPNAF 4 & 5,0 & 5 & 4 & 6 & 3 & 7 \\
\hline CPNAF 5 & 3,7 & 4 & 3 & 4 & 2 & 6 \\
\hline CPNAF GERAL & 4,1 & 4 & 4 & 5 & 2 & 6 \\
\hline LFS 1 & 4,4 & 4,5 & 4 & 5 & 3 & 6 \\
\hline LFS 2 & 5,4 & 5 & 4 & 7 & 3 & 8 \\
\hline LFS 3 & 4,8 & 5 & 5 & 5 & 4 & 6 \\
\hline LFS 4 & 5,9 & 6 & 5 & 6 & 5 & 7 \\
\hline LFS 5 & 6,8 & 7 & 6 & 7 & 5 & 8 \\
\hline LFS GERAL & 5,4 & 5 & 5 & 6 & 4 & 7 \\
\hline
\end{tabular}

OHRAC: Ortodontista do Hospital de Reabilitação de Anomalias Craniofaciais, ONAF: Ortodontista não atuante em fissuras, CPHRAC: Cirurgião Plástico do Hospital de Reabilitação de Anomalias Craniofaciais, CPNAF: Cirurgião Plástico não atuante em fissuras, LFS: Leigos com formação superior 


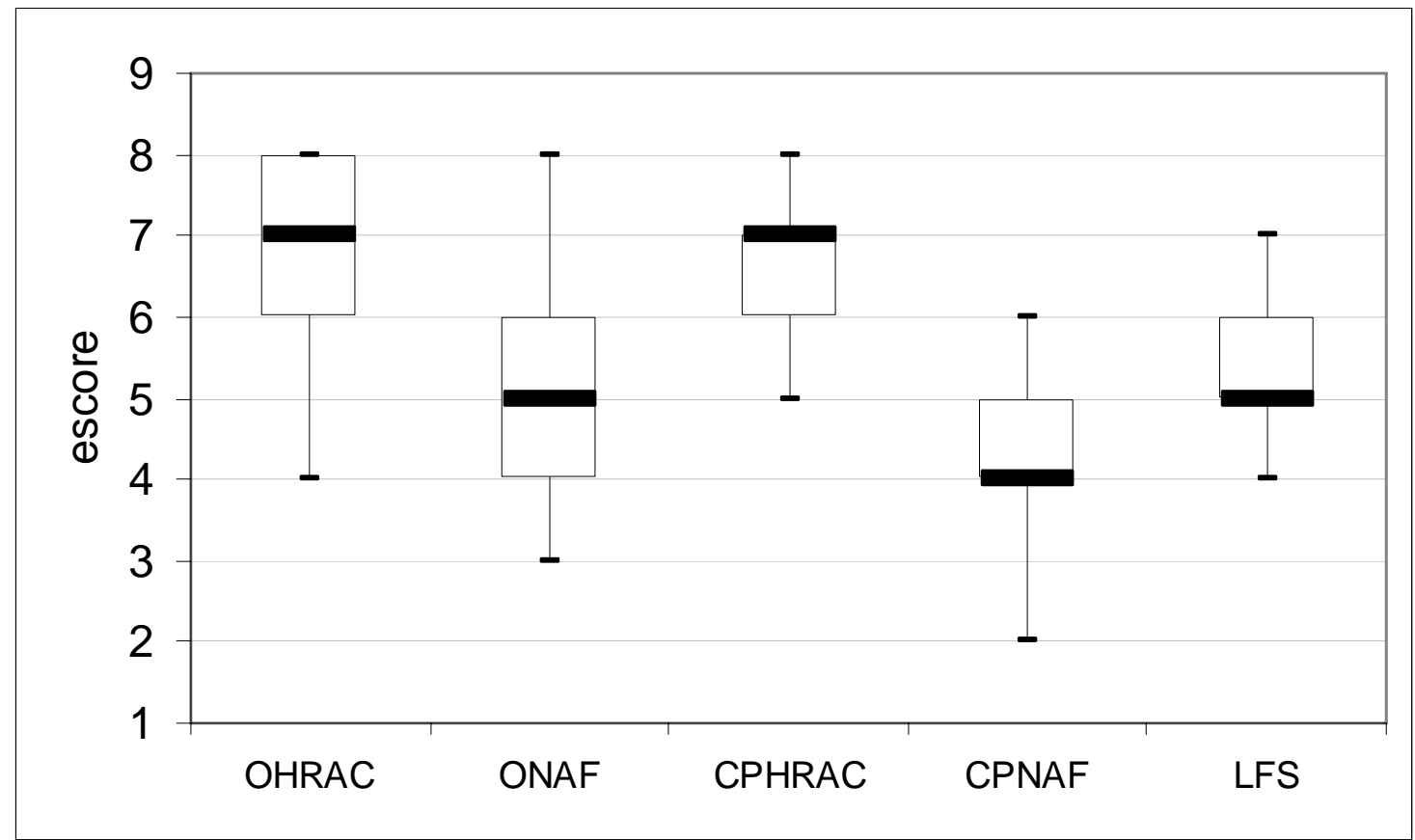

OHRAC: Ortodontista do Hospital de Reabilitação de Anomalias Craniofaciais, ONAF: Ortodontista não atuante em fissuras, CPHRAC: Cirurgião Plástico do Hospital de Reabilitação de Anomalias Craniofaciais, CPNAF: Cirurgião Plástico não atuante em fissuras, LFS: Leigos com formação superior

Figura 14 - Valores da mediana, $1 .^{\circ}$ quartil, 3. ${ }^{\circ}$ quartil, mínimo e máximo por categoria, na 2. ${ }^{a}$ avaliação do lado sem fissura 


\subsection{CONCORDÂNCIA INTER E INTRA-EXAMINADORES}

Para verificar a concordância entre os avaliadores de uma mesma categoria, utilizou-se o Coeficiente de Concordância de Kendall (W).

Na tabela 5 pode-se verificar o Coeficiente de Concordância de Kendall entre os avaliadores de cada categoria na primeira avaliação do lado com fissura.

Estatisticamente define-se que valores de Coeficiente de Kendall próximos a 0,70 são considerados satisfatórios, isto é, há um grau de concordância satisfatório entre os avaliadores de cada categoria. Os valores menores encontrados neste trabalho podem ser creditados ao alto grau de subjetividade que envolve este tipo de avaliação, ainda assim, houve confiabilidade no resultado do teste, validando o método.

Tabela 5 - Coeficiente de Concordância de Kendall (W) entre os avaliadores de cada categoria na 1. ${ }^{a}$ avaliação do lado com fissura

\begin{tabular}{lcc}
\hline \multicolumn{1}{c}{ Categoria } & w & p \\
\hline OHRAC & 0,75 & $0,000^{\star}$ \\
ONAF & 0,74 & $0,000^{\star}$ \\
CPHRAC & 0,55 & $0,000^{\star}$ \\
CPNAF & 0,70 & $0,000^{\star}$ \\
LFS & 0,63 & $0,000^{\star}$ \\
\hline
\end{tabular}

* - concordância estatisticamente significante $(p<0,05)$

OHRAC: Ortodontista do Hospital de Reabilitação de Anomalias Craniofaciais, ONAF: Ortodontista não atuante em fissuras, CPHRAC: Cirurgião Plástico do Hospital de Reabilitação de Anomalias Craniofaciais, CPNAF: Cirurgião Plástico não atuante em fissuras, LFS: Leigos com formação superior 
A tabela 6 apresenta o Coeficiente de Concordância de Kendall entre os avaliadores de cada categoria na segunda avaliação do lado com fissura.

Tabela 6 - Coeficiente de Concordância de Kendall (W) entre os avaliadores de cada categoria na $2 .^{\text {a }}$ avaliação do lado com fissura

\begin{tabular}{lcc}
\hline \multicolumn{1}{r}{ Categoria } & w & p \\
\hline OHRAC & 0,75 & $0,000^{\star}$ \\
ONAF & 0,76 & $0,000^{\star}$ \\
CPHRAC & 0,68 & $0,000^{\star}$ \\
CPNAF & 0,49 & $0,000^{\star}$ \\
LFS & 0,57 & $0,000^{\star}$ \\
\hline
\end{tabular}

* - concordância estatisticamente significante $(p<0,05)$

OHRAC: Ortodontista do Hospital de Reabilitação de Anomalias Craniofaciais, ONAF: Ortodontista não atuante em fissuras, CPHRAC: Cirurgião Plástico do Hospital de Reabilitação de Anomalias Craniofaciais, CPNAF: Cirurgião Plástico não atuante em fissuras, LFS: Leigos com formação superior

A tabela 7 mostra o Coeficiente de Concordância de Kendall entre os avaliadores de cada categoria na primeira avaliação do lado sem fissura.

Tabela 7- Coeficiente de Concordância de Kendall (W) entre os avaliadores de cada categoria na 1. ${ }^{a}$ avaliação do lado sem fissura

\begin{tabular}{|c|c|c|}
\hline Categoria & W & p \\
\hline OHRAC & 0,74 & $0,000^{*}$ \\
\hline ONAF & 0,67 & $0,000^{*}$ \\
\hline CPHRAC & 0,47 & $0,000^{*}$ \\
\hline CPNAF & 0,70 & $0,000^{*}$ \\
\hline LFS & 0,61 & $0,000 *$ \\
\hline
\end{tabular}

* - concordância estatisticamente significante $(p<0,05)$

OHRAC: Ortodontista do Hospital de Reabilitação de Anomalias Craniofaciais, ONAF: Ortodontista não atuante em fissuras, CPHRAC: Cirurgião Plástico do Hospital de Reabilitação de Anomalias Craniofaciais, CPNAF: Cirurgião Plástico não atuante em fissuras, LFS: Leigos com formação superior 
A tabela 8 mostra o Coeficiente de Concordância de Kendall entre os avaliadores de cada categoria na segunda avaliação do lado sem fissura.

Tabela 8 - Coeficiente de Concordância de Kendall (W) entre os avaliadores de cada categoria na $2 .^{\text {a }}$ avaliação do lado sem fissura

\begin{tabular}{|c|c|c|}
\hline Categoria & w & p \\
\hline OHRAC & 0,70 & $0,000^{*}$ \\
\hline ONAF & 0,76 & $0,000^{*}$ \\
\hline CPHRAC & 0,56 & $0,000^{*}$ \\
\hline CPNAF & 0,47 & $0,000^{*}$ \\
\hline LFS & 0,60 & $0,000^{*}$ \\
\hline
\end{tabular}

* - concordância estatisticamente significante $(p<0,05)$

OHRAC: Ortodontista do Hospital de Reabilitação de Anomalias Craniofaciais, ONAF: Ortodontista não atuante em fissuras, CPHRAC: Cirurgião Plástico do Hospital de Reabilitação de Anomalias Craniofaciais, CPNAF: Cirurgião Plástico não atuante em fissuras, LFS: Leigos com formação superior 
Para verificar a concordância de cada examinador nas duas avaliações dos lados com e sem fissura, utilizou-se o Coeficiente de Correlação de Spearman (r) (tabela 9).

Tabela 9 - Coeficiente de Correlação de Spearman (r) entre a 1. ${ }^{a}$ e a $2 .^{a}$ avaliação de cada um dos 25 avaliadores para lados com e sem fissura

\begin{tabular}{|c|c|c|c|c|}
\hline \multirow{2}{*}{ Categoria } & \multicolumn{2}{|c|}{ Com fissura } & \multicolumn{2}{|c|}{ Sem fissura } \\
\hline & $r$ & $\mathbf{p}$ & $r$ & $\mathbf{p}$ \\
\hline OHRAC 1 & 0,87 & $0,000^{\star}$ & 0,89 & $0,000^{*}$ \\
\hline OHRAC 2 & 0,58 & $0,001^{*}$ & 0,71 & $0,000^{*}$ \\
\hline OHRAC 3 & 0,74 & $0,000^{*}$ & 0,75 & $0,000^{*}$ \\
\hline OHRAC 4 & 0,88 & $0,000^{\star}$ & 0,92 & $0,000^{*}$ \\
\hline OHRAC 5 & 0,77 & $0,000^{\star}$ & 0,49 & $0,006^{*}$ \\
\hline ONAF 1 & 0,79 & $0,000^{*}$ & 0,79 & $0,000^{*}$ \\
\hline ONAF 2 & 0,80 & $0,000^{*}$ & 0,80 & $0,000^{*}$ \\
\hline ONAF 3 & 0,70 & $0,000^{*}$ & 0,69 & $0,000^{*}$ \\
\hline ONAF 4 & 0,71 & $0,000^{\star}$ & 0,61 & $0,000^{*}$ \\
\hline ONAF 5 & 0,71 & $0,000^{*}$ & 0,61 & $0,000^{*}$ \\
\hline CPHRAC 1 & 0,78 & $0,000^{\star}$ & 0,43 & $0,018^{\star}$ \\
\hline CPHRAC2 & 0,65 & $0,000^{\star}$ & 0,60 & $0,000^{*}$ \\
\hline CPHRAC3 & 0,23 & $0,225 n s$ & 0,40 & $0,028^{*}$ \\
\hline CPHRAC 4 & 0,58 & $0,001^{*}$ & 0,54 & $0,002^{*}$ \\
\hline CPHRAC 5 & 0,82 & $0,000^{*}$ & 0,79 & $0,000^{*}$ \\
\hline CPNAF1 & 0,60 & $0,001^{*}$ & 0,61 & $0,000^{*}$ \\
\hline CPNAF 2 & 0,60 & $0,000^{*}$ & 0,22 & $0,249 \mathrm{~ns}$ \\
\hline CPNAF 3 & 0,84 & $0,000^{\star}$ & 0,82 & $0,000^{*}$ \\
\hline CPNAF 4 & 0,68 & $0,000^{*}$ & 0,68 & $0,000^{*}$ \\
\hline CPNAF 5 & 0,43 & $0,017^{*}$ & 0,43 & $0,017^{*}$ \\
\hline LFS 1 & 0,73 & $0,000^{\star}$ & 0,57 & $0,001^{*}$ \\
\hline LFS 2 & 0,71 & $0,000^{\star}$ & 0,81 & $0,000^{*}$ \\
\hline LFS 3 & 0,52 & $0,003^{*}$ & 0,51 & $0,004^{*}$ \\
\hline LFS 4 & 0,52 & $0,003^{*}$ & 0,61 & $0,000^{*}$ \\
\hline LFS 5 & 0,68 & $0,000^{*}$ & 0,83 & $0,000 *$ \\
\hline
\end{tabular}

* - correlação estatisticamente significante $(p<0,05)$

ns - correlação estatisticamente não significante

OHRAC: Ortodontista do Hospital de Reabilitação de Anomalias Craniofaciais, ONAF: Ortodontista não atuante em fissuras, CPHRAC: Cirurgião Plástico do Hospital de Reabilitação de Anomalias Craniofaciais, CPNAF: Cirurgião Plástico não atuante em fissuras, LFS: Leigos com formação superior 


\subsection{COMPARAÇÃO DOS ESCORES ATRIBUÍDOS POR CATEGORIA DE EXAMINADOR}

A tabela 10 mostra o grau de Concordância de Kendall (W) entre as categorias para o lado com fissura na primeira e segunda avaliação, e a tabela 11 igualmente para o lado sem fissura.

Tabela 10 - Concordância de Kendall (W) entre as categorias, para o lado com fissura, na $1 .^{\mathrm{a}} \mathrm{e}$ na $2 .^{\text {a }}$ avaliações

\begin{tabular}{ccc}
\hline Avaliação & w & p \\
\hline 1. $^{\text {a }}$ Avaliação & 0,74 & $0,000^{*}$ \\
2. $^{\text {a }}$ Avaliação & 0,72 & $0,000^{*}$ \\
\hline
\end{tabular}

* - concordância estatisticamente significante $(p<0,05)$

Tabela 11 - Concordância de Kendall (W) entre as categorias, para o lado sem fissura, na $1^{\mathrm{a}} \mathrm{e}$ na $2{ }^{\mathrm{a}}$ avaliações

\begin{tabular}{ccc}
\hline Avaliação & W & p \\
\hline 1. $^{\text {a }}$ Avaliação & 0,76 & $0,000^{*}$ \\
2. $^{\text {a }}$ Avaliação & 0,72 & $0,000^{*}$ \\
\hline
\end{tabular}

* - concordância estatisticamente significante $(p<0,05)$ 


\subsection{COMPARAÇÃO DOS LADOS COM E SEM FISSURA}

Para comparar se existe diferença entre os lados com fissura e sem fissura nos escores atribuídos foi utilizado o Teste de Wilcoxon. A tabela 12 mostra o Teste de Wilcoxon para comparação entre os lados com e sem fissura na primeira avaliação.

Tabela 12 - Teste de Wilcoxon para comparação entre os lados com fissura e sem fissura na 1. ${ }^{\mathrm{a}}$ avaliação

\begin{tabular}{lccc}
\hline \multicolumn{1}{r}{ Categoria } & $\mathbf{T}$ & $\mathbf{Z}$ & $\mathbf{p}$ \\
\hline OHRAC & 13,5 & 0,630 & $0,529 \mathrm{~ns}$ \\
ONAF & 3,5 & 1,468 & $0,142 \mathrm{~ns}$ \\
CPHRAC & 23,0 & 1,572 & $0,116 \mathrm{~ns}$ \\
CPNAF & 23,0 & 0,000 & $1,000 \mathrm{~ns}$ \\
LFS & 19,5 & 2,508 & $0,012^{*}$ \\
\hline
\end{tabular}

* - diferença estatisticamente significante $(p<0,05)$

ns - diferença estatisticamente não significante

T: estatística do Teste de Wilcoxon; Z: distribuição normal de probabilidades

OHRAC: Ortodontista do Hospital de Reabilitação de Anomalias Craniofaciais, ONAF: Ortodontista não atuante em fissuras, CPHRAC: Cirurgião Plástico do Hospital de Reabilitação de Anomalias Craniofaciais, CPNAF: Cirurgião Plástico não atuante em fissuras, LFS: Leigos com formação superior 


\subsection{CLASSIFICAÇÃO DA AMOSTRA}

Para comparar se as categorias têm tendência de atribuir escores mais altos ou baixos umas das outras na classificação da amostra, utilizou-se o Teste de Friedman; este acusando diferença estatisticamente significante; indicou a utilização do Teste de Student-Newman-Keuls para comparações múltiplas.

O Teste de Friedman para comparação entre as categorias para os escores atribuídos mostrou diferença estatisticamente significante entre as categorias $\left(\chi^{2}=\right.$ 96,13; $\mathrm{p}=0,000)$. O Teste de Student-Newman-Keuls para comparações múltiplas identificou diferenças significantes entre todas as categorias exceto cirurgiões plásticos (CPNAF) e ortodontistas (ONAF).

A tabela 13 mostra a média, mediana, $1 .^{\circ}$ quartil, $3 .^{\circ}$ quartil, mínimo e máximo dos escores atribuídos por categoria na primeira avaliação do lado com fissura.

Tabela 13 - Média, mediana, $1 .^{\circ}$ quartil, 3. ${ }^{\circ}$ quartil, mínimo e máximo dos escores atribuídos por categoria na 1. avaliação do lado com fissura

\begin{tabular}{lcccccc}
\hline \multicolumn{1}{c}{ Categoria } & Média & Mediana & 1. $^{\circ}$ quartil & 3. $^{\circ}$ quartil & Mínimo & Máximo \\
\hline OHRAC & 7,2 & 7,5 & 6 & 8 & 4 & 9 \\
ONAF & 4,3 & 4 & 3 & 5 & 3 & 6 \\
CPHRAC & 6,1 & 6 & 5 & 7 & 4 & 8 \\
CPNAF & 4,3 & 4 & 3 & 5 & 3 & 6 \\
LFS & 4,9 & 5 & 4 & 6 & 3 & 7 \\
\hline
\end{tabular}

OHRAC: Ortodontista do Hospital de Reabilitação de Anomalias Craniofaciais, ONAF: Ortodontista não atuante em fissuras, CPHRAC: Cirurgião Plástico do Hospital de Reabilitação de Anomalias Craniofaciais, CPNAF: Cirurgião Plástico não atuante em fissuras, LFS: Leigos com formação superior

Teste de Student-Newman-Keuls 
Na tabela 14 e figura 15, observa-se a distribuição das classificações atribuídas pelos 25 examinadores na primeira avaliação do lado com fissura.

Tabela 14 - Distribuição das classificações atribuídas pelos 25 avaliadores na 1. a avaliação do lado com fissura

\begin{tabular}{|c|c|c|c|c|c|c|}
\hline \multirow{2}{*}{ Avaliador } & \multicolumn{2}{|c|}{ Desagradável } & \multicolumn{2}{|c|}{ Aceitável } & \multicolumn{2}{|c|}{ Agradável } \\
\hline & $\mathbf{n}$ & $\%$ & $\mathbf{n}$ & $\%$ & $n$ & $\%$ \\
\hline OHRAC 1 & 0 & 0,0 & 7 & 23,3 & 23 & 76,7 \\
\hline OHRAC 2 & 0 & 0,0 & 3 & 10,0 & 27 & 90,0 \\
\hline OHRAC 3 & 1 & 3,3 & 14 & 46,7 & 15 & 50,0 \\
\hline OHRAC 4 & 5 & 16,7 & 6 & 20,0 & 19 & 63,3 \\
\hline OHRAC 5 & 0 & 0,0 & 9 & 30,0 & 21 & 70,0 \\
\hline OHRAC GERAL & 0 & 0,0 & 9 & 30,0 & 21 & 70,0 \\
\hline ONAF 1 & 8 & 26,7 & 17 & 56,7 & 5 & 16,7 \\
\hline ONAF 2 & 10 & 33,3 & 18 & 60,0 & 2 & 6,7 \\
\hline ONAF 3 & 7 & 23,3 & 21 & 70,0 & 2 & 6,7 \\
\hline ONAF 4 & 2 & 6,7 & 26 & 86,7 & 2 & 6,7 \\
\hline ONAF 5 & 16 & 53,3 & 14 & 46,7 & 0 & 0,0 \\
\hline ONAF GERAL & 9 & 30,0 & 21 & 70,0 & 0 & 0,0 \\
\hline$\overline{\text { CPHRAC } 1}$ & 0 & 0,0 & 13 & 43,3 & 17 & 56,7 \\
\hline CPHRAC 2 & 0 & 0,0 & 27 & 90,0 & 3 & 10,0 \\
\hline CPHRAC 3 & 9 & 30,0 & 14 & 46,7 & 7 & 23,3 \\
\hline CPHRAC 4 & 0 & 0,0 & 10 & 33,3 & 20 & 66,7 \\
\hline CPHRAC 5 & 9 & 30,0 & 11 & 36,7 & 10 & 33,3 \\
\hline CPHRAC GERAL & 0 & 0,0 & 17 & 56,7 & 13 & 43,3 \\
\hline CPNAF 1 & 11 & 36,7 & 18 & 60,0 & 1 & 3,3 \\
\hline CPNAF 2 & 11 & 36,7 & 19 & 63,3 & 0 & 0,0 \\
\hline CPNAF 3 & 1 & 3,3 & 24 & 80,0 & 5 & 16,7 \\
\hline CPNAF 4 & 5 & 16,7 & 25 & 83,3 & 0 & 0,0 \\
\hline CPNAF 5 & 7 & 23,3 & 22 & 73,3 & 1 & 3,3 \\
\hline CPNAF GERAL & 8 & 26,7 & 22 & 73,3 & 0 & 0,0 \\
\hline LFS 1 & 14 & 46,7 & 16 & 53,3 & 0 & 0,0 \\
\hline LFS 2 & 12 & 40,0 & 14 & 46,7 & 4 & 13,3 \\
\hline LFS 3 & 6 & 20,0 & 22 & 73,3 & 2 & 6,7 \\
\hline LFS 4 & 0 & 0,0 & 15 & 50,0 & 15 & 50,0 \\
\hline LFS 5 & 0 & 0,0 & 18 & 60,0 & 12 & 40,0 \\
\hline LFS GERAL & 5 & 16,7 & 22 & 73,3 & 3 & 10,0 \\
\hline
\end{tabular}

OHRAC: Ortodontista do Hospital de Reabilitação de Anomalias Craniofaciais, ONAF: Ortodontista não atuante em fissuras, CPHRAC: Cirurgião Plástico do Hospital de Reabilitação de Anomalias Craniofaciais, CPNAF: Cirurgião Plástico não atuante em fissuras, LFS: Leigos com formação superior 


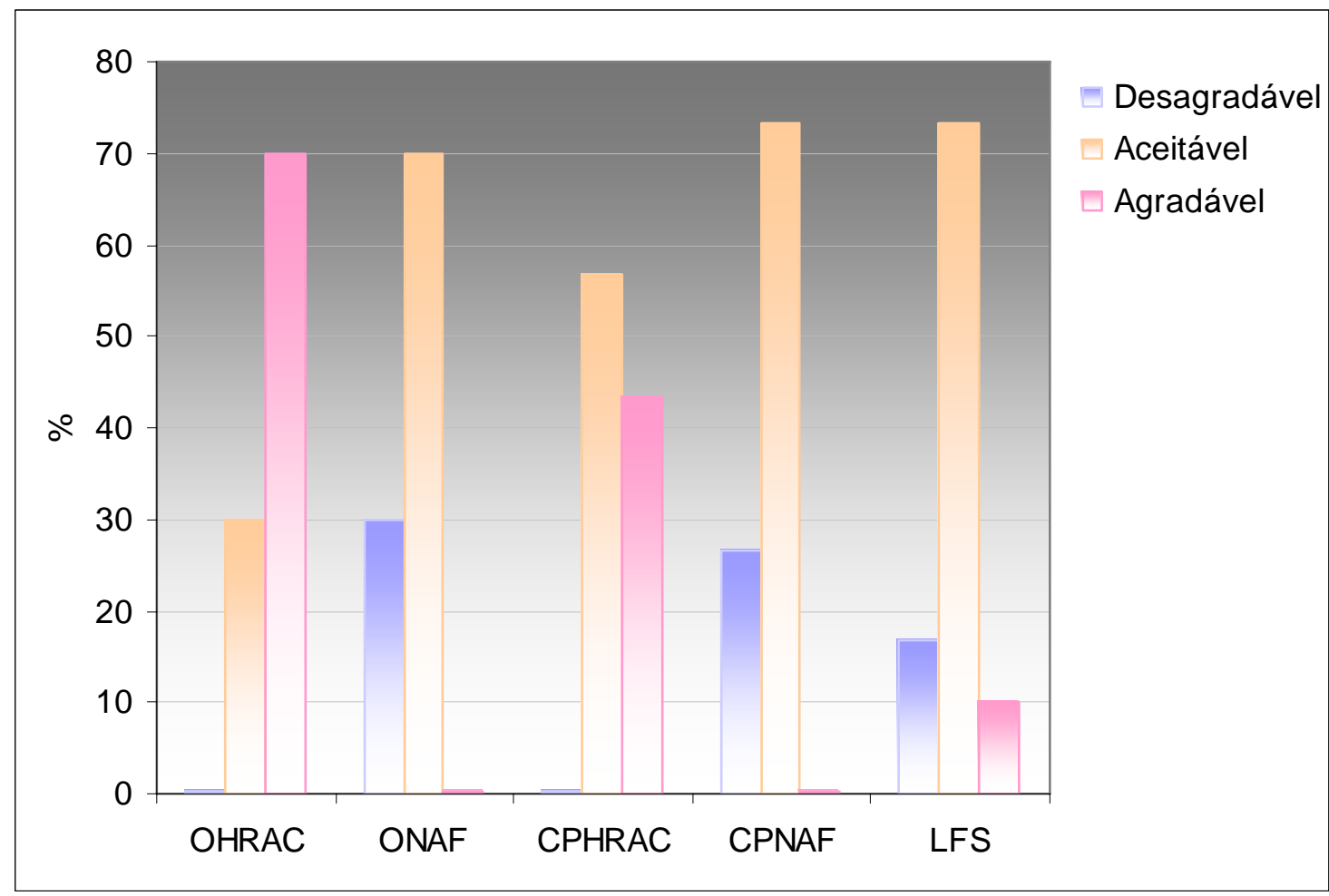

OHRAC: Ortodontista do Hospital de Reabilitação de Anomalias Craniofaciais, ONAF: Ortodontista não atuante em fissuras, CPHRAC: Cirurgião Plástico do Hospital de Reabilitação de Anomalias Craniofaciais, CPNAF: Cirurgião Plástico não atuante em fissuras, LFS: Leigos com formação superior

Figura 15 - Distribuição das classificações por categoria de avaliador, na 1. ${ }^{a}$ avaliação do lado com fissura 


\subsection{ESTRUTURAS RESPONSÁVEIS PELA CLASSIFICAÇÃo EM ESTETICAMENTE Desagradável}

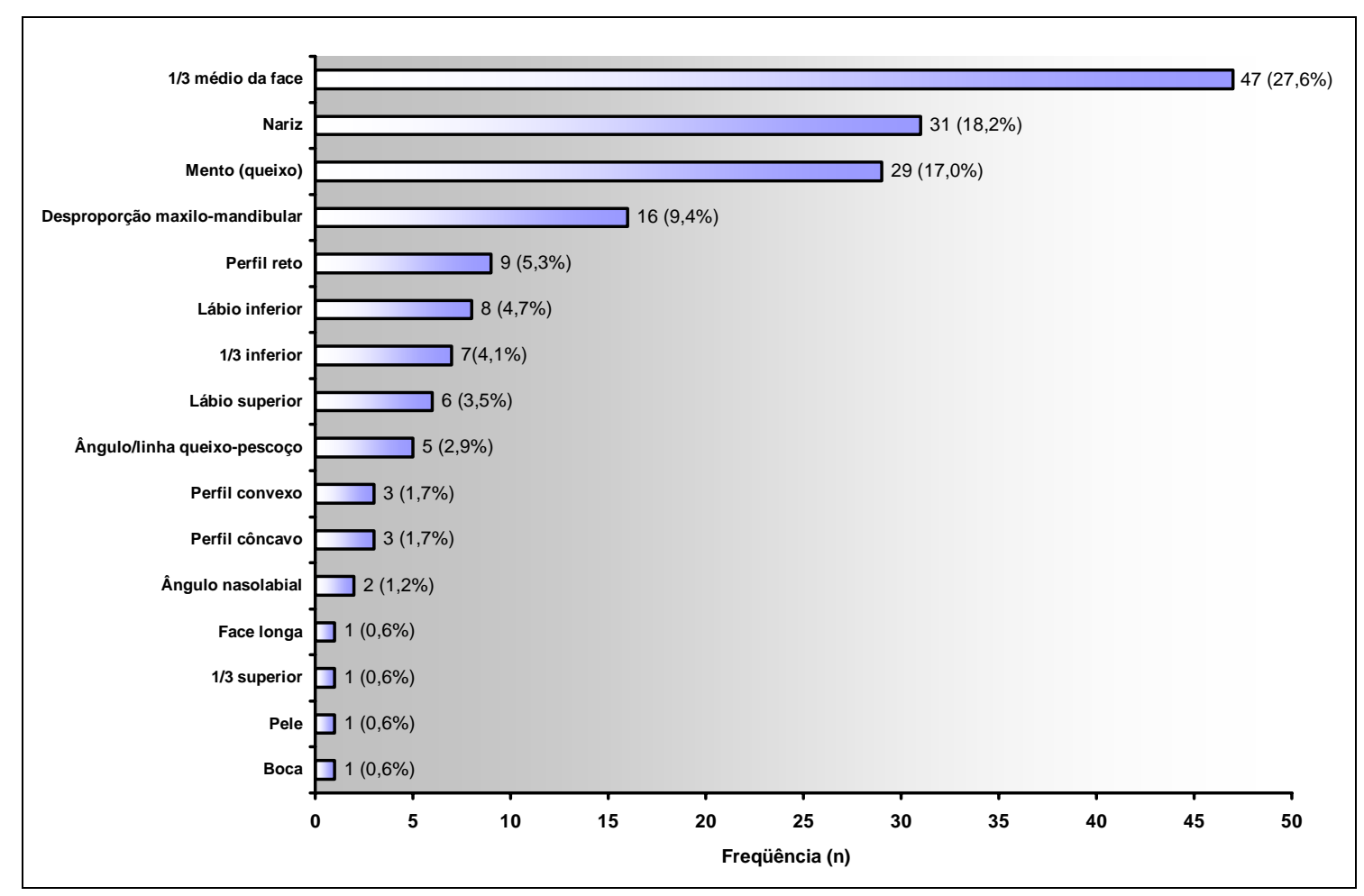

Figura 16 - Representativa das estruturas do perfil facial citadas pelos examinadores como esteticamente desagradável 
ISCUSSÃO 


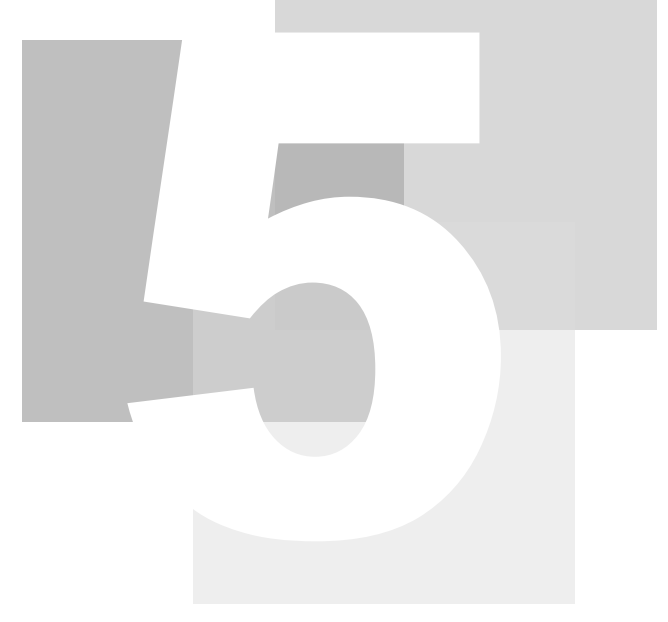

\section{DISCUSSÃo}

presente trabalho considera a face do paciente adulto reabilitado, e a metodologia adotada foi baseada na dissertação de Reis (2001). Por meio de fotografias de perfis faciais, foi possível a classificação estética por agradabilidade de uma amostra de pacientes adultos, não sindrômicos, leucodermos, de ambos os gêneros, com fissura transforame incisivo unilateral, reabilitados no HRAC-USP com alta do setor de Ortodontia e nenhuma indicação para qualquer cirurgia plástica que envolvesse a estética facial. Para essa avaliação, foram selecionados 25 profissionais de diversas áreas de atuação, dentre eles, ortodontistas (OHRAC) e cirurgiões plásticos (CPHRAC) que atuam no HRACUSP e lidam diretamente com a reabilitação de fissuras, ortodontistas (ONAF) e cirurgiões plásticos (CPNAF) que não atuam na reabilitação de pacientes com fissura, bem como leigos com formação superior (LFS). Esse universo variado de examinadores se fez necessário por ser o conceito de beleza muito subjetivo e variar individualmente. Além disso, é interessante conhecer se as diferentes categorias de profissionais e os leigos têm conceitos diferentes de beleza, de acordo com sua área de atuação. Phillips et al (1992) 
realizaram trabalho com o objetivo de testar a semelhança na avaliação da atratividade facial entre três grupos de indivíduos com diferentes formações profissionais (leigos, ortodontistas e estudantes de odontologia) e, ao mesmo tempo, avaliar a preferência do examinador por uma das três diferentes vistas (frente sorrindo, frente e perfil). Houve diferença na avaliação dos três grupos, sugerindo que qualquer estudo semelhante deva utilizar um grupo heterogêneo de avaliadores composto por pessoas pertencentes a diferentes categorias profissionais.

Uma das proposições do presente trabalho foi a classificação da amostra por agradabilidade em categorias estéticas (esteticamente desagradável, aceitável e agradável) utilizando-se um método subjetivo: a análise facial dos perfis direito e esquerdo, por meio de fotografias dos pacientes selecionados.

\subsection{CONCORDÂNCIA INTER E INTRA-EXAMINADORES}

Cada um dos examinadores foi convidado a realizar duas avaliações em um período mínimo de uma semana entre elas. As tabelas 1 e 3 e figuras 11 e 13, respectivamente, mostram o resultado da primeira avaliação para cada um dos lados, com e sem fissura. As tabelas 2 e 4 e figuras 12 e 14, respectivamente, ilustram o resultado da segunda avaliação para ambos os lados. A fim de analisar se houve concordância estatisticamente significante entre os avaliadores de cada categoria, entre a primeira e a segunda avaliação, foi utilizado o Coeficiente de Concordância de Kendall (W). As tabelas 5 e 7; 6 e 8, respectivamente primeira e segunda avaliações de ambos os lados com e sem fissura, mostram que houve concordância estatisticamente significante entre os avaliadores de cada categoria para as duas avaliações.

Analisando-se os resultados da tabela 5, observou-se que os ortodontistas (ONAF), e os ortodontistas atuantes na reabilitação de fissuras (OHRAC) foram os que apresentaram maior concordância entre si, gerando um Coeficiente de Concordância de Kendall de 0,74 e 0,75 respectivamente. Essas duas categorias de examinadores atribuíram medianas das notas que definiram os limites mínimo e máximo da escala (4,0 e 7,5 respectivamente) (tabela 13), reforçando uma vez mais a hipótese de que os ortodontistas do HRAC (OHRAC) têm uma noção muito clara do que é possível 
conseguir em termos de resultado estético facial em pacientes com fissura, diferente dos ortodontistas (ONAF) que não possuem essa experiência e fazem o seu julgamento baseado na normalidade absoluta. Na seqüência, vieram os cirurgiões plásticos (CPNAF) com um coeficiente de concordância entre si de 0,70. Convém lembrar que também atribuíram notas baixas aos pacientes $(4,0)$ (tabela 13), provavelmente pelos mesmos motivos que os ortodontistas (ONAF). Os leigos (LFS) e os cirurgiões plásticos do HRAC (CPHRAC) apresentaram coeficiente de concordância de 0,63 e 0,55 respectivamente.

A tabela 9 analisa o Coeficiente de Correlação de Spearman (r) indicando que houve correlação estatisticamente significante entre as notas dos examinadores nas duas avaliações para os lados com e sem fissura, com exceção do CPHRAC 3 na avaliação do lado com fissura $(p=0,225)$ e do CPNAF 2 do lado sem fissura $(p=0,249)$. O Coeficiente de Correlação de Spearman varia de -1 a +1 e, quando próximo a 1 , indica boa correlação entre as variáveis testadas. O resultado encontrado evidencia que houve homogeneidade nas notas para a maioria dos examinadores. Ambos os Coeficientes, Kendall e Spearman, mostraram que a metodologia aplicada neste estudo, mesmo sendo subjetiva, é reprodutível, o que confere confiabilidade ao resultado do teste.

\subsection{COMPARAÇÃO DOS ESCORES ATRIBUÍDOS POR CATEGORIA DE EXAMINADOR}

A fim de verificar se houve concordância entre as categorias na avaliação dos lados com e sem fissura, o Coeficiente de Concordância de Kendall foi aplicado. As tabelas 10 e 11 mostram que houve concordância estatisticamente significante entre as categorias para o lado com e sem fissura nas duas avaliações (W próximo de 0,7 ). A percepção do que é belo ou não belo sofreu discreta variação. Pode-se inferir que os conceitos de beleza seguem um determinado padrão, isto é, o belo e o não belo tendem a ser reconhecidos pelas diferentes categorias de avaliadores. Com base em estatísticas, entende-se que a população em geral é capaz de reconhecer tais conceitos.

Com a aplicabilidade dos testes até então citados (sub-itens 5.1 e 5.2), foi possível concluir que não houve diferença estatisticamente significante entre as duas avaliações para ambos os lados, com e sem fissura; desse modo, optou-se por considerar 
na discussão somente as notas obtidas na primeira avaliação. As tabelas 6 e 8 foram analisadas mas não discutidas, pois revelam os resultados da segunda avaliação dos lados com e sem fissura, respectivamente.

\subsection{COMPARAÇÃO DOS LADOS COM E SEM FISSURA}

Analisando a tabela 12 pode-se observar que não houve diferença estatisticamente significante entre as categorias para ambos os lados, com e sem fissura; exceção feita aos leigos (LFS) (p=0,012) que atribuíram a nota média 4,9 (tabela 1) para o lado com fissura e 5,3 (tabela 3) para o lado sem fissura, denotando discreta variação. Dessa forma, embasados pela estatística, optou-se por trabalhar somente com as notas atribuídas ao perfil do lado com fissura, porisso, a tabela 7 não foi discutida. Embora a fissura seja unilateral, o aspecto facial de impacto ao final da reabilitação diz respeito à deficiência da face média, já que, em grande parte, os problemas de tecido mole foram reparados pela cirurgia plástica. O ângulo nasolabial, o ápice nasal e a projeção malar, denunciadores da deficiência maxilar, quando observados em uma vista de perfil, tendem a mascarar a assimetria facial presente nas fissuras unilaterais. Isso explica a atribuição de notas semelhantes para os lados com e sem fissura.

\subsection{CLASSIFICAÇÃO DA AMOSTRA}

A tabela 1 apresenta as notas atribuídas na primeira avaliação do lado com fissura pelos 25 avaliadores aos perfis da amostra selecionada. Pode-se observar que a mediana das notas atribuídas pelos examinadores foram, respectivamente, para os ortodontistas e cirurgiões plásticos do HRAC 7,5 e 6,0; leigos (LFS) 5,0; e, finalmente, os ortodontistas e cirurgiões plásticos (ONAF e CPNAF) que conferiram igualmente a mediana 4,0. Parece-nos lícito afirmar que houve diferenças entre os avaliadores na classificação da amostra. Esse comportamento faz sentido uma vez que a avaliação da beleza reflete a óptica do avaliador e ela não está isenta da sua experiência profissional. 
Transpareceu o esperado: que os profissionais que têm experiência na malformação em questão atribuíram notas mais altas para a estética final da face. Entre esses profissionais, os ortodontistas do HRAC, por monitorarem constantemente a oclusão e o crescimento da face e, portanto, conhecerem as limitações que o processo de reabilitação impõe aos indivíduos com fissuras foram os mais condescendentes no julgamento estético.

Os cirurgiões plásticos do HRAC mostraram-se mais exigentes em sua avaliação do que os ortodontistas do HRAC, ainda assim, a mediana para estes cirurgiões plásticos foi maior do que aquela atribuída para as demais categorias, com exceção dos ortodontistas do HRAC. Pode-se inferir que os ortodontistas e cirurgiões plásticos do HRAC estão satisfeitos com os resultados obtidos e habituados com a limitação estética inerente à presença da fissura, mesmo após a completa reabilitação (notas 7,5 e 6,0 respectivamente), diferentemente das demais categorias nas quais o parâmetro de comparação é o indivíduo sem fissura.

Noar (1992) realizou estudo na Inglaterra em que cirurgiões plásticos, ortodontistas e fonoaudiólogos com interesse no manejo de indivíduos com fissura e, em sua maioria, integrantes de uma equipe de reabilitação foram convidados a classificar, por meio de um questionário, o resultado do tratamento de seus pacientes. A amostra foi constituída por adolescentes entre 16 e 25 anos com fissura transforame incisivo unilateral e a avaliação baseou-se em quatro aspectos: tratamento, aparência facial e fala, aspectos sociais e emocionais e o sucesso obtido com o tratamento. Diferenças na metodologia entre o presente trabalho e o de Noar (1992) impediram uma comparação fidedigna dos resultados. Desse modo, pode-se apenas inferir que, contrariamente aos resultados encontrados neste estudo, os profissionais ingleses não estavam particularmente satisfeitos com os resultados do tratamento. Apesar de sentirem que obtiveram sucesso em seu desempenho, somente 39\% deles estavam satisfeitos com os resultados das cirurgias de nariz e lábio, 58,6\% com a finalização ortodôntica e $47 \%$ estavam satisfeitos com a fala. Também sentiram que os pacientes foram emocional e socialmente afetados por suas fissuras e que se sentiam da mesma forma em relação a si próprios sob todos os aspectos. Podemos considerar que os profissionais ingleses de certo modo relevaram em suas avaliações a limitação da presença do defeito anatômico. No HRAC-USP, os profissionais foram mais realistas 
ou conformados diante da tese de que o defeito congênito afasta a idéia da perfeição nos resultados estéticos faciais finais obtidos.

Avaliando os resultados do presente trabalho, considerando a opinião dos leigos, dos ortodontistas e cirurgiões plásticos que não lidam com reabilitação (LFS, ONAF e CPNAF), observou-se que suas avaliações criteriosas, expressas por meio de escores inferiores (5,0; 4,0 e 4,0 respectivamente) (tabelas 1, 13 e figura 11), manifestaram que o padrão facial do indivíduo reabilitado causou impacto pouco positivo, representando a distância real que a face reabilitada guarda do normal.

Segundo Farkas (1987), o senso estético está relacionado a vários aspectos, tais como: condições sócio-econômicas, fatores geográficos e conceitos culturais. Entretanto, via de regra, é na face que a estética é analisada inicialmente, e é pela face, que o individuo se apresenta à sociedade, sendo reconhecido por seus semelhantes. É inegável, portanto, que a estética assume grande importância na construção da autoestima e na inter-relação pessoal.

Apesar de ser um processo de avaliação subjetivo, foi possível observar, por meio da confiabilidade dos testes aplicados, que houve concordância entre os examinadores no tocante ao conceito de beleza, e que este é aquilatável e, provavelmente, ligado à proporcionalidade e à simetria dos terços faciais. O padrão facial do indivíduo com fissura, sabidamente face longa (Capelozza Filho e Silva Filho 1992, Silva Filho et al 1993), somada à retrusão do terço médio e inferior da face, certamente é uma característica marcante que destoa do conceito de beleza atribuído à população em geral.

A tabela 13 mostra a média, mediana, $1 .^{\circ}$ quartil, $3 .^{\circ}$ quartil, mínimo e máximo dos escores atribuídos por categoria na primeira avaliação do lado com fissura. O Teste de Student-Newman-Keuls foi utilizado para comparações múltiplas, mostrando diferença estatisticamente significante entre todas as categorias, exceto entre os ortodontistas e cirurgiões plásticos não atuantes em fissuras (ONAF e CPNAF, respectivamente). Isso provavelmente se explica por serem duas categorias que realizam a avaliação utilizando como parâmetro de comparação o ideal, bastando, para isso, observar as baixas notas $(4,0$ e 4,0) atribuídas por elas e, por isso, a homogeneidade expressa em suas avaliações. A figura 11 mostra, por meio de um gráfico, os valores da mediana, $1 .^{\circ}$ quartil, $3 .^{\circ}$ quartil, mínimo e máximo por categoria na primeira avaliação 
do lado com fissura, revelando claramente a diferença entre as referidas notas, com exceção dos ortodontistas e cirurgiões plásticos (ONAF e CPNAF, respectivamente).

A tabela 14 e a figura 15 demonstram a distribuição da amostra entre os conceitos de classificação utilizados no presente trabalho, ou seja, esteticamente desagradável, aceitável e agradável.

Os ortodontistas atuantes no HRAC classificaram a maioria dos pacientes (21 pacientes; 70\% da amostra) em esteticamente agradável; 9 indivíduos (30\% da amostra) foram considerados esteticamente aceitáveis e nenhum tido como esteticamente desagradável. A ausência de pacientes com face desagradável, do ponto de vista dos ortodontistas do HRAC, deve-se ao fato de eles terem sido tratados e recebido alta pelo término do processo reabilitador. Uma vez reabilitados, espera-se a devolução de uma face no limite da possibilidade, mesmo que as bases apicais mostrem diferenças notórias de uma face morfologicamente íntegra. No conceito dos ortodontistas experientes em reabilitação de fissuras, essa face representa o limite terapêutico. Ninguém melhor que o ortodontista para reconhecer o limite da correção, com ou sem cirurgia ortognática. A verdade é que, mesmo quando bem tratada, dentro dos princípios e possibilidades vigentes, a face adulta na fissura transforame incisivo unilateral reabilitada, como rotina, se distancia da morfologia facial sem fissura. O ortodontista tem ciência dessa diferença intangível pela terapia.

Os ortodontistas desabituados com fissuras (ONAF), não classificaram nenhum indivíduo como esteticamente agradável e consideraram 70\% da amostra (21 pacientes) como esteticamente aceitáveis e 30\% (9 pacientes) como esteticamente desagradáveis. A avaliação destes profissionais técnicos foi importante por ser isenta de vícios, tal qual aconteceu com os profissionais do HRAC. A opinião daqueles foi mais crítica porque o parâmetro de comparação foi a normalidade. Os profissionais que aprendem a lidar com fissuras estabelecem limites, alterando seus objetivos terapêuticos.

Os cirurgiões plásticos do HRAC classificaram 13 pacientes como esteticamente agradáveis (43,3\% da amostra), 17 como esteticamente aceitáveis (56,7\% da amostra) e nenhum foi considerado esteticamente desagradável. Isso é vício, porque o perfil facial do paciente da figura 8 é desagradável. O fato dos ortodontistas e cirurgiões plásticos do HRAC desconsiderarem este fato coloca em cheque se esses indivíduos podem definir a qualidade de um processo reabilitador. Os cirurgiões plásticos do HRAC, mesmo não lidando diretamente com o crescimento facial do indivíduo com fissura, têm idéia da 
face adulta pelo contato com os pacientes que comparecem ao setor de cirurgia para as cirurgias plásticas secundárias. A repetição do desenho da face adulta incute no cirurgião o limite da reabilitação.

Os cirurgiões plásticos (CPNAF) não classificaram nenhum paciente como esteticamente agradável; 73,3\% (22 pacientes) foram considerados esteticamente aceitáveis e 26,7\% (8 pacientes) receberam a classificação de esteticamente desagradáveis. O raciocínio para explicar a conceituação desse grupo é o mesmo dos ortodontistas não atuantes em fissuras (ONAF).

Finalmente, os leigos (LFS) fizeram a seguinte classificação: 10\% da amostra (3 pacientes) foram esteticamente agradáveis; 73,3\% (22 pacientes) esteticamente aceitáveis e 16,7\% da amostra (5 pacientes) foram vistos como esteticamente desagradáveis. Essa talvez seja a avaliação mais importante: como a sociedade vê o paciente reabilitado? E a resposta é boa ou no mínimo razoável. Basta considerar que somados os pacientes aceitáveis (73,3\%) aos agradáveis (10\%) têm-se um total de 83,3\% que podem ser considerados esteticamente satisfatórios. Em uma população de indivíduos sem fissura, este dado aproxima-se de 92\% (Capelozza 2004) (aceitáveis somados aos agradáveis totalizaram 92\%). Portanto, a diferença não é tão acentuada, levando à conclusão de que o resultado encontrado no presente trabalho aproxima-se daquele obtido para a população sem fissura.

\subsection{ESTRUTURAS RESPONSÁVEIS PELA CLASSIFICAÇÃo EM EsteticAMENTE DESAGRADÁVEL}

No momento da avaliação das fotografias, foi solicitado aos examinadores que identificassem as estruturas do perfil facial responsáveis pelas notas de 1 a 3 quando o paciente foi considerado esteticamente desagradável. Na medida do possível, procurouse manter a nomenclatura citada pelos próprios examinadores, inferindo-se termos técnicos quando as citações eram leigas.

Analisando-se a figura 16, pode-se observar que as estruturas mais freqüentemente citadas pelos examinadores como responsáveis pelo conceito esteticamente desagradável foram o terço médio da face, com 47 citações (27,64\%) e o 
nariz citado 31 vezes (18,23\%). Essas duas estruturas, freqüentemente observadas no perfil facial, constituem alvo de grande preocupação por parte da equipe de reabilitação. Isto faz sentido, pois o terço médio da face, representado pela maxila e o nariz, é a principal estrutura atingida pelo defeito e, mesmo após a sua completa reabilitação o paciente, na maioria das vezes, ainda permanece com retrusão da face média. Em ordem decrescente de importância foram ainda citados: mento 29 vezes (17,05\%), desproporção maxilomandibular 16 vezes (9,41\%), perfil reto 9 vezes (5,29\%), lábio inferior 8 vezes (4,70\%), terço inferior 7 vezes ((4,11\%), lábio superior 6 vezes (3,52\%), ângulo/linha-queixo pescoço 5 vezes (2,94\%), perfil convexo e perfil côncavo foram igualmente citados 3 vezes (1,76\%), ângulo nasolabial 2 vezes (1,17\%), face longa, 1/3 superior, pele e boca receberam 1 citação cada (0,58\%).

$\mathrm{Na}$ classificação geral, a amostra foi considerada esteticamente aceitável. No entanto, esse resultado tem pouca valia quando agrupamos as categorias de examinadores. Não há como afirmar qual a categoria correta em seu julgamento; não existe certo ou errado; a beleza é um conceito altamente subjetivo e individual e está presente em indivíduos com ou sem fissura. O que parece claro, é que os profissionais que lidam com a reabilitação das fissuras labiopalatinas conhecem bem as limitações quanto aos resultados estéticos finais, contrariamente aos profissionais leigos em fissura (ONAF e CPNAF), que demonstraram um grau maior de exigência por compararem o indivíduo com fissura em relação ao ideal. Por sua vez, a opinião dos leigos foi importante para aquilatar a qualidade da reabilitação .

A beleza humana refere-se à morfologia, ou seja, aos traços anatômicos da área avaliada. Na face, numa avaliação de perfil, a beleza é determinada por inúmeros fatores subjetivos como: a cor e a textura da pele, a espessura do lábio superior e inferior, o contorno da curvatura lábio-mentoniana, o desenho do nariz, a presença e tamanho dos cílios, bem como a cor e o corte de cabelo. Parece claro que muitas dessas características independem completamente da presença da fissura e, ao mesmo tempo, influenciam a avaliação da beleza numa face com fissura. A avaliação da beleza numa face com fissura, sem dúvida, reflete o resultado do processo reabilitador, mas por outro lado conta também com nuances que influenciam o avaliador.

A reabilitação permite à face tratada uma avaliação estética que varia dependendo do examinador. Os mais condescendentes são os profissionais que atuam na área, principalmente os ortodontistas. Isto reflete a reconhecida impotência dos 
métodos terapêuticos disponíveis para avaliar os efeitos da fissura e suas conseqüências. Ao mesmo tempo, essa tendência em aceitar como bom o que não o é, coloca em dúvida a aptidão desses profissionais para julgar os resultados de um processo reabilitador. Prevendo isso, a linha de pesquisa da qual esse é apenas um trabalho, prevê na metodologia, avaliação técnica por profissionais (ortodontistas e cirurgiões plásticos) que não militam na área.(ONAF e CPNAF, respectivamente). É deles o contraponto que, de um modo isento, identifica o quão distante do normal está a face do paciente reabilitado. Essa diferença entre o aceito pelos ortodontistas e cirurgiões plásticos do HRAC e recusada pelos ortodontistas e cirurgiões plásticos que não atuam na área de reabilitação em fissuras .(ONAF e CPNAF, respectivamente), não é necessariamente um defeito desse processo. As limitações trazidas pela fissura são reconhecidas na literatura, mas admiti-las e entender sua magnitude deve ser um fator a estimular a compreensão de que, o que é possível hoje não é suficiente.

Ainda como protocolo nessa linha de pesquisa, leigos com formação profissional (LFS) são colocados como avaliadores. Suas impressões são as mais importantes para o paciente e, em conseqüência, para os reabilitadores. Representa como os pacientes são vistos por aqueles que desfrutam do seu convívio. Felizmente, conforme observado nesse trabalho, a avaliação não é ruim. Os esforços do HRAC não foram inúteis. 
ONCLUSÕES 


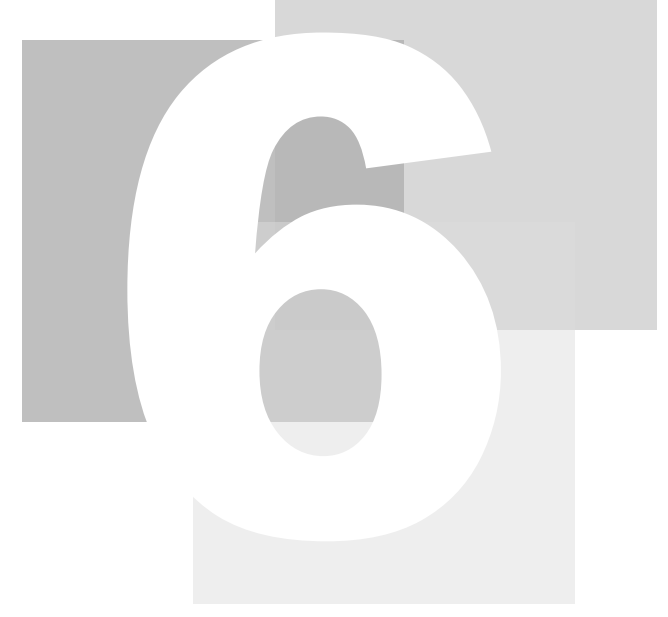

\section{CONCLUSÕES}

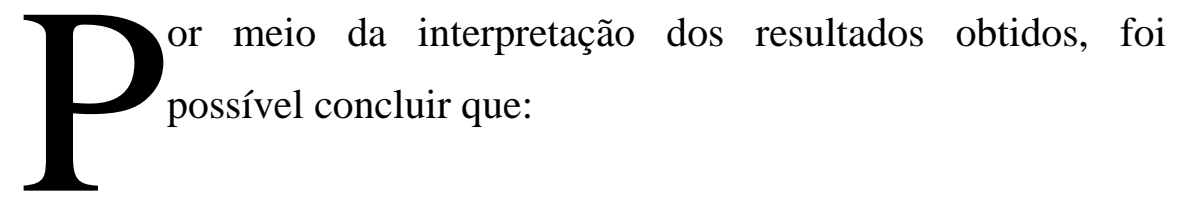

- a estética do perfil facial dos pacientes adultos pertencentes à amostra estudada foi considerada pelos ortodontistas do HRACUSP como esteticamente agradável (70\%); os cirurgiões plásticos do HRAC-USP a classificaram como esteticamente aceitável (56,7\%); os ortodontistas sem experiência com reabilitação de fissuras (ONAF), consideraram os pacientes esteticamente aceitáveis (70\%); os cirurgiões plásticos não atuantes em fissuras (CPNAF) classificaram a amostra como esteticamente aceitável (73,3\%) e os leigos (LFS) a consideraram esteticamente aceitável (73,3\%).

- não houve diferença estatisticamente significante na avaliação dos perfis faciais dos lados com e sem fissura. Sendo assim, não se pode afirmar que o lado do perfil com fissura é o pior. 
- as estruturas do perfil facial responsáveis pela classificação dos indivíduos da amostra no grupo esteticamente desagradável foram: o 1/3 médio da face com 47 citações (27,6\%), seguido pelo nariz citado 31 vezes (18,2\%) e mento com 29 citações (17\%).

- houve diferença estatisticamente significante na avaliação intergrupos de examinadores. Os profissionais que atuam na área de fissuras labiopalatinas atribuíram melhores notas aos perfis faciais do que aqueles que não têm experiência em reabilitação. 
ONSIDERAÇÕES FINAIS 


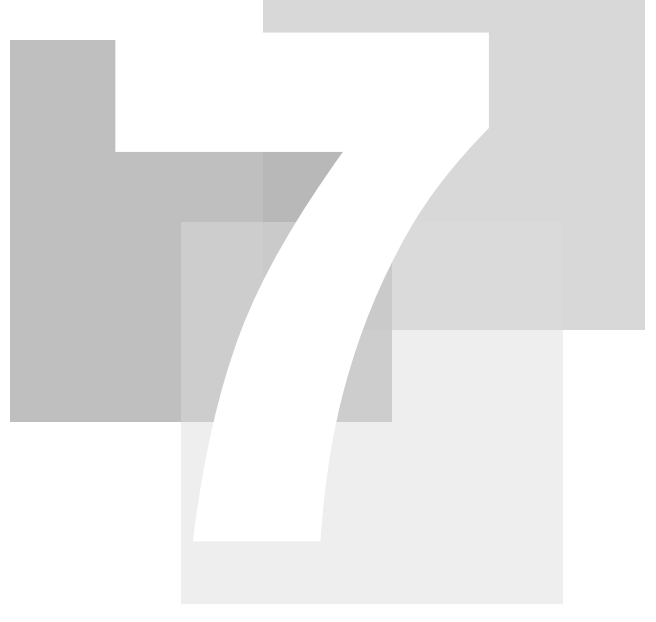

\section{CONSIDERAÇÕES FINAIS}

o longo destas três décadas de atuação, o Hospital de
Reabilitação de Anomalias Craniofaciais vem passando por
modificações estruturais importantes. Tem procurado conhecer seu passado, rever seus protocolos, aprender com seus erros. O Setor de Ortodontia tem-se deparado com desafios importantes, cada vez maiores em busca de excelência nos resultados estéticos e funcionais oferecidos aos indivíduos com fissura.

O aparecimento do enxerto ósseo alveolar secundário, a partir da década de 90, trouxe a oportunidade de transformar a maxila fendida num osso único, capaz de permitir a irrupção do canino permanente na área antes fissurada. O tratamento ortodôntico foi então dividido em duas fases, pré e pós-enxerto. Isso representou mudanças nos protocolos de tratamento, atitudes corajosas de profissionais mais que corajosos!

A heterogeneidade da amostra exigiu cautela na análise dos dados. Os objetivos de tratamento mudaram ao longo desses anos, a ausência do enxerto ósseo prejudicava a finalização ortodôntica e os planejamentos eram limitados a alinhamentos e nivelamentos prévios à reabilitação protética. A cirurgia ortognática se deparava com as 
frágeis osteossínteses em busca da estabilidade. O advento da fixação rígida ocasionou melhores resultados funcionais e estéticos, embora o padrão de crescimento tenha sempre desempenhado importante papel no resultado final do tratamento.

É nesse contexto que devem ser analisados os dados relativos ao tratamento ortodôntico dos pacientes da amostra selecionada, explanados nos anexos 2 e 3. Os resultados foram interpretados por meio da mediana, o que possibilitou excluir os extremos e obter dados mais próximos da realidade.

O início do tratamento ortodôntico foi, em média, aos 12,4 anos, diferente do que ocorre atualmente quando os pacientes com fissuras que envolvem o rebordo alveolar são chamados a comparecerem ao Setor de Ortodontia para receberem o tratamento ortodôntico pré-enxerto, por volta dos 8-9 anos de idade. A idade cronológica apenas respeita um protocolo de intenções cirúrgicas, porém o status biológico da irrupção do canino é que determina a época ideal para a realização do enxerto ósseo alveolar secundário (EOA). Os dados relativos ao final do tratamento ortodôntico revelaram uma mediana de 19,3 anos. A mediana obtida para a duração do tratamento ortodôntico dessa amostra foi de 6,9 anos, um tempo adequado em se tratando de reabilitação de fissuras labiopalatinas. O tratamento ortodôntico normalmente se inicia antes da irrupção do canino permanente e estende-se até o final do crescimento craniofacial.

No entanto, outros fatores importantes são tidos como responsáveis pelo longo tratamento: 1) dificuldade em cumprir as agendas de retorno por parte dos pacientes, em função de fatores geo-econômicos; 2) falta de cobrança dos pacientes e familiares aos profissionais, permitindo agirem sem preocupação com datas e previsões de finalização; 3) socialização da ortodontia no HRAC-USP; e 4) impossibilidade de cumprimento das etapas terapêuticas para todos os tipos de cirurgia, incluindo enxerto ósseo e cirurgia ortognática devido à demanda de pacientes. A qualidade dos serviços prestados fica comprometida em decorrência da demanda. Esse é um princípio lógico aplicado a qualquer serviço, não exclusivamente ao HRAC-USP.

A maior parte da amostra, 28 pacientes (93,3\%) receberam atendimento no Setor de Ortodontia. Apenas 2 pacientes (6,7\%) não quiseram ser submetidos ao tratamento ortodôntico/cirúrgico convencional.

No presente trabalho, a idade mediana encontrada para a realização do enxerto foi 16,1 anos. Dentre os pacientes da amostra, 6 (20\%) submeteram-se à cirurgia de 
EOA simultaneamente à cirurgia ortognática, realizada somente após a maturidade esquelética, o que contribuiu para o aumento da mediana encontrada. Dos 30 pacientes selecionados 18, (60\%) foram submetidos à cirurgia de enxerto ósseo alveolar isolada, ou simultaneamente à cirurgia ortognática. A experiência adquirida pela equipe durante esses anos com a realização do EOA contribuiu para a sua instituição definitiva no protocolo de atendimento do HRAC-USP.

Dos 30 pacientes selecionados para a amostra, 8 (26,6\%) foram submetidos à cirurgia ortognática. A mediana encontrada para a idade desta cirurgia foi 19,5 anos, um resultado satisfatório quando se considera que esse procedimento é indicado apenas após a maturidade esquelética, no entanto, deve-se considerar também a grande demanda do setor de cirurgia ortognática que contribui para este resultado. Um fato curioso observado no presente estudo foi a constatação de que o paciente com a melhor classificação estética da amostra selecionada não realizou cirurgia ortognática durante o tratamento, e o pior classificado foi submetido a esse procedimento. Novamente a soberania do padrão de crescimento do indivíduo com fissura contribuiu para a qualidade do resultado do tratamento. Os resultados cirúrgicos estão dentro dos limites pré-estabelecidos, como: preparo pré-cirúrgico, limite imposto pelos arcos dentários para descompensação suficiente, tensão do tecido mole determinada pela amplitude inicial da fissura, bem como pelo número de cirurgias plásticas repetitivas. O problema é que os pacientes indicados para cirurgia ortognática já apresentam deformidades faciais além do limite da ortodontia.

O controle da estabilidade dos casos finalizados sempre foi rotina no Setor de Ortodontia. Dentre os 30 pacientes da amostra, 14 (46,6\%) ainda estão em controle utilizando placa de Hawley e 16 (53,3\%) receberam alta definitiva. Isso representa a preocupação com a qualidade do tratamento oferecido pela equipe e a responsabilidade que esta assume perante os resultados finais obtidos.

$\mathrm{Na}$ verdade, esses pacientes finalizados são privilegiados, pois conseguiram cumprir uma trajetória longa de reabilitação, e o HRAC-USP conseguiu oferecer condições para a finalização do tratamento. Está cada vez mais difícil esse contexto no HRAC-USP. O que pode ter melhorado nos últimos anos dentro da reabilitação é a racionalização das condutas, tornando menos exausto o processo reabilitador do paciente, o que acaba interferindo nos resultados. 
Peferências Bibliográficas 


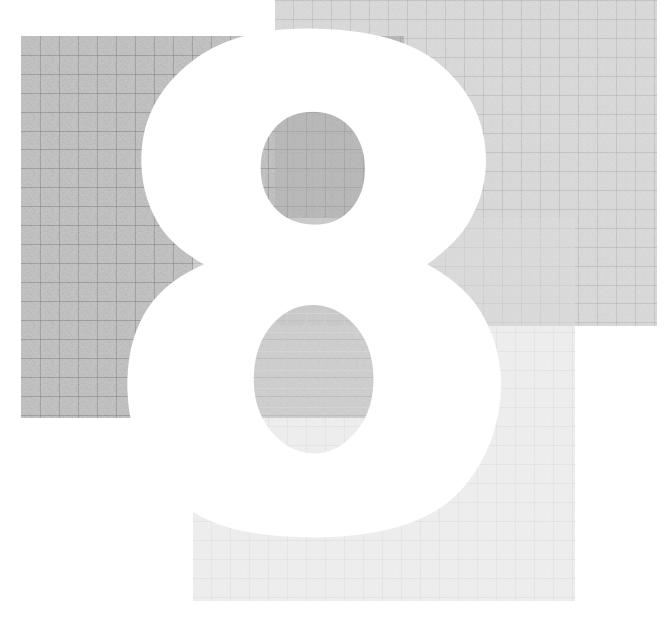

\section{REFERÊNCIAS BIBLIOGRÁFICAS}

Andrade D, Angerami ELS. A auto estima em adolescentes com e sem fissura de lábio e/ou palato. Rev latinoam. enfermagem 2001; 9:37-41.

Angle EH. Treatment of malocclusion of the teeth: Angle's system. 7th ed. Philadelphia: S. S. White; 1907.

Arnett WG, Bergman R. Facial keys to orthodontic diagnosis and treatment planning. I. Am J Orthod Dentofacial Orthop 1993a; 103:299-312.

Arnett WG, Bergman R. Facial keys to orthodontic diagnosis and treatment planning. II. Am J Orthod Dentofacial Orthop 1993b; 103:395-411.

Asher-Macdade C, Brattström V, Dahl E, Mcwillian J, Molsted K, Plint DA, et al. A six-center international study of treatment outcome in patients with clefts of the lip and palate. IV. Assessment of nasolabial appearance. Cleft Palate Craniofac J 1992; 29:409-12. 
Bass NM. The aesthetic analysis of the face. Eur J Orthod 1991; 13:343-50.

Bertier CE. Tratamento cirúrgico da fissura labial unilateral. In: Carreirão S, Lessa S, Zanini SA. Tratamento das fissuras labiopalatinas. Rio de Janeiro: Revinter; 1996. p.67-75.

Bishara SE, Olin WH. Surgical repositioning of the premaxilla in complete bilateral cleft lip and palate. Angle Orthod 1972; 42:139-147.

Broadbent BH. A new X-Ray technique and its application to orthodontic. Angle Orthod 1931; 1:45-66.

Broder HL, Smith FB, Strauss RP. Effects of visible and invisible orofacial defects on self-perception and adjustment across developmental eras and gender. Cleft Palate Craniofac J 1994; 31:429-36.

Burstone CJ. The integumental profile. Am J Orthod 1958; 44:1-25.

Bütow KW. A lateral photometric analysis for aesthetic - orthognatic treatment. $J$ Maxillofac Surg 1984; 12:201-7.

Capelozza Filho L. Normas para diagnóstico. In: Capelozza Filho L, editor. Diagnóstico em ortodontia. Maringá: Dental Press; 2004. p.47-76.

Capelozza Filho L, Silva Filho OG. Abordagem interdisciplinar no tratamento das fissuras labiopalatais. In: Mélega JC. editor. Cirurgia plástica fundamentos e arte: cirurgia reparadora da cabeça e pescoço. Rio de Janeiro: Medsi, 2002. p.59-88.

Capelozza Filho L, Silva Filho OG. Fissuras lábio-palatais. In: Petrelli E, editor. Ortodontia para fonoaudiologia. Curitiba: Lovise; 1992. p195-239. 
Capelozza Filho L, Almeida AM, Ursi WJ. Rapid maxillary expansion in cleft lip and patients. J Clin Orthod 1994; 28:34-9.

Capelozza Filho L, Cavassan AO, Silva Filho OG. Avaliação do crescimento craniofacial em portadores de fissuras transforame incisivo unilateral: estudo transversal. Rev Bras Cir 1987; 77:97-106.

Capelozza Filho L, Normando ADC, Silva Filho OG. Isolated influences of lip and palate surgery on facial growth: comparison of operated and unoperated male adults with UCLP. Cleft Palate Craniofac J 1996; 33:51-6.

Castilha E, Lopes-Camelo JS, Paz JE. Atlas geográfico de las malformaciones congênitas en Sudamérica. Rio de Janeiro: Fiocruz; 1995. p.58-9.

Chitarra JN, Gontijo L, Melo EMF, Leite EB. O uso da fotocélula para eliminação da sombra nas fotografias faciais para documentação odontológica. Rev Dental Press Ortodon Ortop Facial 2003; 8:59-62.

Clifford E, Crocker EC, Pope B. Psychological findings in the adulthood of 98 cleft lippalate children. Plast Reconstr Surg 1972; 50:234-7.

Cooke MS. Five-year reproducibility of natural head posture: a longitudinal study. Am J Orthod Dentofacial Orthop 1990; 97:489-94.

Cooke MS, Wei SHY. The reproducibility of natural head posture: a methodological study. Am J Orthod Dentofacial Orthop 1988; 93:280-8.

Crawford EC. Clinical orthodontic photography. II. Face photography. Aust Orthod J 1987; 10:114-8.

Crawford EC. The face - an orthodontic perspective. Aust Orthod J 1991; 12:13-22. 
Czarnecki ST, Nanda RS, Currier GF. Perceptions of a balanced facial profile. Am J Orthod Dentofacial Orthop 1993; 104:180-7.

Dierkes JM. The beauty of the face: an orthodontic perspective. J Am Dental Assoc 1987; v.89-95. [Special Issue].

Downs WB. Analysis of the dentofacial profile. Angle Orthod 1956; 26:191-212.

El-Mangoury NH, Mostafa YA, Rasmy EM, Salah A. Faciometrics: a new syntax for facial feature analysis. Int J Adult Orthodon Orthognath Surg 1996; 11:71-82.

Enemark H, Friede H, Paulin G, Semb G, Abyholm F, Bolund S, et al. Lip and nose morphology in patients with unilateral cleft lip and palate from four Scadinavian centres. Scand J Plast Resconstr Surg Hand Surg 1993; 27:42-7.

Farkas LG, Kolar JC. Anthropometrics and art in the aesthetics of women's faces. Clin Plast Surg 1987; 14:599-616.

Ferrario VF, Chiarella S, Miani A, Tartaglia G. Craniofacial morphometry by photographic evaluations. Am J Orthod Dentofacial Orthop 1993; 103:327-37.

Fricker JP. Standardized facial photography. Aust Orthod J 1982; 7:168-73.

Friede H, Enemark H, Semb G, Abyholm F, Bolund S, Lilja J, et al. Craniofacial and occlusal characteristics in unilateral cleft lip and palate patients from four Scadinavian centres. Scand J Plast Resconstr Surg Hand Surg 1991; 25:269-76.

Garcia JR, Neme CMB, Chinellato MCMP. Body-image in adult patients with cleft lip palate: an analysis through human figure drawing. Braz J Dysmorphol Speech-Hear Disord 1999; 2:17-26. 
Gnoinski WM. Early maxillary orthopaedics as a supplement to conventional primary surgery in complete cleft lip and palate cases: long term results. J Oral Maxillofac Surg 1982; 10:165-72.

Heller A, Tidmarsh W, Pless IB. A psychological functioning of young adults born with cleft lip or palate: a follow up study. Clin Pediatr 1981; 20:459-65.

Holdaway RA. Changes in relationships of points A and B during orthodontic treatment. Am J Orthod 1956; 42:176-93.

Holdaway RA. A soft - tissue cephalometric analysis and its use in orthodontic treatment planning. Am J Orthod Dentofacial Orthop 1983; 84:1-28.

Hotz MM. Orofacial development under adverse conditions. Eur J Orthod 1983; 5:91103.

Hotz MM, Gnoinski W. Comprehensive care of cleft lip and palate children at Zürich University: a preliminary report. Am J Orthod 1976; 70:481-504.

Jacobson A. Planning for orthognathic surgery - art or science? Int J Adult Orthodon Orthognath Surg 1990; 5:217-24.

Jefferson Y. Skeletal types: keys to unraveling mystery of facial beauty and its biologic significance. J Gen Orthod 1996; 7:7-25.

Johanson B, Ohlsson A, Friede H, Ahlgren J. A follow-up study of cleft lip and palate patients treated with orthodontics, secondary bone grafting and prosthetic rehabilitation. Scand J. Plast Reconstr Surg 1974; 8:121-35.

Kwon HJ, Waite DE, Stickel FR, Chisholm T, McParland F. The management of alveolar clefts defects. J Am Dent Assoc 1981; 102:848-53. 
Lundströn F, Lundströn A. Natural head position as base for cephalometric analysis. Am J Orthod Dentofacial Orthop 1992; 101:244-7.

Mars M, Asher-Mcdade C, Brattstrom V, Dahl E, McWilliam J, Molsted K, et al. A six-center international study of treatment outcome in patients with clefts of the lip and palate. III. Dental arch relationships. Cleft Palate Craniofac J 1992; 29:405-8.

Michiels G, Sather AH. Validity and reliability of facial profile evaluation in vertical and horizontal dimensions from lateral cephalograms and lateral photographs. Int $J$ Adult Orthodon Orthognath Surg 1994; 9:43-54.

Millard Junior, DR. Cleft craft: the evolution of its surgery. Boston: Little Brown; 1976.v.1.

Molsted K, Dahl E, Battstrom V, McWilliam J, Semb G. A six-center international study of treatment outcome in patients with clefts of the lip and palate: evaluation of maxillary asymmetry. Cleft Palate Craniofac J 1993; 30:22-8.

Molsted K, Asher-Mcdade C, Brattstrom V, Dahl E, Mars M, McWilliam J, et al. A six-center international study of treatment outcome in patients with clefts of the lip and palate. II. Craniofacial form and soft tissue profile. Cleft Palate Craniofac J 1992; 29:398-404.

Moorrees CFA. Analysis of the facial profile - commentary. Angle Orthod 1992; 62:133.

Moorrees CFA, Kean M. Natural head position, a basic consideration in the interpretation of cephalometric radiographs. Am J Phys Anthropol 1958; 16:213-34.

Morris W. An orthodontic view of dentofacial esthetics. Compend Contin Educ Dent 1994; 15:378-90. 
Motohashi N, Pruzansky S. Long-term effects of premaxillary excision in patients with complete bilateral cleft lips and palates. Cleft Palate J 1981; 18:177-87.

Neger, M, Newark NJA. A quantative method for the evaluation of the soft - tissue facial profile. Am J Orthod 1959; 45:738-51.

Nicholson PT, Plint DA. A long-term study of rapid maxillary expansion and bone grafting in cleft lip and palate patients. Eur J Orthod 1989; 11:186-92.

Noar JH. A questionnaire survey of attitudes and concerns of three professional groups involved in the cleft palate team. Cleft Palate Craniofac J 1992; 29:92-5.

Normando ADC, Silva Filho OG , Capelozza Filho L. Influence of surgery on maxillary growth in cleft lip and/or palate patients. J Cranio Maxillofac Surg 1992; 20:111-8.

Ozawa TO. Avaliação dos efeitos da queiloplastia e palatoplastia primária sobre o crescimento dos arcos dentários de crianças com fissura transforame incisivo unilateral aos 5 6 anos de idade [tese]. Araraquara: Faculdade de Odontologia de Araraquara, Universidade Estadual Paulista “Júlio de Mesquita Filho”; 2001.

Peng L, Cooke MS. Fifteen-year reproducibility of natural head posture: a longitudinal study. Am J Orthod Dentofacial Orthop 1999; 16:82-5.

Pereira ACMM. Auto-conceito e auto-estima em indivíduos com fissura labiopalatina: Influência do tipo de fissura e do tempo de convivência com a mesma [dissertação]. Bauru: Hospital de Reabilitação de Anomalias Craniofaciais, Universidade de São Paulo; 2000.

Phillips C, Tulloch C, Dann C. Rating of facial attractiveness. Community Dent Oral Epidemiol 1992; 20:214-20. 
Pruzansky S. Factors determining arch form in clefts of the lip and palate. Am $J$ Orthodont 1955; 41:827-51.

Pruzansky S. Pre-surgical orthopedics and bone grafting for infants with cleft lip and palate: a dissent. Cleft Palate J 1964; 1:164-87.

Reis SAB. Análise facial numérica e subjetiva do perfil e análise da relação oclusal sagital em brasileiros, adultos, leucodermas, não tratados ortodonticamente [dissertação]. São Bernardo do Campo: Universidade Metodista de São Paulo; 2001.

Rickets RM. Esthetics, environment and the law of lip relation. Am J Orthod 1968; 54:272-89.

Ross RB, Johnston MC. Cleft lip and palate. Baltimore: Williams Willians; 1972.

Ross RB. Treatment variables affecting facial growth in complete unilateral cleft lip and palate. I: Treatment affecting growth. Cleft Palate J 1987; 24:5-77.

Semb G. Effect of alveolar bone grafting on maxillary growth in unilateral cleft lip and palate patients. Cleft Palate J 1988; 25:288-95.

Semb G. A study of facial growth in patients with bilateral cleft lip and palate treated by the Oslo CLP team. Cleft Palate J 1991a; 28:22-39.

Semb G. A study of facial growth in patients with unilateral cleft lip and palate treated by the Oslo CLP team. Cleft Palate Craniofacial J 1991b; 28:1-21.

Shaw WC, Addy M, Dummer PM, Ray C, Frude N. Dental and social effect of malocclusion and effectiveness of orthodontic treatment: a strategy for investigation. Community Dent Oral Epidemiol 1986; 14:60-4. 
Shaw WC, Asher-McDade C, Brattstrom V, Dahl E, McWilliam J, Molsted K, et al. A six-center international study of treatment outcome in patients with clefts of the lip and palate. I. Principles and study design. Cleft Palate Craniofac J 1992a; 29:393-7.

Shaw WC, Dahl E, Asher-McDade C, Battstrom V, Mars M, McWilliam J, et al. A sixcenter international study of treatment outcome in patient with clefts of the lip and palate. V. General discussion and conclusions. Cleft Palate Craniofac J 1992b; 29:4138.

Silva Filho OG, Lauris RCM, Cavassan AO. Pacientes fissurados de lábio e palato: efeitos suscitados pela queiloplastia. Ortodontia 1990; 23:25-34.

Silva Filho OG, Normando ADC, Capelozza Filho L. Mandibular growth in patients with clefts lip and/or cleft palate - the influence of the cleft type. Amer J Orthodont Dentofac Orthop 1993; 104:269-75.

Silva Filho OG, Normando ADC, Capelozza Filho L. Mandibular morphology and spatial position in patients with clefts: intrinsic or iatrogenic? Cleft Palate Craniofac $J$ 1992a; 29:369-75.

Silva Filho OG, Ramos AL, Abdo RCC. The influence of unilateral cleft lip and palate on maxillary dental arch morphology. Angle Orthod 1992b; 62:283-90.

Silva Filho OG, Ferrari Júnior FM, Rocha DL, Souza Freitas JA. Classificação das fissuras lábio-palatais: breve histórico, considerações clínicas e sugestão de modificação. Rev Bras Cir 1992c; 82:59-65.

Silva Filho OG, Ramos AL, Capelozza Filho L. Influência da queiloplastia nas dimensões e forma do arco dentário superior em adultos fissurados de lábio e palato. Rev Soc Bras Odontol 1991a; 1:269-75.

Silva Filho OG, Ramos AL, Abdo RCC. Morfologia dos arcos dentários em pacientes portadores de fissura de lábio e palato, não operados. Ortodontia 1991b; 24:9-17. 
Silva Filho OG, Valladares Neto J, Capelozza Filho L, Souza Freitas JA. Influência da queiloplastia sobre a morfologia craniofacial em fissura bilateral completa de lábio e palato. Ortodontia 2001; 34:17-26.

Silva Filho OG, Capelozza Filho L, Werneck V, Souza Freitas JA. Abordagem ortodôntica ao paciente com fissura unilateral completa de lábio e palato. Ortodontia 1998; 31:32-44.

Silva Filho OG, Ferrari Júnior FM, Capelozza Filho L, Albuquerque MVP. Enxerto ósseo alveolar em pacientes fissurados: realidade e perspectivas. Ortodontia 1995; 28:34-45.

Silva Filho OG, Telles SG, Ozawa TO, Capelozza Filho L Secondary bone graft and eruption of the permanent canine in patients with alveolar clefts: literature review and case report. Angle Orthod 2000; 70:74-178.

Skinazi GLS, Lindauer SJ, Isaacson RJ. Chin, nose and lips normal ratios in young men and women. Am J Orthod Dentofacial Orthop 1994; 106:518-23.

Spina VR, Ludovici O. Tratamento da fissura lábio palatal em duas etapas. Rev Lat Amer Cir Plast 1968; 12:150-60.

Spina V, Kamakura L, Lapa F. Surgical management of bilateral cleft lip. An Plast Surg 1978; 7:497-505.

Spina V, Psillankis JM, Lapa FS, Ferreira MC. Classificação das fissuras lábiopalatinas: sugestão de modificação. Rev Hosp Clin Fac Med S Paulo 1972; 27:5-6.

Tourne LPM, Bevis RL, Cavanaugh G. A validity test of cephalometric variables as a measure of clinical applicability in anteroposterior profile assessment. Int J Adult Orthodon Orthognath Surg 1993; 8:95-112. 
Vargervik K. Growth characteristics of the premaxilla and orthodontic treatment principles in bilateral cleft lip and palate. Cleft Palate J 1983; 20:289-302.

Vargervik K. Orthodontic management of unilateral cleft lip and palate. Cleft Palate $J$ $1981 ; 18: 256-70$.

Zarem HA. Standards of photography. Plast Reconstr Surg 1984; 74:137-44. 


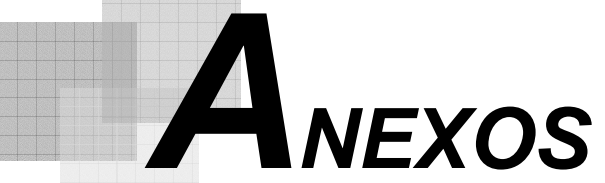


Anexo 1 - Protocolo de intenções cirúrgicas defendido pelo HRAC-USP para reabilitação das fissuras

\begin{tabular}{|c|c|c|c|c|c|}
\hline Cirurgia & $\begin{array}{c}\text { Pré-forame } \\
\text { unilateral }\end{array}$ & $\begin{array}{l}\text { Pré-forame } \\
\text { Bilateral }\end{array}$ & $\begin{array}{c}\text { Transforame } \\
\text { Unilateral }\end{array}$ & $\begin{array}{c}\text { Transforame } \\
\text { Bilateral }\end{array}$ & Pós-forame \\
\hline \multirow{2}{*}{ Queiloplastia } & \multirow{2}{*}{3 meses } & $\begin{array}{c}3 \text { meses } \\
\text { (tempo único) }\end{array}$ & 3 meses & $\begin{array}{c}3 \text { meses } \\
\text { (tempo único) }\end{array}$ & - \\
\hline & & $\begin{array}{l}3 \text { meses e } 6 \text { meses } \\
\text { ( } 2 \text { tempos cirúrgicos) }\end{array}$ & & $\begin{array}{l}3 \text { meses e } 6 \text { meses } \\
\text { ( } 2 \text { tempos cirúrgicos) }\end{array}$ & \\
\hline Palatoplastia & - & - & 12 meses & 12 meses & 12 meses \\
\hline $\begin{array}{c}\text { Queiloplastia } \\
\text { definitiva + } \\
\text { columela }\end{array}$ & - & 6 anos & - & 6 anos & - \\
\hline $\begin{array}{c}\text { Enxerto ósseo } \\
\text { secundário }\end{array}$ & $\begin{array}{l}9-12 \\
\text { anos }\end{array}$ & $\begin{array}{l}9-12 \\
\text { anos }\end{array}$ & $\begin{array}{c}9-12 \\
\text { anos }\end{array}$ & $\begin{array}{l}9-12 \\
\text { anos }\end{array}$ & - \\
\hline $\begin{array}{c}\text { Cirurgia } \\
\text { ortognática }\end{array}$ & - & - & $\begin{array}{l}\text { Maturidade } \\
\text { esquelética }\end{array}$ & $\begin{array}{l}\text { Maturidade } \\
\text { esquelética }\end{array}$ & - \\
\hline
\end{tabular}

FONTE: Capelozza Filho L, Silva Filho OG. Abordagem interdisciplinar no tratamento das fissuras labiopalatinas. In: Mêlega JC, editor. Cirurgia plástica fundamentos e arte: cirurgia reparadora da cabeça e pescoço. Rio de Janeiro: Medsi; 2002, p.59-88. 
Anexo 2 - Dados relativos ao tratamento ortodôntico-cirúrgico dos pacientes da amostra

\begin{tabular}{|c|c|c|c|c|c|c|c|c|}
\hline Paciente & TO & $\begin{array}{l}\text { Início TO } \\
\text { (anos) }\end{array}$ & $\begin{array}{c}\text { Final TO } \\
\text { (anos) }\end{array}$ & $\begin{array}{l}\text { Duração } \\
\text { TO (anos) }\end{array}$ & $\begin{array}{c}\text { EOA } \\
\text { (anos) }\end{array}$ & $\begin{array}{c}\text { Co } \\
\text { (anos) }\end{array}$ & $\begin{array}{c}\text { Controle } \\
\text { Hawley }\end{array}$ & $\begin{array}{l}\text { Alta TO } \\
\text { (anos) }\end{array}$ \\
\hline 1 & $\operatorname{sim}$ & $12 \mathrm{a} 7 \mathrm{~m}$ & $19 a 2 m$ & $6 a 7 m$ & & & & $19 \mathrm{a} 7 \mathrm{~m}$ \\
\hline 2 & $\operatorname{sim}$ & $11 a$ & $17 \mathrm{a} 10 \mathrm{~m}$ & $6 a 10 m$ & & & & $21 a$ \\
\hline 3 & $\operatorname{sim}$ & $12 \mathrm{a} 3 \mathrm{~m}$ & $22 \mathrm{a} 5 \mathrm{~m}$ & $11 \mathrm{a} 2 \mathrm{~m}$ & $19 a 7 m$ & $19 \mathrm{a} 7 \mathrm{~m}$ & & $27 a$ \\
\hline 4 & $\operatorname{sim}$ & $18 \mathrm{a} 8 \mathrm{~m}$ & $26 a 5 m$ & $7 \mathrm{a} 9 \mathrm{~m}$ & & & $\operatorname{sim}$ & \\
\hline 5 & $\operatorname{sim}$ & $14 \mathrm{a} 6 \mathrm{~m}$ & $17 \mathrm{a} 7 \mathrm{~m}$ & $3 a 1 m$ & & & & $18 \mathrm{a} 5 \mathrm{~m}$ \\
\hline 6 & $\operatorname{sim}$ & $12 \mathrm{a} 5 \mathrm{~m}$ & $18 \mathrm{a} 4 \mathrm{~m}$ & $5 a 11 m$ & $17 \mathrm{a} 9 \mathrm{~m}$ & $17 \mathrm{a} 9 \mathrm{~m}$ & & $19 \mathrm{a} 4 \mathrm{~m}$ \\
\hline 7 & $\operatorname{sim}$ & $4 \mathrm{a} 10 \mathrm{~m}$ & $18 \mathrm{a} 4 \mathrm{~m}$ & $12 \mathrm{a} 6 \mathrm{~m}$ & $14 \mathrm{a} 10 \mathrm{~m}$ & & & $20 \mathrm{a} 2 \mathrm{~m}$ \\
\hline 8 & $\operatorname{sim}$ & $10 \mathrm{a} 10 \mathrm{~m}$ & $19 \mathrm{a} 5 \mathrm{~m}$ & $8 \mathrm{a} 7 \mathrm{~m}$ & $15 a 1 m$ & & & $22 \mathrm{a} 7 \mathrm{~m}$ \\
\hline 9 & sim & $12 \mathrm{a} 6 \mathrm{~m}$ & $15 a$ & $2 \mathrm{a} 6 \mathrm{~m}$ & & & & $20 \mathrm{a} 1 \mathrm{~m}$ \\
\hline 10 & $\operatorname{sim}$ & 11 a $3 m$ & $19 a$ & $7 \mathrm{a} 9 \mathrm{~m}$ & $17 \mathrm{a} 6 \mathrm{~m}$ & & & $20 \mathrm{a} 4 \mathrm{~m}$ \\
\hline 11 & $\operatorname{sim}$ & $12 \mathrm{a} 3 \mathrm{~m}$ & $22 \mathrm{a} 8 \mathrm{~m}$ & $10 \mathrm{a} 5 \mathrm{~m}$ & $21 \mathrm{a} 10 \mathrm{~m}$ & $21 \mathrm{a} 10 \mathrm{~m}$ & $\operatorname{sim}$ & \\
\hline 12 & sim & $10 \mathrm{a} 9 \mathrm{~m}$ & $20 \mathrm{a} 8 \mathrm{~m}$ & $9 \mathrm{a} 11 \mathrm{~m}$ & $17 \mathrm{a} 1 \mathrm{~m}$ & $17 \mathrm{a} 1 \mathrm{~m}$ & $\operatorname{sim}$ & \\
\hline 13 & $\operatorname{sim}$ & $12 \mathrm{a} 3 \mathrm{~m}$ & $18 \mathrm{a} 10 \mathrm{~m}$ & $6 \mathrm{a} 7 \mathrm{~m}$ & $14 \mathrm{a} 11 \mathrm{~m}$ & & & $21 \mathrm{a} 3 \mathrm{~m}$ \\
\hline 14 & $\operatorname{sim}$ & $19 \mathrm{a} 1 \mathrm{~m}$ & $22 \mathrm{a} 5 \mathrm{~m}$ & $3 a 4 m$ & & & & $24 a 7 m$ \\
\hline 15 & $\operatorname{sim}$ & $12 \mathrm{a} 5 \mathrm{~m}$ & $22 \mathrm{a} 4 \mathrm{~m}$ & $9 \mathrm{a} 11 \mathrm{~m}$ & $21 \mathrm{a} 8 \mathrm{~m}$ & $21 \mathrm{a} 8 \mathrm{~m}$ & sim & \\
\hline 16 & $\operatorname{sim}$ & $13 \mathrm{a} 11 \mathrm{~m}$ & $21 a$ & $7 \mathrm{a} 1 \mathrm{~m}$ & $16 a$ & & $\operatorname{sim}$ & \\
\hline 17 & $\operatorname{sim}$ & $12 \mathrm{a} 3 \mathrm{~m}$ & $21 \mathrm{a} 9 \mathrm{~m}$ & $9 a 8 m$ & $13 a 1 m$ & 19a $10 \mathrm{~m}$ & $\operatorname{sim}$ & \\
\hline 18 & sim & $15 \mathrm{a} 6 \mathrm{~m}$ & $19 a 5 m$ & $3 a 11 \mathrm{~m}$ & & & & $21 \mathrm{a} 1 \mathrm{~m}$ \\
\hline 19 & sim & $10 a$ & $17 \mathrm{a} 4 \mathrm{~m}$ & $7 \mathrm{a} 4 \mathrm{~m}$ & $13 a 2 m$ & & & $18 \mathrm{a} 5 \mathrm{~m}$ \\
\hline 20 & $\operatorname{sim}$ & $11 \mathrm{a} 3 \mathrm{~m}$ & $19 a$ & $8 a$ & $10 \mathrm{a} 11 \mathrm{~m}$ & & & $19 \mathrm{a} 6 \mathrm{~m}$ \\
\hline 21 & $\operatorname{sim}$ & $13 a 5 m$ & $19 a 6 m$ & $6 a 1 m$ & & & $\operatorname{sim}$ & \\
\hline 22 & $\operatorname{sim}$ & $13 a 3 m$ & $21 \mathrm{a} 8 \mathrm{~m}$ & $8 \mathrm{a} 8 \mathrm{~m}$ & $20 a 2 m$ & $20 a 2 m$ & $\operatorname{sim}$ & \\
\hline 23 & sim & $13 \mathrm{a} 1 \mathrm{~m}$ & 19a $10 \mathrm{~m}$ & $6 a 9 m$ & $16 a 3 m$ & & $\operatorname{sim}$ & \\
\hline 24 & $\operatorname{sim}$ & $9 a 8 m$ & $16 a 8 m$ & $7 a$ & $13 a 8 m$ & & $\operatorname{sim}$ & \\
\hline 25 & não & & & & & & & $16 a$ \\
\hline 26 & sim & $16 \mathrm{a} 4 \mathrm{~m}$ & $17 \mathrm{a} 6 \mathrm{~m}$ & $1 \mathrm{a} 9 \mathrm{~m}$ & & & sim & \\
\hline 27 & não & & & & & & & $16 \mathrm{a} 2 \mathrm{~m}$ \\
\hline 28 & $\operatorname{sim}$ & $15 \mathrm{a} 1 \mathrm{~m}$ & $16 a 5 m$ & $1 \mathrm{a} 4 \mathrm{~m}$ & & & sim & \\
\hline 29 & $\operatorname{sim}$ & $10 \mathrm{a} 10 \mathrm{~m}$ & $15 \mathrm{a} 9 \mathrm{~m}$ & $4 \mathrm{a} 11 \mathrm{~m}$ & $9 \mathrm{a} 10 \mathrm{~m}$ & & sim & \\
\hline 30 & sim & $18 \mathrm{a} 4 \mathrm{~m}$ & $22 \mathrm{a} 4 \mathrm{~m}$ & $4 a$ & $19 \mathrm{a} 4 \mathrm{~m}$ & $19 a 4 m$ & $\operatorname{sim}$ & \\
\hline Mediana & & $12 a 4 m$ & $19 a 3 m$ & $6 a 9 m$ & $16 a 1 m$ & $19 a 5 m$ & & $20 \mathrm{a} 1 \mathrm{~m}$ \\
\hline
\end{tabular}

TO: tratamento ortodôntico; EOA: enxerto ósseo alveolar; CO: cirurgia ortognática 
Anexo 3 - Dados relativos ao tratamento ortodôntico-cirúrgico dos pacientes da amostra

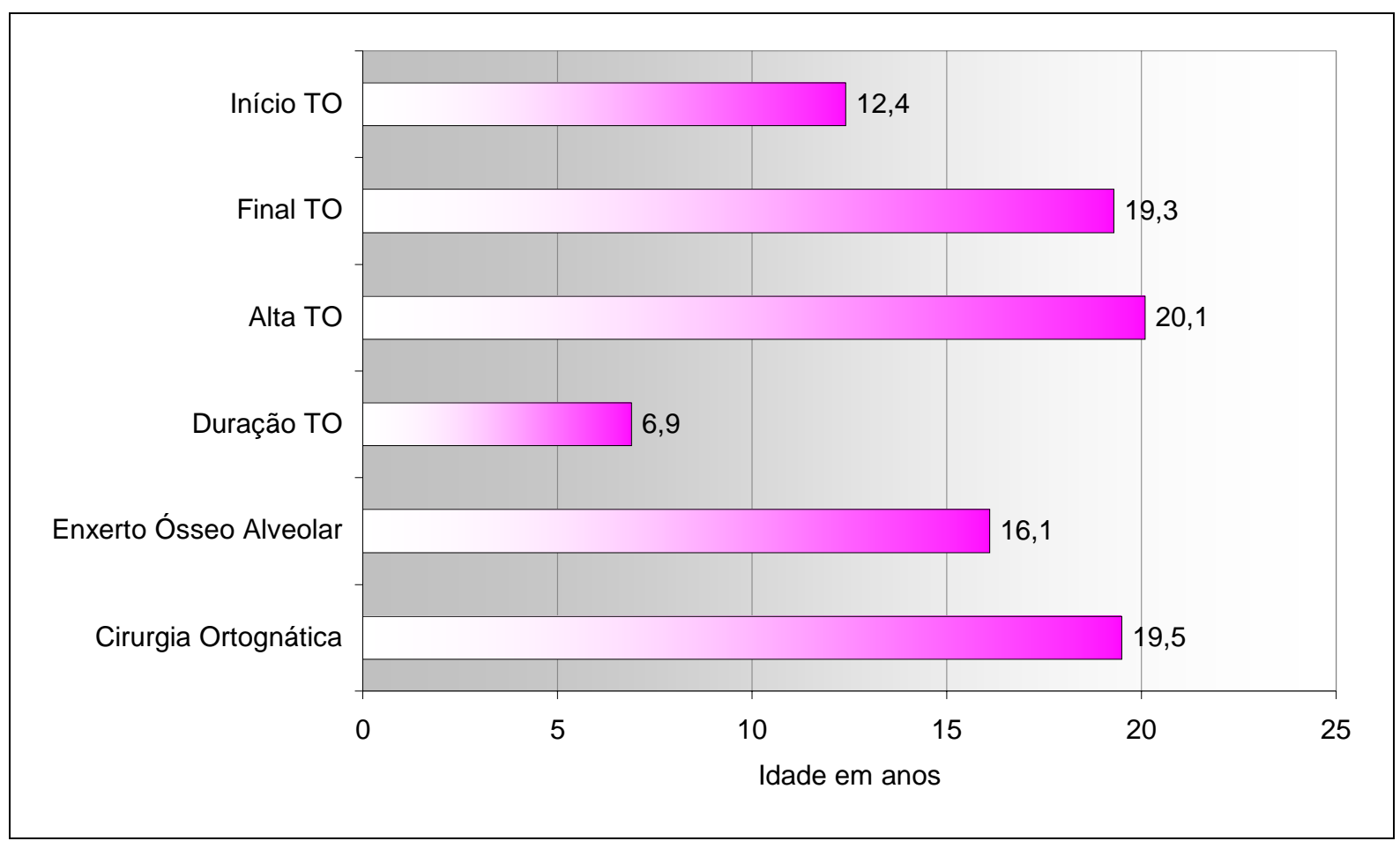

TO: Tratamento Ortodôntico 
Anexo 4 - Carta de Aprovação do Comitê de Ética

Ofício $n^{\circ}$ 093/2003-UEP-CEP

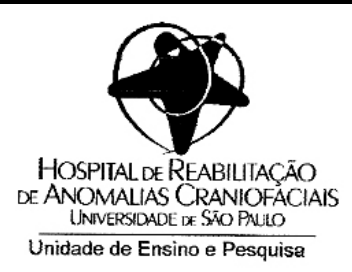

Bauru, 30 de junho de 2003.

Prezado(a) Senhor(a)

Comunicamos que em reunião realizada no dia 25 de junho de 2003, pelo Comitê de Ética em Pesquisa, o projeto de pesquisa abaixo de autoria de V.S ${ }^{a}$, foi aprovado, por este Comitê.

TíTULO: Avaliação da estética facial e da relação oclusal dos pacientes portadores de fissura transforame incisivo unilateral reabilitados pelo HRAC

CURSO: Mestrado

Atenciosamente

PROF. DR. ROBERTO LOUREIRO AIARINGONI

Coordenador do Comitê de Ética em Pesquisa do HRAC-USP

$\operatorname{Ilmo}(\mathrm{a}) \operatorname{Sr}(\mathrm{a})$

Dra. Araci Malagodi de Almeida

Ortodontia - HRAC/USP 
Anexo 5 - Termo de consentimento livre e esclarecido

$\mathrm{Eu}$ portador de RG $\mathrm{N}^{\circ}$

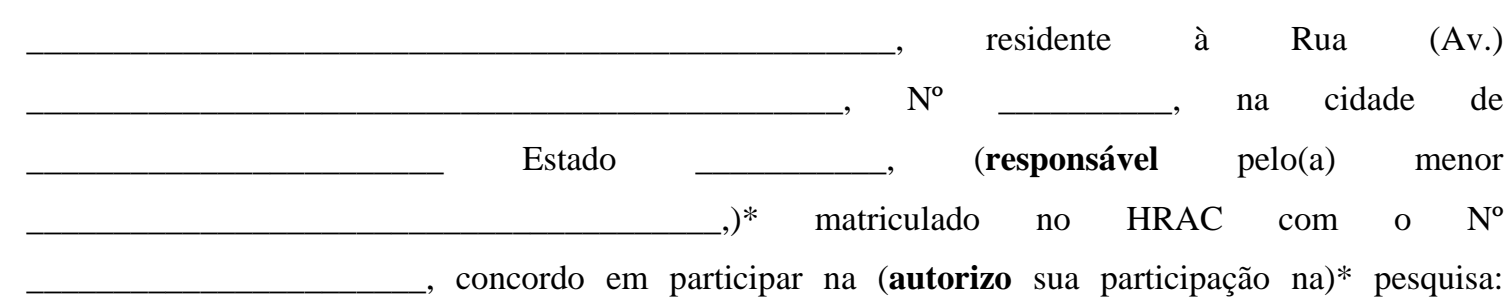

“Avaliação da estética facial e da relação oclusal dos pacientes portadores de fissura transforame incisivo unilateral reabilitados pelo HRAC”, realizada por: Araci Malagodi de Almeida No do Conselho 26373 (São Paulo), sob orientação do Dr. Leopoldino Capelozza Filho, No do Conselho 10963 (São Paulo).

$\mathrm{Eu}$, portador de RG $\mathrm{N}^{\circ}$ declaro verdadeiras as afirmações relatadas. Declaro ainda estar ciente de que esta é uma seleção para pesquisa de análise oclusal, facial e cefalométrica desenvolvida pela cirurgiã-dentista Araci Malagodi de Almeida, aluna do curso de Mestrado em Fissuras Orofaciais do Hospital de Reabilitação de Anomalias Craniofaciais - USP. Aceito ter a face fotografada de frente e perfil com a cabeça posicionada no cefalostato e concedo ao HRAC USP totais direitos quanto ao uso do material coletado com finalidade de ensino e divulgação, dentro das normas vigentes, tais como a publicação em jornais e/ou revistas científicas do país e do exterior.

Estou ciente também de que minha participação é voluntária e dela posso desistir a qualquer momento, sem explicar os motivos e sem comprometer meu tratamento no HRAC.

Bauru,

Assinatura do Paciente (Responsável)*

* em caso de menor de idade $(<21$ anos).

Nome do Pesquisador Responsável: Araci Malagodi de Almeida

Endereço Institucional: Rua Silvio Marchione, 3-20

Cidade: Bauru Estado: SP CEP: 17043-900 Telefone: 3235-8146 
Anexo 6 - Fotografias reduzidas dos 60 perfis faciais (30 do lado direito e 30 do esquerdo) dos pacientes da amostra
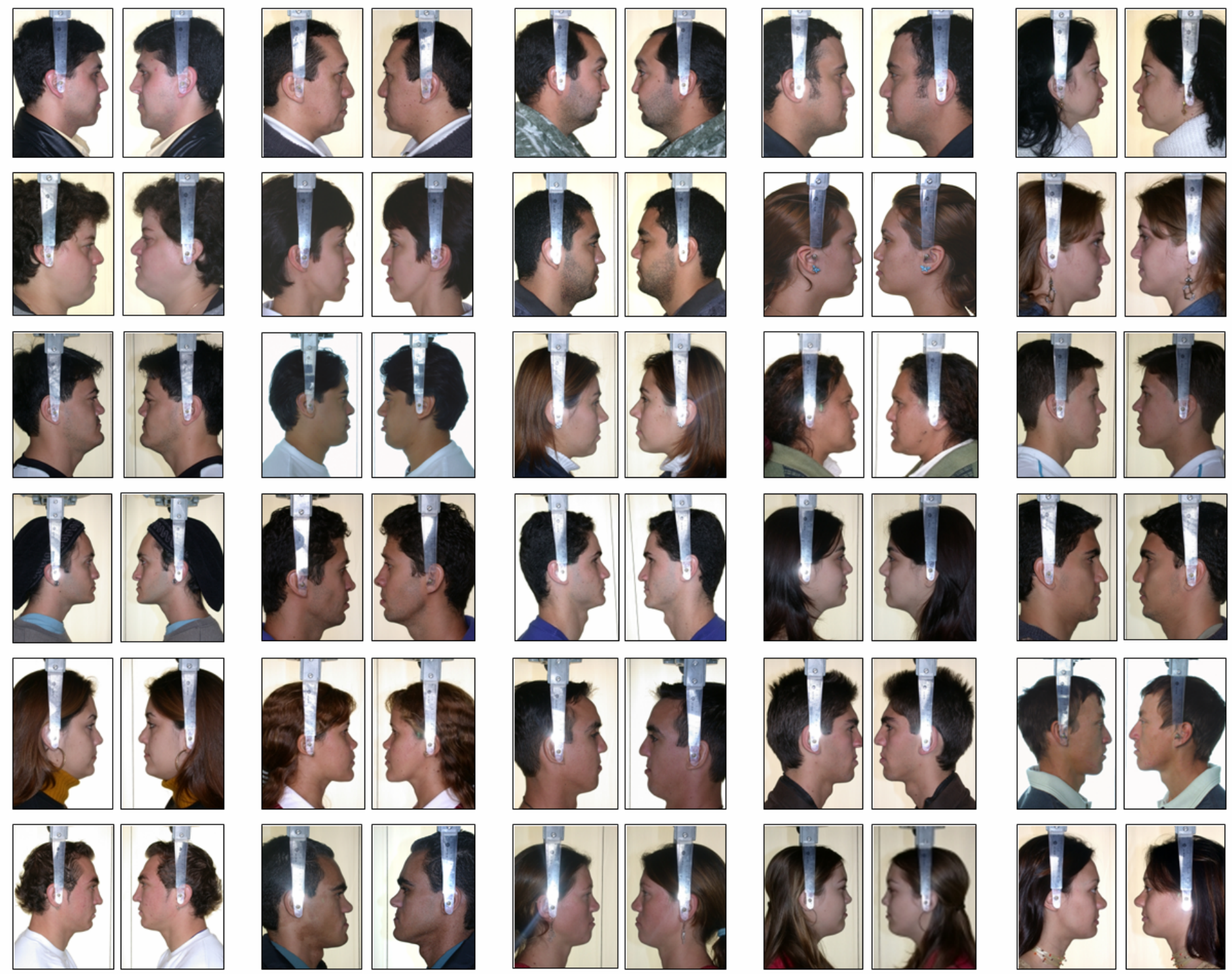
Anexo 7 - Especificações da Câmera fotográfica

\begin{tabular}{|l|l|}
\hline Câmera digital & Coolpix 995 Nikon \\
\hline Modo (M) & Manual \\
\hline Ajuste de abertura (f) & 9.3 \\
\hline Ajuste de velocidade & $1 / 125$ segundos \\
\hline Qualidade de imagem & Normal \\
\hline Tamanho da imagem & UXGA (1600 X 1200) \\
\hline Ajuste de sensibilidade & ASA 100 \\
\hline Flash & Ligado \\
\hline
\end{tabular}


Anexo 8 - Ficha de orientação para classificação estética do perfil facial

Caro(a) Sr(a) (nome do examinador),

Agradecemos antecipadamente sua disponibilidade em nos auxiliar neste trabalho.

Apresentaremos um álbum contendo fotografias faciais de indivíduos de ambos os sexos. Solicitaremos que, no máximo em 30 segundos, sejam dadas notas de 1 a 9 considerando a aparência estética do indivíduo fotografado.

Solicitamos que seja utilizado o seguinte critério de avaliação:

Notas:

1, 2 ou 3: aparência esteticamente desagradável

4, 5 ou 6: aparência esteticamente aceitável

7, 8 ou 9: aparência esteticamente agradável

Caso as notas sejam 1, 2 ou 3, favor descrever o motivo pelo qual você considerou o indivíduo esteticamente desagradável.

Antecipadamente gratos,

Araci Malagodi de Almeida

Pesquisadora

Prof. Dr. Leopoldino Capelozza Filho

Orientador 
Anexo 9 - Ficha de classificação estética

\begin{tabular}{|c|c|c|c|}
\hline Indivíduo & $\begin{array}{l}\text { Nota perfil } \\
\text { direito }\end{array}$ & $\begin{array}{l}\text { Nota perfil } \\
\text { esquerdo }\end{array}$ & Se a nota foi 1,2 ou 3 favor explicar porque \\
\hline 01 & & & \\
\hline 02 & & & \\
\hline 03 & & & \\
\hline 04 & & & \\
\hline 05 & & & \\
\hline 06 & & & \\
\hline 07 & & & \\
\hline 08 & & & \\
\hline 09 & & & \\
\hline 10 & & & \\
\hline 11 & & & \\
\hline 12 & & & \\
\hline 13 & & & \\
\hline 14 & & & \\
\hline 15 & & & \\
\hline 16 & & & \\
\hline 17 & & & \\
\hline 18 & & & \\
\hline 19 & & & \\
\hline 20 & & & \\
\hline 21 & & & \\
\hline 22 & & & \\
\hline 23 & & & \\
\hline 24 & & & \\
\hline 25 & & & \\
\hline 26 & & & \\
\hline 27 & & & \\
\hline 28 & & & \\
\hline 29 & & & \\
\hline 30 & & & \\
\hline
\end{tabular}



Anexo 10 - Notas atribuídas pelos examinadores na $1^{\mathrm{a}}$ avaliação aos perfis faciais direito e esquerdo dos pacientes da amostra

\begin{tabular}{|c|c|c|c|c|c|c|c|c|c|c|c|c|c|c|c|c|c|c|c|c|c|c|c|c|c|c|c|c|c|c|c|c|c|c|c|c|c|c|c|c|c|c|c|c|c|c|c|c|c|c|c|c|}
\hline \multirow{4}{*}{$\begin{array}{ll}\mathrm{Pac} \\
\end{array}$} & \multirow{4}{*}{ Gen } & \multirow{4}{*}{ Fiss } & \multicolumn{50}{|c|}{ Examinadores } \\
\hline & & & \multicolumn{10}{|c|}{ Ortodontistas HRAC } & \multicolumn{10}{|c|}{ Ortodontistas (ONAF) } & & Cirt & urgiõ & ões F & Plásti & icos & $(\mathrm{CP})$ & $\mathrm{HR}$ & AC) & & & & urgi & ões & Plás & ticos & $\mathrm{s}(\mathrm{C})$ & PNA & & & & eigo & $\mathrm{scol}$ & $\mathrm{m}$ fo & rma & ação & sup & perior & $r(\mathrm{LF}$ & \\
\hline & & & & $E 1$ & & $=2$ & & $E 3$ & & 54 & $E S$ & & & & & & & 8 & & $=9$ & & 10 & & 11 & & & E1: & & E1 & & E1 & & $E 1$ & & E1 & & E1 & & E] & & & & & & & & & E23 & & E24 & & 225 \\
\hline & & & $P D$ & $P E$ & $P D$ & $\mathrm{PE}$ & PD & $P E$ & $P D$ & $P E$ & PD & $\mathrm{PE}$ & PD & $\mathrm{PE}$ & $\mathrm{PD}$ & $\mathrm{PE}$ & $P D$ & $\mathrm{PE}$ & $P D$ & $\mathrm{PE}$ & $\mathrm{PD}$ & $P E$ & $P D$ & $\mathrm{PE}$ & PD & $\mathrm{PE}$ & PD & $\mathrm{PE}$ & \begin{tabular}{l|l|}
$\mathrm{PD}$ \\
\end{tabular} & $\mathrm{PE}$ & PD & $\mathrm{PE}$ & $\mathrm{PD}$ & $\mathrm{PE}$ & PD & $\mathrm{PE}$ & $\mathrm{PD}$ & & $\mathrm{PD}$ & $\mathrm{PE}$ & $\mathrm{PD}$ & $\mathrm{PE}$ & $P D$ & $P E$ & PD & $P E$ & PD & $P E$ & $=P D$ & \begin{tabular}{|l|l|}
$P E$ \\
\end{tabular} & $\mathrm{PD}$ & PE \\
\hline P1 & $M$ & D & 9 & 9 & 8 & 9 & 8 & 8 & 8 & 8 & 8 & 8 & 6 & 6 & 5 & 5 & 6 & 5 & 6 & 6 & 2 & 2 & 8 & 8 & 5 & 5 & 3 & 3 & 9 & 9 & 8 & 8 & 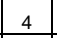 & 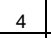 & 4 & 4 & 5 & 5 & 4 & 4 & 4 & 4 & 6 & 5 & 3 & 3 & 5 & 5 & 6 & 6 & 7 & 7 \\
\hline P2 & $M$ & $\mathrm{~F}$ & 9 & 9 & 9 & 9 & 8 & 8 & 7 & 7 & 8 & 8 & 7 & 7 & 7 & 7 & 5 & 4 & 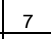 & 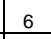 & 2 & 2 & 8 & 8 & 5 & 5 & 4 & 4 & 9 & 7 & 9 & 9 & . & . & 4 & 4 & 5 & 5 & 4 & 4 & 4 & 4 & 6 & 5 & 7 & 6 & 4 & 4 & 6 & 6 & 8 & 8 \\
\hline P3 & M & $\mathrm{E}$ & 6 & 5 & 7 & 7 & 7 & 7 & 5 & 5 & 7 & 7 & 3 & 3 & 3 & 3 & 3 & 3 & & & & & & 4 & - & 5 & 3 & & 1 & 6 & 5 & 3 & 3 & & & 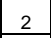 & 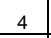 & 4 & 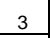 & 3 & 1 & 1 & 3 & 3 & 3 & 3 & 2 & 2 & 5 & 5 & 6 & 6 \\
\hline P4 & M & - & 9 & 9 & 8 & 8 & 8 & 8 & 7 & 7 & 7 & 7 & 4 & 4 & 4 & 4 & 4 & 4 & b & 5 & & & & 7 & 6 & 6 & 3 & 3 & 8 & 7 & 9 & 6 & 4 & & 4 & 4 & 5 & 5 & 4 & 4 & 5 & 5 & 3 & 3 & 3 & 3 & 5 & 3 & 5 & 5 & 6 & 6 \\
\hline $\begin{array}{l}85 \\
\end{array}$ & F & E & & $\stackrel{g}{9}$ & 9 & 9 & 9 & 9 & 9 & 9 & 8 & 8 & 4 & 4 & 6 & 6 & 5 & 4 & & & & & & 8 & & 7 & 4 & 4 & 9 & $\underline{9}$ & 8 & 8 & & & & 5 & 6 & & & & & & 4 & 4 & 5 & & 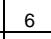 & 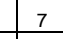 & 9 & 9 & 7 & 7 \\
\hline $\begin{array}{l}P 6 \\
\end{array}$ & F & $E$ & 8 & 8 & 8 & 8 & 8 & 8 & 7 & 7 & 7 & 5 & 3 & 3 & 3 & 3 & 5 & 4 & 4 & 4 & & & & 6 & $\epsilon$ & 6 & 3 & 3 & 7 & 6 & 3 & 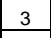 & 3 & & 3 & 3 & 4 & 4 & 4 & 4 & 4 & & 3 & 3 & 3 & 3 & 5 & 3 & 5 & 5 & 5 & 5 \\
\hline P8 & M & $E$ & 9 & 9 & 9 & 9 & 8 & 8 & 8 & 8 & 8 & 8 & 5 & 5 & 5 & 5 & 5 & 5 & 5 & 5 & 4 & 4 & -1 & 6 & 6 & 6 & 6 & 5 & 8 & 7 & 5 & 4 & 5 & 5 & 5 & 5 & 6 & 6 & 4 & 4 & 6 & 6 & 4 & 4 & 7 & 7 & 7 & 5 & 6 & 6 & 6 & 5 \\
\hline P9 & $F$ & $E$ & 8 & 8 & 9 & 9 & 7 & 7 & 7 & 7 & 7 & 7 & 5 & 5 & 5 & 4 & 4 & 5 & 5 & 5 & 4 & 4 & 6 & 7 & 6 & 6 & 5 & 4 & 8 & 8 & 5 & 5 & 4 & 4 & 4 & 4 & 7 & 7 & 5 & 5 & 7 & 7 & 4 & 4 & 7 & 7 & 8 & 6 & 7 & 7 & 6 & 6 \\
\hline $\mathrm{P} 10$ & $F$ & $E$ & 9 & 9 & 9 & 9 & 8 & 7 & 9 & 9 & 9 & 8 & 7 & 7 & 7 & 6 & 7 & 7 & 6 & 6 & 5 & 5 & 8 & 7 & 7 & 7 & 5 & 4 & 8 & 8 & 8 & 7 & 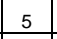 & 5 & 4 & 4 & 7 & 7 & 6 & 6 & 6 & 6 & 5 & 5 & 7 & 6 & 8 & 7 & 8 & 8 & 7 & 6 \\
\hline P11 & $M$ & D & 6 & 6 & 6 & 6 & 6 & 6 & 2 & 2 & 4 & 4 & 3 & 3 & 3 & 3 & 3 & 3 & 3 & 3 & 1 & 1 & 6 & 6 & 5 & 5 & 3 & 3 & 7 & 7 & 3 & 3 & 3 & 3 & 2 & 2 & 4 & 4 & 4 & 4 & 3 & 3 & 3 & 3 & 3 & 3 & 4 & 4 & 4 & 4 & 6 & 5 \\
\hline $\mathrm{P} 12$ & M & D & 7 & 6 & 9 & 8 & 5 & 4 & 5 & 5 & 8 & 8 & 5 & 4 & 5 & 3 & 4 & 4 & 5 & 5 & 3 & 3 & 7 & 7 & 4 & 4 & 4 & 3 & 6 & 6 & 7 & 6 & 4 & 4 & 4 & 4 & 5 & 5 & 5 & 5 & 5 & 5 & 5 & 5 & 4 & 3 & 6 & 3 & 5 & 5 & 7 & 6 \\
\hline P13 & 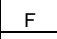 & $E$ & 8 & 8 & 8 & 8 & 5 & 5 & 8 & 8 & 9 & 8 & 6 & 6 & 4 & 4 & 7 & 7 & 7 & 7 & 5 & 5 & 7 & 7 & 6 & 6 & 5 & 3 & 7 & 7 & 5 & 6 & 5 & 5 & 4 & 4 & 7 & 7 & 5 & 5 & 5 & 5 & 4 & 4 & 4 & 4 & 6 & 6 & 7 & 7 & 7 & 7 \\
\hline P14 & $\mathrm{F}$ & D & 6 & 6 & 6 & 6 & 4 & 6 & 4 & 4 & 7 & 7 & 3 & 3 & 4 & \begin{tabular}{|l|} 
\\
\end{tabular} & 4 & 4 & 4 & 4 & 2 & 4 & 4 & 5 & 5 & 5 & 4 & 5 & 6 & 7 & 3 & 4 & 3 & 3 & 2 & 2 & 5 & 5 & 5 & 5 & 2 & 2 & 3 & 3 & 3 & 3 & 2 & 5 & 6 & 6 & 5 & 6 \\
\hline P15 & M & $E$ & 8 & 8 & 9 & 9 & 7 & 7 & 7 & 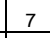 & 8 & 8 & 7 & 7 & 6 & 6 & 4 & 4 & 6 & 6 & 6 & $\epsilon$ & $\underline{9}$ & 9 & 6 & 6 & 6 & 5 & 8 & 8 & 8 & 6 & 5 & 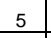 & 4 & 4 & 6 & 6 & 6 & 6 & 5 & 5 & 5 & 5 & 8 & 7 & 7 & 5 & 9 & 9 & 7 & 7 \\
\hline P16 & M & $E$ & 7 & 6 & 8 & 8 & 6 & 6 & 5 & 5 & 6 & 6 & 4 & 4 & 4 & 3 & 3 & 2 & 4 & 4 & 2 & & 7 & 6 & 4 & 4 & 7 & 6 & 6 & 6 & 3 & 2 & 3 & 3 & 2 & 2 & 3 & 3 & 4 & 4 & 3 & 3 & 3 & 3 & 4 & 3 & 4 & 3 & 6 & 6 & 7 & 5 \\
\hline P19 & $F$ & D & 8 & 9 & 9 & 9 & 7 & 8 & 9 & 9 & 8 & 9 & 7 & 7 & 6 & 6 & 5 & 6 & 6 & 6 & 6 & 6 & 8 & 8 & 6 & 6 & 6 & 6 & 8 & 8 & 9 & 9 & 0 & 6 & 4 & 4 & 7 & 7 & 6 & 6 & 6 & 6 & 5 & 5 & 7 & 8 & 6 & 6 & 8 & 8 & 8 & 8 \\
\hline P20 & M & $E$ & 9 & 9 & 9 & 9 & 8 & 8 & 8 & 8 & 8 & 9 & 6 & 6 & 5 & 5 & 5 & 4 & 6 & 6 & 5 & 5 & 7 & 7 & 6 & 6 & 8 & 7 & 8 & 7 & 6 & I & 5 & 5 & 5 & 5 & 6 & 6 & 4 & 4 & 6 & 6 & 5 & 6 & 6 & 6 & 6 & 4 & 7 & 7 & 7 & 7 \\
\hline P21 & $\mathrm{F}$ & $E$ & \begin{tabular}{|l|} 
\\
\end{tabular} & 9 & 9 & 9 & 8 & 8 & 9 & 9 & 7 & 8 & 7 & 7 & 7 & 7 & 6 & 5 & 5 & 5 & 5 & 5 & 7 & 7 & 6 & 6 & 7 & 7 & 7 & 7 & 6 & 5 & 5 & 5 & 3 & 3 & 7 & 7 & 5 & 5 & 6 & 6 & 5 & 4 & 5 & 5 & 7 & 5 & 7 & 7 & 7 & 8 \\
\hline P22 & $F$ & $E$ & 8 & 7 & 7 & 7 & 6 & 6 & 7 & 7 & 7 & 7 & 3 & 3 & 3 & 3 & 5 & 5 & 4 & 4 & 3 & 3 & 7 & 7 & 7 & 7 & 8 & 8 & 8 & 8 & 6 & 6 & 2 & 2 & 3 & 3 & 5 & 5 & 3 & 3 & 3 & 3 & 3 & 3 & 3 & 3 & 5 & 5 & 6 & 6 & 7 & 7 \\
\hline $\mathrm{P} 23$ & $\mathrm{M}$ & $E$ & 7 & 7 & 7 & 7 & 6 & 5 & 3 & 3 & 5 & 5 & 3 & 3 & 3 & 3 & 3 & 3 & 3 & 3 & 3 & 1 & 6 & 5 & 4 & 4 & 3 & 3 & 6 & 5 & 5 & 3 & 3 & 3 & 1 & 1 & 4 & 4 & 3 & 3 & 3 & 3 & 4 & 4 & 4 & 3 & 4 & 3 & 5 & 5 & 5 & 6 \\
\hline P24 & $\mathrm{M}$ & $D$ & 7 & 7 & 7 & 8 & 5 & 4 & 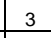 & 4 & 5 & 6 & 4 & 5 & 3 & 4 & 4 & 5 & 4 & 4 & 2 & 2 & 5 & 6 & 5 & 5 & 7 & 7 & 5 & 6 & 3 & 6 & 3 & 3 & 4 & 4 & 5 & 5 & 3 & 3 & 5 & 5 & 4 & 5 & 5 & 6 & 6 & 5 & 7 & 7 & 6 & 6 \\
\hline P25 & $\mathrm{M}$ & $E$ & 8 & 8 & 8 & 9 & 6 & 0 & 5 & 5 & 5 & 5 & 4 & 4 & 4 & 4 & 4 & 4 & 4 & 4 & 4 & 4 & 5 & 6 & 6 & 6 & 7 & 8 & 6 & 7 & 7 & 7 & 4 & 4 & 5 & 5 & 5 & 5 & 4 & 4 & 4 & 4 & 3 & 4 & 5 & 4 & 6 & 5 & 7 & 7 & 6 & 6 \\
\hline P26 & $M$ & $E$ & 9 & 9 & 8 & 9 & 5 & 5 & 7 & 7 & 7 & 8 & 4 & 4 & 5 & 5 & 4 & 4 & 5 & 5 & 4 & 4 & 8 & 8 & 5 & 5 & 8 & 8 & 8 & 7 & 6 & 6 & 5 & 5 & 4 & 4 & 6 & 6 & 5 & 5 & 4 & 4 & 3 & 3 & 4 & 4 & 5 & 5 & 7 & 1 & 6 & 6 \\
\hline P27 & M & $D$ & 5 & 6 & 6 & 6 & 3 & 4 & 3 & 3 & 4 & 4 & 3 & 3 & 3 & 3 & 3 & 3 & 4 & 4 & 2 & 2 & 5 & 4 & 4 & 4 & 5 & 5 & 7 & 8 & 3 & 4 & 3 & 3 & 3 & 3 & 4 & 4 & 4 & 4 & 3 & 3 & 3 & 3 & 3 & 3 & 4 & 3 & 6 & 6 & 6 & 6 \\
\hline P28 & $F$ & $D$ & 8 & 9 & 7 & 7 & 5 & 4 & 5 & 5 & 7 & 8 & 4 & 4 & 4 & 4 & 4 & 4 & 5 & 5 & 2 & 2 & 5 & 5 & 5 & 5 & 6 & 7 & 6 & 6 & 3 & 4 & 5 & 5 & 4 & 4 & 4 & 4 & 4 & 4 & 5 & 5 & 3 & 3 & 4 & 4 & 4 & 5 & $r$ & 7 & 5 & 6 \\
\hline P29 & $F$ & $E$ & 6 & 6 & 7 & 7 & 4 & 4 & 3 & 3 & 5 & 5 & 3 & 3 & 3 & 3 & 3 & 3 & 5 & 5 & 3 & 3 & 5 & 5 & 5 & 5 & 4 & 3 & 5 & 5 & 14 & 5 & 0 & 3 & 3 & 13 & 4 & 4 & 3 & 3 & 4 & 4 & 3 & 3 & 3 & 3 & 4 & 4 & 6 & 6 & 6 & 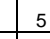 \\
\hline 30 & $F$ & $E$ & 9 & 9 & 9 & 9 & 6 & 7 & 9 & 9 & 9 & 9 & 4 & 5 & 5 & 5 & 4 & 5 & 5 & 5 & 6 & 6 & 7 & 7 & 6 & 6 & 8 & 8 & 7 & 7 & 6 & 5 & 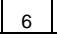 & 6 & 3 & 3 & 5 & 5 & 5 & 5 & 5 & 5 & 3 & 3 & 4 & 4 & 5 & 4 & 8 & 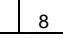 & 7 & 8 \\
\hline
\end{tabular}

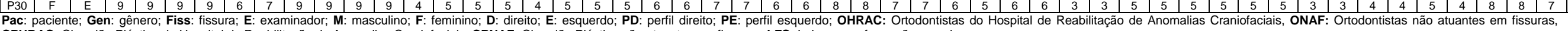

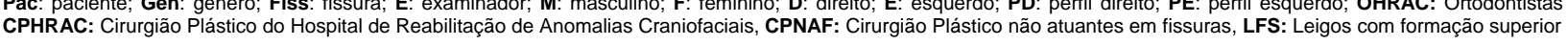


Anexo 11 - Notas atribuídas pelos examinadores na $2^{\mathrm{a}}$ avaliação aos perfis faciais direito e esquerdo dos pacientes da amostra

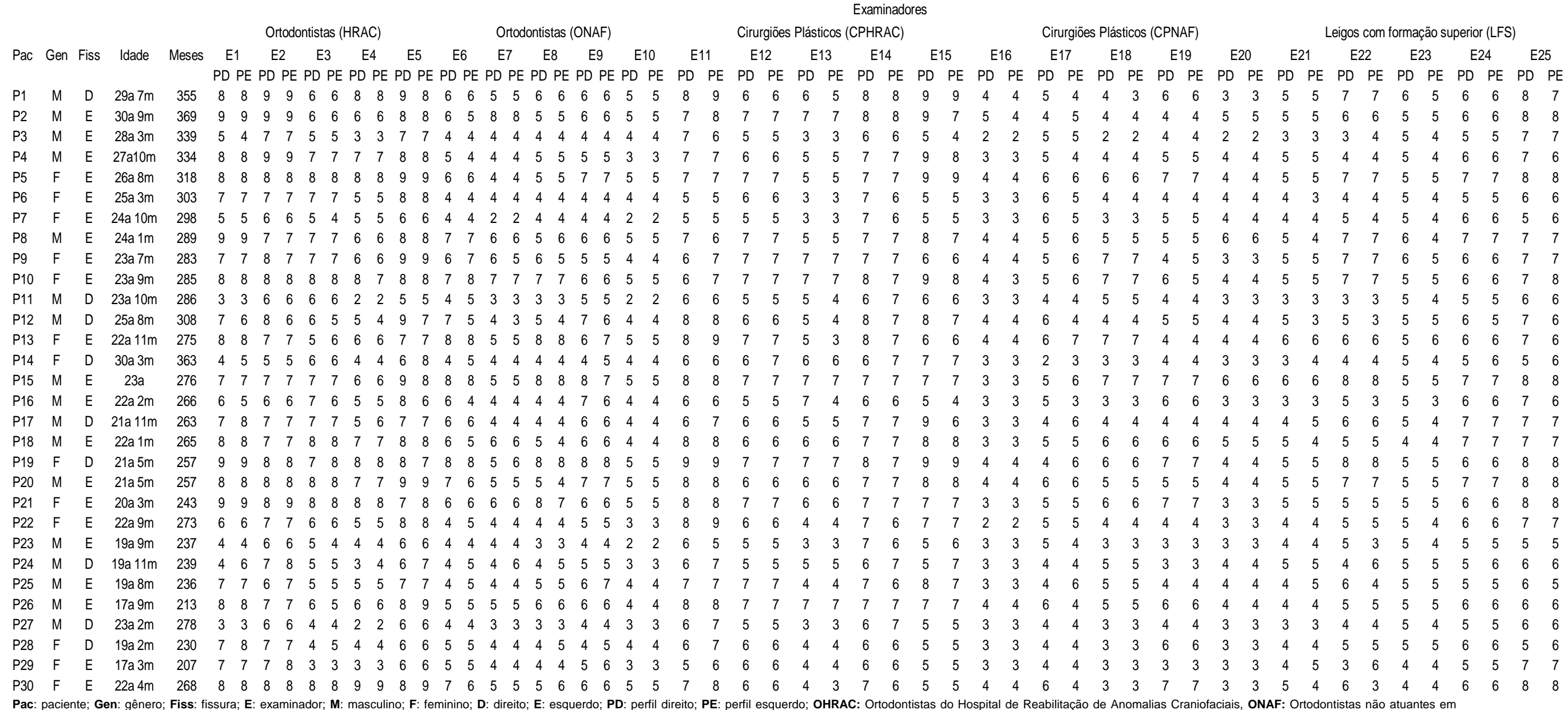

Pac: paciente; Gen: gênero; Fiss: fissura; E: examinador; M: masculino; F: feminino; D: direito; E: esquerdo; PD: perfil direito; PE: perfil esquerdo; OHRAC: Ortodontistas do Hospita
fissuras, CPHRAC: Cirurgiâo Plástico do Hospital de Reabilitaçăo de Anomalias Craniofaciais, CPNAF: Cirurgiẫo Plástico não atuantes em fissuras, LFS: Leigos com formação superior 
Anexo 12 - Figura representativa das notas atribuídas pelos examinadores aos perfis faciais dos lados com (LC) e sem fissura (LS)

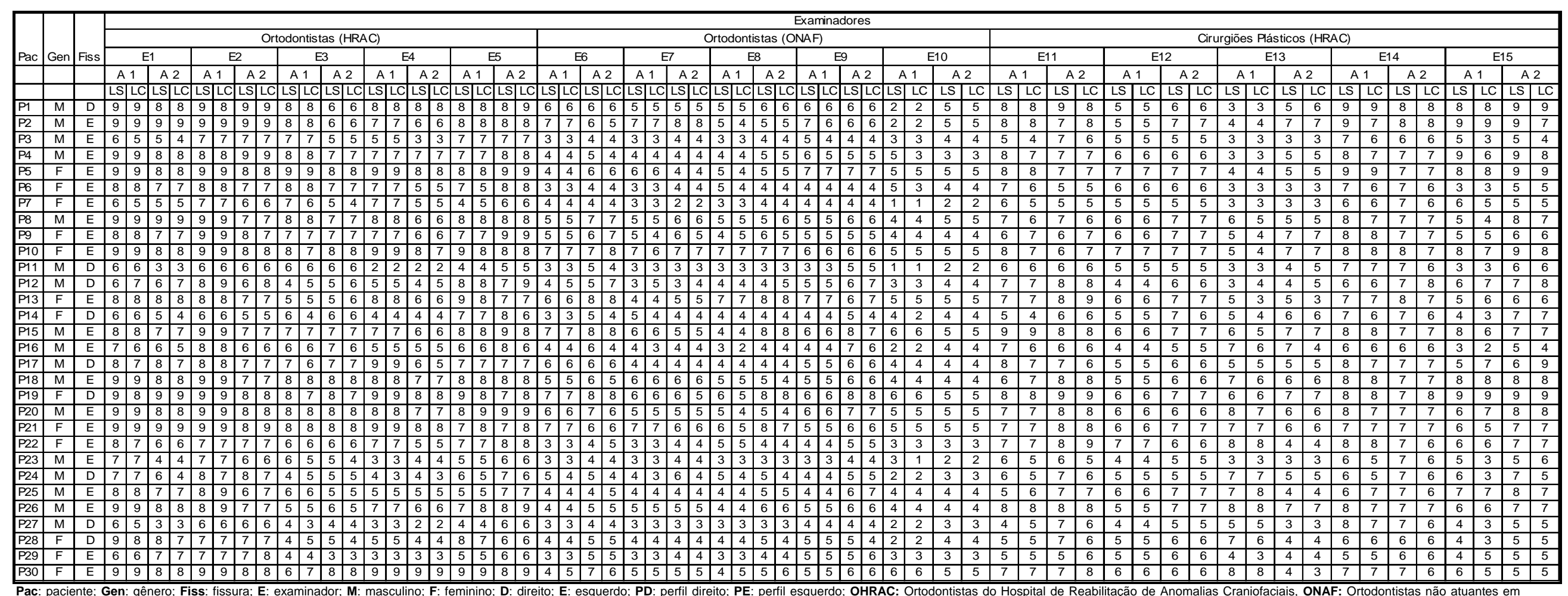

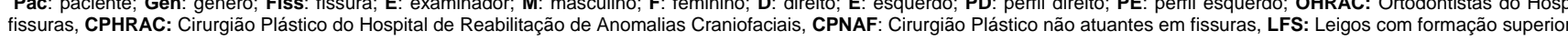


Anexo 12 - Figura representativa das notas atribuídas pelos examinadores aos perfis faciais dos lados com (LC) e sem fissura (LS)

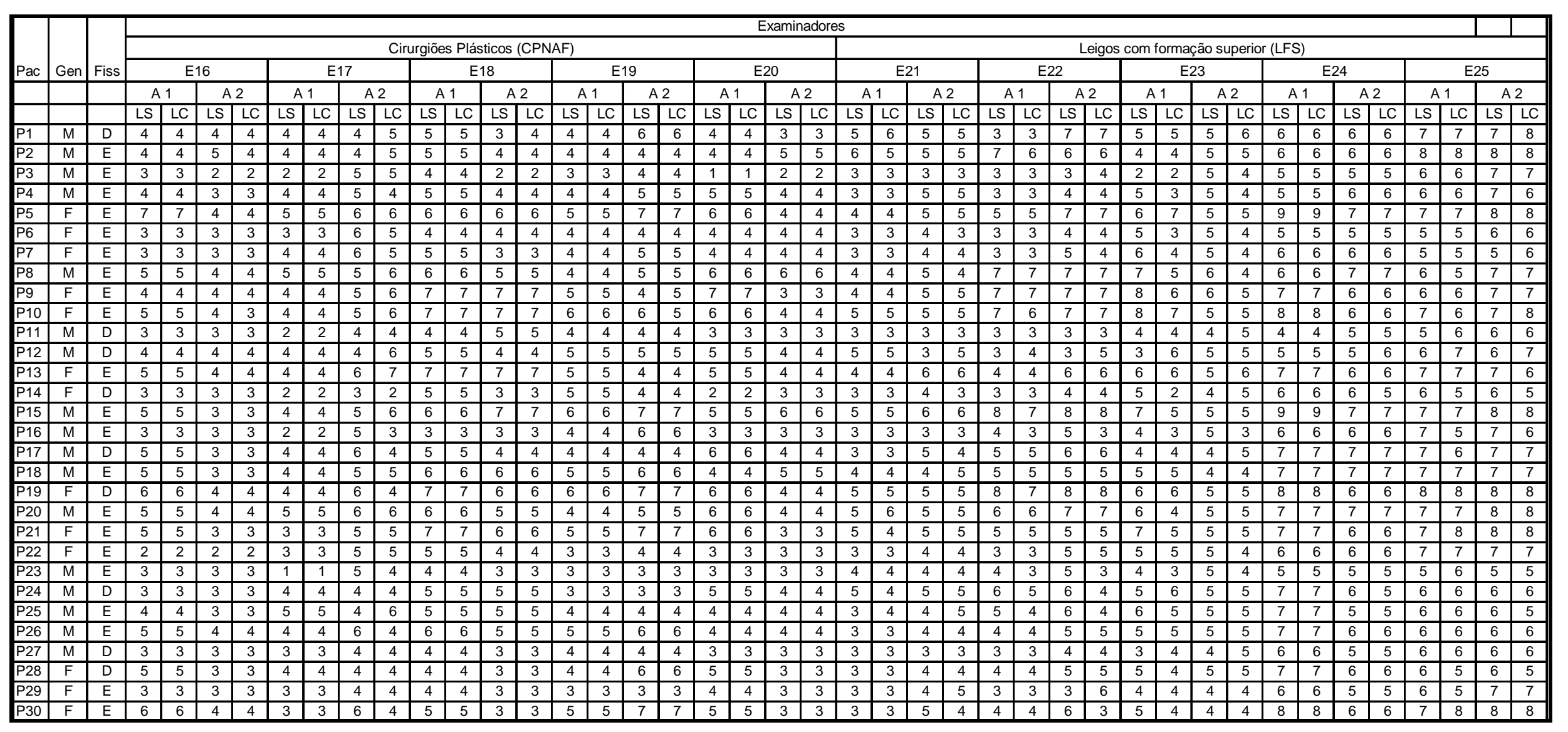

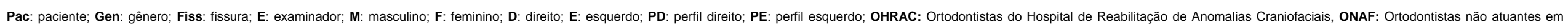
fissuras, CPHRAC: Cirurgião Plástico do Hospital de Reabilitação de Anomalias Craniofaciais, CPNAF: Cirurgião Plástico não atuantes em fissuras, LFS: Leigos com formação superior 
Anexo 13 - Média das notas dadas aos perfis faciais dos 30 pacientes da amostra e média final obtida

\begin{tabular}{|c|c|c|c|c|c|c|}
\hline Paciente & OHRAC & ONAF & CPHRAC & CPNAF & LFS & Média \\
\hline 1 & 8,2 & 5,0 & 6,6 & 4,2 & 5,4 & 5,9 \\
\hline 2 & 8,2 & 5,2 & 6,6 & 4,2 & 5,8 & 6,0 \\
\hline 3 & 6,2 & 3,2 & 4,2 & 2,6 & 3,8 & 4,0 \\
\hline 4 & 7,8 & 5,0 & 6,8 & 4,4 & 4,4 & 5,7 \\
\hline 5 & 8,8 & 5,2 & 7,2 & 5,8 & 6,2 & 6,6 \\
\hline 6 & 7,2 & 4,0 & 4,8 & 3,6 & 4,4 & 4,0 \\
\hline 7 & 6,0 & 3,0 & 4,8 & 4,0 & 4,2 & 4,4 \\
\hline 8 & 8,4 & 4,8 & 5,6 & 5,2 & 5,4 & 5,8 \\
\hline 9 & 7,6 & 4,6 & 6,0 & 5,0 & 6,4 & 5,9 \\
\hline 10 & 8,4 & 6,2 & 6,6 & 5,6 & 6,4 & 6,6 \\
\hline 11 & 4,8 & 2,6 & 4,8 & 3,2 & 4,0 & 3,9 \\
\hline 12 & 6,8 & 4,4 & 5,6 & 4,6 & 5,4 & 5,3 \\
\hline 13 & 7,4 & 5,8 & 5,8 & 5,2 & 5,6 & 5,9 \\
\hline 14 & 5,4 & 3,4 & 4,4 & 3,4 & 3,8 & 4,1 \\
\hline 15 & 7,8 & 5,8 & 6,8 & 5,2 & 6,6 & 6,4 \\
\hline 16 & 6,2 & 3,0 & 4,8 & 3,0 & 4,0 & 4,2 \\
\hline 17 & 7,4 & 4,6 & 6,2 & 4,8 & 5,0 & 5,6 \\
\hline 18 & 8,4 & 5,0 & 6,8 & 4,8 & 5,6 & 6,1 \\
\hline 19 & 8,2 & 6,0 & 7,4 & 5,8 & 6,8 & 6,8 \\
\hline 20 & 8,6 & 4,8 & 6,8 & 5,2 & 6,0 & 6,3 \\
\hline 21 & 8,6 & 5,8 & 6,4 & 5,2 & 5,8 & 6,3 \\
\hline 22 & 6,8 & 3,6 & 7,2 & 3,2 & 4,8 & 5,1 \\
\hline 23 & 5,4 & 2,6 & 4,0 & 2,8 & 4,2 & 3,8 \\
\hline 24 & 5,4 & 3,4 & 5,0 & 4,0 & 5,6 & 4,7 \\
\hline 25 & 6,6 & 4,0 & 6,8 & 6,4 & 5,2 & 5,8 \\
\hline 26 & 7,6 & 4,4 & 6,8 & 4,8 & 5,0 & 5,7 \\
\hline 27 & 4,2 & 3,0 & 4,8 & 3,4 & 4,4 & 3,9 \\
\hline 28 & 6,4 & 3,8 & 5,0 & 4,4 & 4,6 & 4,8 \\
\hline 29 & 5,0 & 3,4 & 4,6 & 3,4 & 4,2 & 4,1 \\
\hline 30 & 8,6 & 5,2 & 6,6 & 4,8 & 5,4 & 6,1 \\
\hline
\end{tabular}

OHRAC: Ortodontistas do Hospital de Reabilitação de Anomalias Craniofaciais, ONAF: Ortodontistas não atuantes em fissuras, CPHRAC: Cirurgião Plástico do Hospital de Reabilitação de Anomalias Craniofaciais, CPNAF: Cirurgião Plástico não atuantes em fissuras, LFS: Leigos com formação superior 